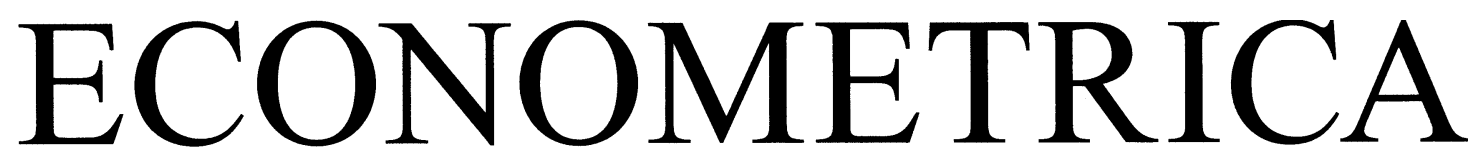

JOURNAL OF THE ECONOMETRIC SOCIETY

An International Society for the Advancement of Economic Theory in its Relation to Statistics and Mathematics

http://www.econometricsociety.org/

Econometrica, Vol. 82, No. 4 (July, 2014), 1443-1508

ENDOGENOUS LIQUIDITY AND DEFAULTABLE BONDS

\author{
ZHIGUO He \\ Booth School of Business, University of Chicago, Chicago, IL 60637, U.S.A., and \\ NBER \\ KONSTANTIN MILBRADT \\ Kellogg School of Management, Northwestern University, Evanston, IL 60208, \\ U.S.A., and NBER
}

The copyright to this Article is held by the Econometric Society. It may be downloaded, printed and reproduced only for educational or research purposes, including use in course packs. No downloading or copying may be done for any commercial purpose without the explicit permission of the Econometric Society. For such commercial purposes contact the Office of the Econometric Society (contact information may be found at the website http://www.econometricsociety.org or in the back cover of Econometrica). This statement must be included on all copies of this Article that are made available electronically or in any other format. 


\title{
ENDOGENOUS LIQUIDITY AND DEFAULTABLE BONDS
}

\author{
By Zhiguo He AND Konstantin MiLbRAdT ${ }^{1}$
}

This paper studies the interaction between default and liquidity for corporate bonds that are traded in an over-the-counter secondary market with search frictions. Bargaining with dealers determines a bond's endogenous liquidity, which depends on both the firm fundamental and the time-to-maturity of the bond. Corporate default decisions interact with the endogenous secondary market liquidity via the rollover channel. A default-liquidity loop arises: Assuming a relative illiquid secondary bond market in default, earlier endogenous default worsens a bond's secondary market liquidity, which amplifies equity holders' rollover losses, which in turn leads to earlier endogenous default. Besides characterizing in closed form the full interdependence between liquidity and default for credit spreads, our calibrated model can jointly match empirically observed credit spreads and liquidity measures of bonds across different rating classes.

KEYWORDS: Positive feedback, liquidity, over-the-counter market, secondary bond market, structural models for credit risk, transaction cost for corporate bonds, bid-ask spread.

\section{INTRODUCTION}

THE RECENT 2007-2008 FINANCIAL CRISIS and the ongoing sovereign crisis have vividly demonstrated the important interaction between default and liquidity in financial markets. Liquidity tends to dry up for assets when solvency becomes a concern, reflected by soaring liquidity premia; in the meantime, default is looming closer in response to worsening liquidity in financial markets. This paper studies the endogenous interactions between default and liquidity in the context of corporate bond markets. ${ }^{2}$

\footnotetext{
${ }^{1}$ For helpful comments, we thank Kerry Back (Rice), Nittai Bergman (MIT), Bruce Carlin (UCLA), Hui Chen (MIT), Peter Feldhutter (LBS), Richard Green (CMU), Nicolae Garleanu (UC Berkeley), Barney Hartman-Glaser (Duke), Burton Hollifield (CMU), Gustavo Manso (UC Berkeley), Holger Mueller (NYU), the editor, three anonymous referees, and seminar participants of the MIT Sloan lunchtime workshop, NYU lunchtime workshop, Columbia GSB lunchtime workshop, Chicago Booth Finance lunch, NBER Microstructure meeting, ASU winter conference, Duke-UNC asset pricing conference, Texas Finance Festival, UNC, Boston University, University of Colorado at Boulder, INSEAD, Imperial College London, UCLA Anderson, WFA 2012, SED 2012, NBER SI Asset Pricing meeting, Gerzensee ESSFM 2012, Northwestern Kellogg, Copenhagen Business School, Tilburg University, Erasmus University, University of Amsterdam, Utah Winter Finance Conference 2013, and London Business School. We are especially grateful to Rui Cui for excellent research assistance. Zhiguo He acknowledges financial support from the Center for Research in Security Prices at the University of Chicago Booth School of Business.

${ }^{2}$ Corporate bond markets, for both financial and nonfinancial firms, make up a large part of the U.S. financial system. According to flow of funds, the values of corporate bonds reached about 4.7 trillion in the first quarter of 2010, which consists of about one third of total liabilities of U.S. corporate businesses.
} 
It has been well documented that secondary corporate bond markets-which are mainly over-the-counter (OTC) markets-are much less liquid than equity markets. ${ }^{3}$ Edwards, Harris, and Piwowar (2007) (hereafter EHP07) and Bao, Pan, and Wang (2011) documented a strong empirical pattern that the liquidity for corporate bonds (measured as transaction costs) deteriorates dramatically for bonds with lower rating classes, that is, bonds that are issued by firms closer to default. Indeed, recent research, for example, Dick-Nielsen, Feldhütter, and Lando (2012) and Friewald, Jankowitsch, and Subrahmanyam (2012), has shown that liquidity in corporate bond markets dried up substantially during the 2007-2008 crisis, and more so for bonds with speculative grade than for bonds with investment grade. To deliver such empirical regularity, we model endogenous liquidity in the secondary corporate bond market as a search-based over-the-counter (OTC) market á la Duffie, Gârleanu, and Pedersen (2005) (hereafter DGP05). Bond investors, if hit by idiosyncratic liquidity shocks, face holding costs for holding the asset and thus want to divest of it. To trade, they meet intermediary dealers with a certain matching technology and then trade at an endogenous bid-ask spread. Similarly to DGP05, the endogenous bid-ask spread is given by the dealer's bargaining power multiplying the valuation wedge between investors who have been hit by liquidity shocks (called $L$ investors) and investors who have not (called $H$ investors), which depends on not only the bond's time-to-maturity but also the firm's distanceto-default. The novelty of the paper stems from the latter connection, which gives rise to an endogenous relation between secondary market bond liquidity and a bond's default risk as, for example, embodied by its rating.

The endogenous default decision by equity holders affected by rollover losses is the second important ingredient for understanding the defaultliquidity interaction in the corporate bond market. This mechanism is borrowed from Leland and Toft (1996) (hereafter LT96), where a firm continuously rolls over (or refinances) maturing bonds, that is, equity holders pay the principal back on maturing bonds, and at the same time reissue the bonds with the same principal and coupon at market prices. When firm fundamentals deteriorate, equity holders will face heavier rollover losses due to falling prices of newly issued bonds. Equity holders default optimally when absorbing further losses is unprofitable, at which point bond investors with defaulted claims step in to recover part of the firm value.

\footnotetext{
${ }^{3}$ For instance, Edwards, Harris, and Piwowar (2007) studied the U.S. OTC secondary trades in corporate bonds and estimated the transaction cost to range from 30 to $100 \mathrm{bps}$, and Bao, Pan, and Wang (2011) found even larger numbers. The fact that equity markets-while being presumably subject to more asymmetric information problems-are more liquid highlights the importance of search friction in corporate bond markets. Other empirical papers that investigate secondary bond market liquidity are Hong and Warga (2000), Schultz (2001), Green, Hollifield, and Schurhoff (2007a, 2007b), Harris and Piwowar (2006), and Jankowitsch, Nagler, and Subrahmanyam (2013).
} 
The secondary market liquidity of defaulted bonds, that is, bonds of firms that have defaulted, is important in deriving the endogenous bond liquidity before the firm defaults. Motivated by empirical facts, we make two additional assumptions. First, we assume that bankruptcy leads to a delay in the payout of any cash due to lengthy court proceedings. Second, we assume that the secondary market for defaulted bonds, like the secondary market for predefault bonds, exhibits search frictions and thus illiquidity. We solve for the post-default bond valuations in closed form.

With the post-default bond valuations as boundary conditions, in Section 3 we then solve the system of partial differential equations (PDEs) that describes the bond valuations before the firm defaults. ${ }^{4}$ With the closed-form solution for bond valuations in hand, we solve for the equity valuation and the endogenous default boundary by solving an ordinary differential equation (ODE) in closed form.

We focus on the situation where the post-default secondary market is more illiquid than the pre-default secondary market, an empirical regularity shown in EHP07 and Jankowitsch, Nagler, and Subrahmanyam (2013). In the context of our theoretical framework, we provide a simple analytic sufficient condition for this situation to hold. This sufficient condition essentially requires the (dollar) valuation wedge of default-free infinite-maturity bonds to be less than the valuation wedge of post-default bonds. Under this condition, the endogenous bid-ask spread is shown to be decreasing in the firm's distance-to-default, a robust empirical pattern documented in EHP07 and Bao, Pan, and Wang (2011).

Intriguingly, our model features a positive feedback loop between default and liquidity in the secondary corporate bond market. Imagine an exogenous negative cash flow shock pushing the firm closer to default. Because defaulted bonds suffer greater illiquidity, even before default the increasing chance of facing an illiquid post-default secondary market hurts the $L$ type bond sellers when bargaining with dealers. This gives rise to two effects. The first is a wedge effect, that is, the valuation wedge between $H$ and $L$ investors goes up, resulting in greater transaction costs and a worsening pre-default secondary market liquidity. The second is a level effect, that is, the bond holding value goes down because the looming default leads bond investors to put more weight on the severe post-default illiquidity. These two forces feed back to the primary market where $H$ investors, who understand that later they may be hit by liquidity shocks, are purchasing newly issued bonds. The wider refinancing gap between the newly issued bond prices and promised principals gives rise to heavier rollover losses, causing equity holders to default earlier, and so on and so forth. The outcome of this spiral is a unique fixed-point bankruptcy threshold at which equity holders default.

\footnotetext{
${ }^{4}$ This arises because bond valuations depend on firm fundamental, the bond's time-tomaturity, and the liquidity state of bond holders.
} 
The result that bid-ask spreads decrease with distance-to-default relies on the exogenous assumption that default triggers bond investors to face a more illiquid post-default secondary market as expressed in a greater valuation wedge. However, we emphasize that the timing of default, and thus the firm size at default and the valuation wedge of post-default bonds, are endogenously determined in the model. Because the positive default-liquidity spiral leads equity holders to default earlier at a higher cash flow level, this force gives rise to a higher illiquidity wedge of post-default bonds, strengthening this force further. In this way, the pre-default illiquidity of the secondary market endogenously affects the post-default illiquidity of the secondary market through default.

Our model, thanks to endogenous liquidity, is able to quantitatively explain the empirical pattern of higher bid-ask spreads for lower rated bonds documented in EHP07. We calibrate our model to corporate bonds with six different rating classes ranging from AAA to B. Since one of the key determinants for bond values across various ratings is distance-to-default, our model features desirable parsimony in that we can generate the empirical cross-sectional pattern of illiquidity across credit ratings by adjusting the firm's distance-todefault. We choose holding cost parameters to roughly target the observed percentage bid-ask spread for bonds with investment grade ratings, and then calculate the model implied percentage bid-ask spreads for bonds in other rating classes by matching their leverage ratios. The joint determination of credit spreads and liquidity adds additional discipline to the calibration, and we have an overall good fit cross-sectionally for both bid-ask spreads and credit spreads.

Our paper characterizes a full interdependence between liquidity and default components in the credit spread for corporate bonds. This contrasts with the widely used reduced-form approach in the empirical literature, where it is common to decompose firms' credit spreads into liquidity-premium and default-premium components (e.g., Longstaff, Mithal, and Neis (2005), Beber, Brandt, and Kavajecz (2009), and Schwarz (2010)). To highlight causes versus consequences, we propose a novel model-based decomposition which features liquidity-driven-default and default-driven-liquidity components in addition to pure liquidity and default components. Based on the data in Friewald, Jankowitsch, and Subrahmanyam (2012), we apply this decomposition and quantify the relative contribution of each component to the rise of credit spreads during the 2007-2008 financial crisis. Albeit crude, we believe it is important to understand the impact of liquidity factors upon the credit spread of corporate bonds, and our fully solved structural model and the model-based decomposition are useful in paving the way for more structural approaches in future studies on this topic.

Our paper belongs to the literature on the role of secondary market trading frictions in structural models of corporate finance (Black and Cox (1976), Leland (1994), and LT96). ${ }^{5}$ Ericsson and Renault (2006) analyzed the interac-

\footnotetext{
${ }^{5}$ The secondary bond market trading friction is related to but different from the recent literature on dynamic debt runs such as He and Xiong (2012b), Cheng and Milbradt (2012), and
} 
tion between secondary liquidity and the bankruptcy-renegotiation in a LT96 framework, and Duffie and Lando (2001) studied credit risk when bond investors only have incomplete information. He and Xiong (2012a) took the simplified secondary market friction in Amihud and Mendelson (1986) so that bond investors hit by liquidity shocks are forced to sell their holdings immediately at a constant proportional transaction cost. Because the bond market liquidity was modeled in an exogenous way, He and Xiong (2012a) could not generate movement in the bid-ask spread in line with default risk. In contrast, our paper endogenizes the secondary market liquidity by microfounding the bond trading in a search-based secondary market, and derives equilibrium liquidity jointly with equilibrium asset prices. Our paper is also related to the literature of debt maturity structure (Diamond (1993), Leland (1998), etc.). As illustrated in Section 5.1, the use of short-term debt with a higher rollover frequency features a trade-off between better liquidity provision and earlier inefficient default. Regarding the liquidity provision of shortterm debt, bond investors hit by liquidity shocks can either sell to dealers or sit out shocks by waiting to receive the face value when the bond matures. Shorter maturity improves upon the waiting option, resulting in a lower rent extracted by dealers and thus greater secondary market liquidity. On the other hand, equity holders are absorbing rollover gains/losses ex post. As illustrated in LT96 and shown in He and Xiong (2012a) and Diamond and $\mathrm{He}$ (2013), shorter-term debt with a higher rollover frequency leads to heavier rollover losses in bad times and thus an inefficiently earlier default. This trade-off allows us to endogenize the firm's initial choice of debt maturity, and unlike traditional capital structure models, an optimal finite maturity structure can arise. We borrow from the search-based asset-pricing literature as represented by DGP05, Duffie, Gârleanu, and Pedersen (2007), Weill (2007), Lagos and Rocheteau (2007), Lagos and Rocheteau (2009), Biais and Weill (2009), Feldhütter (2012), among others. To our knowledge, this literature with a concentration on OTC markets has thus far focused on the determinants of contact intensities and behavior of intermediaries, while eschewing time-varying asset fundamentals; for instance, Feldhütter (2012) studied the liquidity of corporate bonds but modeled default as an exogenous Poisson event. ${ }^{6}$ We make three contributions to this literature. First, we incorporate the firm's distance-to-default (and the bond's time-to-maturity) in

Suarez, Schroth, and Taylor (2014), which emphasizes the coordination among bondholders whose debt contracts mature at different times.

${ }^{6}$ Endogenous default with stochastic fundamental is one key building block for our paper. Because corporate bond payoffs are highly nonlinear in firm fundamentals, our closed-form solution with stochastic fundamentals is nontrivial. However, the existing literature often assumes infinite maturity and constant asset payoffs. For instance, focusing on a very different market, Vayanos and Weill (2008) used a search framework to explain the difference between off-the-run and onthe-run treasury yields. As far as we know, the only paper with deterministic time dynamics in a search framework is the contemporaneous Afonso and Lagos (2011), which introduced deterministic time dynamics via an end-of-day trading close in the federal funds market. 
deriving the asset (bond) valuations by modeling asset-specific dynamics in the corporate bond market. Second, our paper links secondary market liquidity to a firm's endogenous default. A firm's default can be viewed as a firmwide liquidity event that endogenizes the exogenous aggregate liquidity shock in Feldhütter (2012). Finally, our paper demonstrates that, via the rollover channel, search-based secondary market liquidity can have a significant impact on firms' behavior on the real side.

Another possibility to micro-found secondary market liquidity would be to assume that dealers face adverse selection problems with regard to the bankruptcy recovery value; well-known models of this strand of literature include Kyle (1985), Glosten and Milgrom (1985), Back and Baruch (2004), and Back and Crotty (2013). We take the search-based approach because the OTC market structure fits the secondary market for corporate bonds well. Besides the advantage of being able to be integrated seamlessly into the dynamic firm setting in LT96, the search-based framework is desirable especially considering the fact that equity markets have much higher liquidity while being subject to more severe asymmetric information problems, and the fact that transaction costs are decreasing with trade size (e.g., EHP07). ${ }^{7}$

We lay out the model in Section 2. Section 3 solves the model in closed form, and illustrates the positive default-liquidity spiral. We calibrate our model to match the cross-sectional pattern of bid-ask spread and credit spreads in Section 4. Section 5 provides discussion and Section 6 concludes. All proofs are in the Appendix. The online appendix provides programs and data used in the calibration (He and Milbradt (2014)).

\section{THE MODEL}

We describe in turn the economic environment of the firm, the firm's debt structure, the secondary bond market, the endogenous default of equity holders, and its impact on the secondary bond market.

\subsection{Firm Cash Flows and Stationary Debt Structure}

We consider a continuous-time model in which a firm has assets-in-place that generate (after-tax) cash flows at a rate of $\delta_{t}>0$, where $\left\{\delta_{t}: 0 \leq t<\infty\right\}$ follows a geometric Brownian motion under the risk-neutral probability measure:

$$
\frac{d \delta_{t}}{\delta_{t}}=\mu d t+\sigma d Z_{t}
$$

\footnotetext{
${ }^{7}$ From the modeling technique side, we do not pursue the path of asymmetric information due to the difficulties inherent in tracking persistent private information. For recent progress in adverse selection in search markets, see Lauermann and Wolinsky (2011) and Guerrieri, Shimer, and Wright (2010) (in directed search, rather than random as we assumed here).
} 
where $\mu$ is the constant growth rate of cash flow rate, $\sigma$ is the constant asset volatility, and $\left\{Z_{t}, \mathcal{F}_{t}: 0 \leq t<\infty\right\}$ is a standard Brownian motion on a complete probability space $(\bar{\Omega}, \mathcal{F}, \mathcal{P})$, representing random shocks to the firm fundamental. We assume the risk-free rate $r$ to be constant in this economy.

We follow LT96 in assuming that the firm maintains a stationary debt structure, which gives us a convenient dynamic setting to analyze the interaction between liquidity and default. At each moment in time, the firm has a continuum of bonds outstanding with an aggregate principal of $p$ and an aggregate coupon payment of $c$, where $p$ and $c$ are constants that we take as exogenously given. We normalize the measure of bonds to 1 , so that each bond has a principal face value of $p$ and a coupon flow of $c$. All bonds have an initial maturity $T$ but differ in their current time-to-maturity $\tau \in[0, T]$. Expirations of bonds are uniformly spread out across time ${ }^{8}$ that is, during a time interval $(t, t+d t)$, a fraction $\frac{1}{T} d t$ of the bonds matures and needs to be rolled over (refinanced). Thus, $1 / T$ is the firm's rollover frequency on its debt, and $T / 2$ is the average maturity of the firm's outstanding bonds. As in LT96, we assume that the firm commits to a stationary debt structure, denoted $(c, p, T)$, in the following sense: when a bond matures, the firm will replace it by issuing a new bond with identical (initial) maturity $T$, principal value $p$, and coupon rate $c$, in the primary market.

\subsection{Secondary Bond Market and Search-Based Liquidity}

In this section, we describe the structure of the search-based secondary market for corporate bonds. All bond transactions are intermediated by dealers who form a competitive inter-dealer market. Throughout, following DGP05, we simply assume that each investor can hold either 0 or 1 unit of the bond, while dealers cannot hold any inventory and are thus pure pass-through intermediaries. ${ }^{9}$

\subsubsection{Idiosyncratic Liquidity Shocks}

As in DGP05, bond investors are subject to idiosyncratic independent and identically distributed (i.i.d.) liquidity shocks with intensity $\xi$. Once hit by a shock, an investor needs to search for dealers to trade with. We model this sudden need for liquidity as an asset holding cost of $\chi \equiv \chi_{p} p+\chi_{c} c$, where the positive coefficient $\chi_{p}\left(\chi_{c}\right)$ is the holding cost per unit of principal $p$ (coupon $c$ ).

\footnotetext{
${ }^{8}$ This assumption of staggered debt maturity structure is made for tractability reasons. Recent empirical findings Choi, Hackbarth, and Zechner (2012) show that firms do spread out their debt maturities in practice.

${ }^{9}$ Allowing for non-intermediated bilateral sales raises the issue that an agent waiting on the sideline meets a probabilistic cross-section of maturities. This results in an integral in the system of PDEs that we cannot solve. It is unclear how such bilateral sales would expand the economic mechanism of our model.
} 
It is a priori unclear whether the holding cost after a liquidity shock should be proportional to coupon or principal, ${ }^{10}$ and this modeling allows for more flexibility in calibration for bonds with different ratings. For simplicity, this liquidity status lasts either until the agent sells the bond, or until the bond matures; after either event, the investor exits the market forever. ${ }^{11}$

We call the non-liquidity-shocked investors $H$ - (high) type investors, and the liquidity-shocked investors $L$ - (low) type investors. The individual liquidity shock is uninsurable and thus results in an incomplete market and typedependent valuations, as explained below.

\subsubsection{Dealers and Competitive Dealer Market}

We model the illiquid secondary debt market based on a search friction. An $L$ investor who wants to sell his debt-holdings has to wait an exponential time with intensity $\lambda$ to meet a dealer. Similarly, an $H$ investor who wants to buy has to wait an exponential time with intensity $\lambda$ to meet a dealer. When investors meet a dealer, bargaining occurs over the economic surplus generated. We follow Duffie, Gârleanu, and Pedersen (2007) and assume Nash-bargaining weights $\beta$ of the investor and $1-\beta$ of the dealer, across all dealer-investor pairs.

Suppose that a contact between a type- $L$ investor and a dealer occurs. As in DGP05, the dealer faces a frictionless competitive inter-dealer market with a continuum of other dealers. In other words, a dealer in contact with an $L$ investor can instantaneously sell a bond at a price $M$ to another dealer who is in contact with an $H$ investor. If he does so, the bond travels from the $L$ investor to the $H$ investor via the help of the two dealers who are connected in the inter-dealer market. Denote by $B$ the bid price at which the $L$-type is selling his bond, by $A$ the ask price at which the $H$-type is purchasing this bond, and by $M$ the inter-dealer market price.

Throughout, we impose the following assumption regarding the relative aggregate buy/sell flows coming to the inter-dealer market.

ASSUMPTION 1: The flow of L-type sellers in contact with dealers is smaller than the flow of $H$-type buyers in contact with dealers.

\footnotetext{
${ }^{10}$ Modeling the consequence of liquidity shocks as a positive holding cost is common in the literature; for example, in DGP05, the holding cost is proportional to the constant dividend (coupon) of a perpetual asset. Empirically, EHP07, Table V, shows that, controlling for creditratings, bid-ask spread is increasing in the coupon rate, suggesting that holding cost is increasing in coupon rate as well. Modeling liquidity shocks as a positive holding cost allows for better analytical properties, which greatly simplify the proof of Proposition 4 . As an alternative, in the working paper version (He and Milbradt (2013)), we modeled liquidity shocks by a rise of discount rate $\bar{r}$ above the risk-free rate $r$. The qualitative results are the same; in fact, Appendix A.4 shows that, when liquidity shocks are modeled as a surge of impatience, the implied effective holding cost increases in both coupon and principal.

${ }^{11}$ This simplifying assumption is relaxed in Appendix A.5.
} 
Assumption 1 amounts to assuming that the secondary market is a seller's market, that is, all the trading surplus goes to the seller-dealer pairs. In Appendix A.5, we analyze the agent masses along the equilibrium path by microfounding the search environment, and provide a sufficient condition of initial investor mass for Assumption 1 to hold. In Appendix A.7, we relax the seller's market assumption for the post-default market.

\subsubsection{Equilibrium Bid-Ask Prices}

Denote the value function of an $H(L)$ investor without bond holdings by $D_{H}^{0}\left(D_{L}^{0}\right)$. As $L$ investors exit the market after selling, $D_{L}^{0}=0$ by assumption. The surplus generated from an $H$ investor buying from a dealer who acquires the bond for a price $M$ on the competitive inter-dealer market is

$$
\Pi_{H}=\left(D_{H}-D_{H}^{0}\right)-M .
$$

Because in equilibrium some dealer- $H$-type pairs have to be rationed without purchase due to an abundance of buyers under Assumption 1 and the assumed zero-inventory restriction on the dealers, as shown in DGP05, Bertrand competition in the inter-dealer market drives the surplus $\Pi_{H}$ to zero. ${ }^{12}$ The zero surplus $\Pi_{H}=0$ also implies that $D_{H}^{0}=0$, as there are no other benefits accruing to an $H$ investor without holdings besides some possible claim to a proportion of surplus $\Pi_{H}$ at the next time of trade. Plugging $D_{H}^{0}=0$ into equation (2), we have the inter-dealer market price $M=D_{H}$, which in turn implies

$$
A=M+(1-\beta) \Pi_{H}=D_{H} .
$$

Although $H$ investors have some positive bargaining power, the excess demand from $H$-dealer pairs in a competitive inter-dealer market (Assumption 1) erodes any surplus this bargaining power could extract.

On the sell side, the bargaining within a dealer- $L$-type pair determines the bid price $B$. As a dealer can instantaneously sell at $M=D_{H}$ through the interdealer market, the surplus from trade is (assuming $D_{H}-D_{L}>0$, which is verified later in Proposition 4)

$$
\Pi \equiv \Pi_{L} \equiv M+\left[D_{L}^{0}-D_{L}\right]=D_{H}-D_{L}>0 .
$$

The bid price $B$ at which $L$ investors sell to the dealer thus implements the following surplus splits:

$$
B(\delta, \tau)=\underbrace{D_{L}(\delta, \tau)}_{\text {-type's outside option }}+\underbrace{\beta \cdot \Pi(\delta, \tau)}_{\text {Appropriated surplus }} .
$$

\footnotetext{
${ }^{12}$ Suppose this were not the case and $\Pi_{H}>0$; then $M<\left(D_{H}-D_{H}^{0}\right)$, and a dealer- $H$-type pair could offer a slightly higher price $M^{\prime}>0$ such that $0<\Pi_{H}^{\prime}<\Pi_{H}$ on the inter-dealer market. This would result in a sure trade and thus a sure positive profit. But this cannot occur with an oversupply of buyers.
} 
As sellers are the only investors able to extract surplus from trade, the term seller's market applies. We summarize our findings in the proposition below.

LEMMA 1: Fix valuations $D_{H}>D_{L}$, a condition verified later in Proposition 4. Under Assumption 1, the ask price $A$ and inter-dealer market price $M$ are equal to $D_{H}$, and the bid price is given by $B=\beta D_{H}+(1-\beta) D_{L}$. The dollar bid-ask spread is $A-B=(1-\beta)\left(D_{H}-D_{L}\right)=(1-\beta) \Pi$.

We prove in Proposition 4 that $\Pi=D_{H}-D_{L} \geq 0$ in equilibrium, so that trade occurs whenever an $L$ investor meets with a dealer. $(1-\beta)\left(D_{H}-D_{L}\right)$ gives the endogenous dollar bid-ask spread for corporate bonds. To be consistent with the empirical literature, later we also consider the percentage bidask spread defined as the dollar spread divided by the midpoint of transaction prices (bid price $B$ and ask price $A$ ).

\subsection{Primary Bond Market, Debt Rollover, and Default}

The firm replaces maturing bonds with newly issued ones of identical facevalue in the so-called primary market, where the firm hires a competitive dealer who can place the new debt to bond investors. We allow for a constant proportional issuance cost $\kappa \in[0,1]$, which plays only a minor role for the qualitative results emphasized in this paper. ${ }^{13}$ Per unit of newly issued bond, the firm receives the net proceeds of $(1-\kappa) D_{H}(\delta, T)$, where $D_{H}(\delta, T)$ is the primary market bond valuation given cash flow $\delta$ and time-to-maturity $T$. Here, for simplicity, we assumed that $H$-type investors are also active in the primary market.

The firm's refinancing/rollover activity leads to rollover gains or losses, which are absorbed by equity holders along with cash inflows and coupon payments. Following LT96, we assume that any gain will be immediately paid out to equity holders and any loss will be funded by issuing more equity at the market price. Thus, over the time interval $(t, t+d t)$, the net cash-flow $\left(N C_{t}\right)$ to equity holders (omitting $d t$ ) is given by

$$
N C_{t}=\underbrace{\delta_{t}}_{\mathrm{CF}}-\underbrace{(1-\pi) c}_{\text {Coupon }}+\underbrace{\frac{1}{T}\left[(1-\kappa) D_{H}\left(\delta_{t}, T\right)-p\right]}_{\text {Rollover }} .
$$

The first term is the firm's operating cash flow, and the second term is the after-tax coupon payment with $\pi$ being the marginal tax benefit of corporate

\footnotetext{
${ }^{13}$ Once we move away from the LT96 stationary debt structure assumption, a strictly positive issuance cost becomes important in making the model robust against "infinite rollover" perturbations. Essentially, with $\kappa>0$, we can rule out a strategy in which $T \rightarrow 0$ and the firm always manages to avoid default by judiciously reducing leverage in response to a sequence of negative shocks.
} 
debt. ${ }^{14}$ The third term captures the firm's rollover gains/losses by issuing new bonds to replace maturing bonds, and can be understood as repricing the bonds at a rate of $1 / T$. The maturing $\frac{1}{T} d t$ fraction of bonds requires a principal payment of $p$ each, while the newly issued bonds in the primary market raise proceeds of $(1-\kappa) D_{H}\left(\delta_{t}, T\right)$ each. When the newly issued bond price $D_{H}\left(\delta_{t}, T\right)$ drops so that $(1-\kappa) D_{H}\left(\delta_{t}, T\right)<p$, equity holders have to absorb negative cash-flow stemming from rollover. Thus, the rollover frequency $1 / T$ (or the inverse of debt maturity) affects the extent of rollover losses/gains.

When the firm issues additional equity to fund these rollover losses, the equity issuance dilutes the value of existing shares. ${ }^{15}$ Equity holders are willing to buy more shares and bail out the maturing debt holders as long as the equity value is still positive (i.e., the option value of keeping the firm alive justifies absorbing the rollover losses). When equity holders, protected by limited liability, declare default at an endogenous threshold $\delta_{b}$, equity value drops to zero. In default, creditors can only recover a fraction of the firm's unlevered value from liquidation, ${ }^{16}$ and for simplicity we assume equal seniority of all creditors.

\subsection{Post-Default Secondary Market and Type-Dependent Recovery Factors}

So far, the model followed the standard assumptions in the Leland-type structural corporate bond pricing literature. However, as we introduced liquidity shocks and holding costs, our bankruptcy treatment has to be more nuanced-if bankruptcy leads investors to receive the same bankruptcy proceeds in exchange for the bond regardless of type, $L$ investors may view default as a beneficial outcome. ${ }^{17}$ This "liquidity by default" runs counter to the fact that, in practice, bankruptcy leads to a more illiquid secondary market, the freezing of assets within the company, and a delay in the payout of any cash depending on court proceedings. The Lehman Brothers bankruptcy in September 2008 is a good example of such a delayed payout; after much legal

\footnotetext{
${ }^{14}$ For each dollar received by bond investors, the government is subsidizing $\pi$ dollars, so that equity holders only have to pay $1-\pi$ dollars. The tax advantage of debt $\pi$ affects the equity holders' endogenous default decision.

${ }^{15} \mathrm{~A}$ simple example works as follows. Suppose a firm has 1 billion shares of equity outstanding, and each share is initially valued at $\$ 10$. The firm has $\$ 10$ billion of debt maturing now, but the firm's new bonds with the same face value can only be sold for $\$ 9$ billion. To cover the shortfall, the firm needs to issue more equity. As the proceeds from the share offering accrue to the maturing debt holders, the new shares dilute the existing shares and thus reduce the market value of each share. If the firm only needs to roll over its debt once, then the firm needs to issue $1 / 9$ billion shares and each share is valued at $\$ 9$. The $\$ 1$ price drop reflects the rollover loss borne by each share.

${ }^{16}$ The bankruptcy cost is standard in the trade-off literature, and can be interpreted in different ways, such as loss of customers or legal fees. Interestingly, as we will introduce inefficient delay in court rulings shortly, our analysis goes through even if there is no bankruptcy cost.

${ }^{17}$ This would be the case, for example, for a Credit Default Swap (CDS) contract written on the firm which features immediate payouts at the time of a bankruptcy/credit event.
} 
uncertainty, payouts to the debt holders only started trickling out after about three and a half years.

Motivated by these observations, we model the post-default secondary market for defaulted bonds based on two key assumptions: first, a payout delay due to court proceedings; second, illiquidity frictions in the post-default market akin to the ones in the pre-default market. ${ }^{18}$ We interpret default as a firm-wide liquidity event that shocks the secondary market parameters as trading moves from the pre- to the post-default market (e.g., all bond holders will be paid at the bankruptcy settlement date; holding costs of $L$-type rise for defaulted bonds; etc.). Although we exogenously link this firm-wide liquidity event to default, the timing of default is endogenously determined in our model. As discussed later, this gives us a forward link from pre- to post-default liquidity, which contrasts with Feldhütter (2012), who studied an exogenous firm-wide liquidity event.

Let us use " $b$ " to indicate the post-bankruptcy market. To capture the delayed emergence payout, we assume that a recovery of a fraction $\alpha$ of the unlevered firm value $\frac{\delta_{b}}{r-\mu}$ occurs at an exponential time with intensity $\theta$. For technical convenience, we assume that cash flows stop during the duration of the legal delay. ${ }^{19}$ Post-default, $H$ investors will be hit by liquidity shocks with intensity $\xi_{b}$, the meeting intensity between investors and dealers is $\lambda_{b}$, and the post-default bargaining power of investors is $\beta_{b}$. In contrast to the pre-default market, there is no coupon and all bonds have the same effective expected maturity $1 / \theta$. Consistent with our pre-default holding cost $\chi=\chi_{p} p+\chi_{c} c$, we assume that $L$ investors incur a holding cost of $\chi_{b} \frac{\delta_{b}}{r-\mu}$ that is proportional to the ultimate recovery payout, and the post-default holding cost parameter $\chi_{b}$ may be significantly higher than pre-default cost parameters. ${ }^{20}$ Among the parameters characterizing the post-default secondary market, the default boundary $\delta_{b}$ is endogenously determined by equity holders in the pre-default market, although it is assumed fixed in the post-default market for bond investors and dealers.

\footnotetext{
${ }^{18}$ For evidence on inefficient delay of bankruptcy resolution, see Gilson, John, and Lang (1990) and Ivashina, Smith, and Iverson (2013). For evidence on illiquid secondary market for defaulted bonds, see Jankowitsch, Nagler, and Subrahmanyam (2013).

${ }^{19}$ The cash flow rate $\delta$ restarts at $\delta_{b}$ once the firm emerges out of bankruptcy to obtain an unlevered firm value of $\frac{\delta_{b}}{r-\mu}$ at time of emergence. This assumption, which can be justified by the interpretation that the asset growth requires normal operation, is for ease of exposition only. Because in our model agents are risk neutral, introducing shocks to $\delta_{b}$ during bankruptcy per se is irrelevant for valuation purposes, as long as the ultimate recovery value $\alpha \frac{\delta_{b}}{r-\mu}$ is still below the promised payments to debt holders. Even if $\alpha \frac{\delta_{b}}{r-\mu}$ may exceed the promised payments and thus debt holders may not get the entire payout, deriving the post-default debt valuations amounts to solving a standard linear ODE, and analytical results are available upon request.

${ }^{20}$ In practice, defaulted bonds that require specialized renegotiation skills typically involve greater risk in their recovery payoffs. A higher liquidity holding cost parameter $\chi_{b}$ is a parsimonious way to capture this effect in our risk-neutral setting.
} 
Denote the post-default bond valuations by $D_{H}^{b}$ and $D_{L}^{b}$. Based on the seller's market environment implied by Assumption 1, an argument similar to Proposition 1 gives the following system of equations that determines the valuations:

$$
\begin{aligned}
& r D_{H}^{b}=0+\xi_{b}\left(D_{L}^{b}-D_{H}^{b}\right)+\theta\left(\alpha \frac{\delta_{b}}{r-\mu}-D_{H}^{b}\right), \\
& r D_{L}^{b}=-\chi_{b} \frac{\delta_{b}}{r-\mu}+\lambda_{b} \beta_{b}\left(D_{H}^{b}-D_{L}^{b}\right)+\theta\left(\alpha \frac{\delta_{b}}{r-\mu}-D_{L}^{b}\right) .
\end{aligned}
$$

Solving the system, we get the following post-default valuations.

LEMMA 2: The post-default market valuations $\mathbf{D}^{b}=\left(D_{H}^{b}, D_{L}^{b}\right)^{\top}$ are given by

$$
\mathbf{D}^{b}=\underbrace{\left[\begin{array}{cc}
r+\xi_{b}+\theta & -\xi_{b} \\
-\lambda_{b} \beta_{b} & r+\lambda_{b} \beta_{b}+\theta
\end{array}\right]^{-1}\left[\begin{array}{c}
\theta \alpha \\
\theta \alpha-\chi_{b}
\end{array}\right]}_{\equiv \boldsymbol{\alpha}} \frac{\delta_{b}}{r-\mu},
$$

where $\boldsymbol{\alpha} \equiv\left(\alpha_{H}, \alpha_{L}\right)^{\top}$ with $\alpha_{H}>\alpha_{L}$ are type-dependent effective bankruptcy recovery factors.

To summarize, the post-default secondary market is characterized by a search market with $H$ - and $L$-type investors and fixed parameters $\left(\chi_{b}, \lambda_{b}, \xi_{b}\right.$, $\left.\beta_{b}, \theta, \delta_{b}\right)$. Because the last parameter $\delta_{b}$ is an endogenous variable determined in the pre-default market, it gives rise to an endogenous forward link from preto post-default market liquidity, a topic that we discuss in more depth in Section 3.4.

The valuation wedge $\left(\alpha_{H}-\alpha_{L}\right) \frac{\delta_{b}}{r-\mu}$ represents the dollar bid-ask spread of defaulted bonds. Throughout the paper, we focus on the situation where the illiquidity of the post-default secondary market is sufficiently high (for a precise condition, see Proposition 4). This assumption, which is supported in the empirical findings in Jankowitsch, Nagler, and Subrahmanyam (2013), ${ }^{21}$ allows us to conform our model to the regular empirical pattern that bonds closer to default have higher bid-ask spreads (e.g., EHP07 and Bao, Pan, and Wang (2011)).

Because our paper mainly focuses on corporate bond pricing and its secondary market illiquidity before the firm defaults, the main purpose of Proposition 2 is to introduce type-dependent effective bankruptcy recovery factors $\boldsymbol{\alpha} \equiv\left(\alpha_{H}, \alpha_{L}\right)^{\top}$; that is, at default the $H$ investors' bond valuation is $\alpha_{H} \frac{\delta_{b}}{r-\mu}$,

${ }^{21}$ Jankowitsch, Nagler, and Subrahmanyam (2013) found that trading volume rises after default, but the transaction cost rises to about 280 bps. We interpret rising trading volumes as a symptom of liquidity events where default triggers involuntary fire-sales of bond holdings. 
while the $L$ investors' one is $\alpha_{L} \frac{\delta_{b}}{r-\mu}$, with $\alpha_{L}<\alpha_{H}$. We note that the recovery factors, by serving as boundary conditions for bond valuations in the predefault market, are a sufficient statistic of the outcome of the post-bankruptcy market. As a result, one may treat the type-dependent recovery factors $\boldsymbol{\alpha}$ as an equilibrium outcome of other more sophisticated post-default trading schemes. In other words, any post-default modeling that delivers the same $\boldsymbol{\alpha}$ will be observationally equivalent in its pre-default predictions that Section 3 focuses on. Moreover, this observation also has important implications for our calibration in Section 4: from standard post-default bond trading data (prices, transaction costs, etc.), we can only identify $\alpha_{H}$ and $\alpha_{L}$-which is our task in Section 4.1.3 - but cannot pin down the underlying parameters without further assumptions. We present a richer post-default model without the seller's market assumption in Appendix A.7.

\subsection{Summary of Setup}

The model setup is summarized in the schematic representation given in Figure 1. For exposition purposes, we omit including the bankruptcy event which occurs when $\delta$ reaches the endogenous default threshold $\delta_{b}$.

PRIMARY MARKET: Let us start with the firm. It (re)issues bonds at a price of $D_{H}$ on the primary market to $H$ investors, as represented via the "Reissue" arrow. After the $H$ investors buy the bond, it may mature before either the bankruptcy occurs or a liquidity shock hits. This event is summarized in the "Maturity" arrow, where the firm retires this bond by paying the principal to the investor. This subpart of the graph represents the LT96 model. With

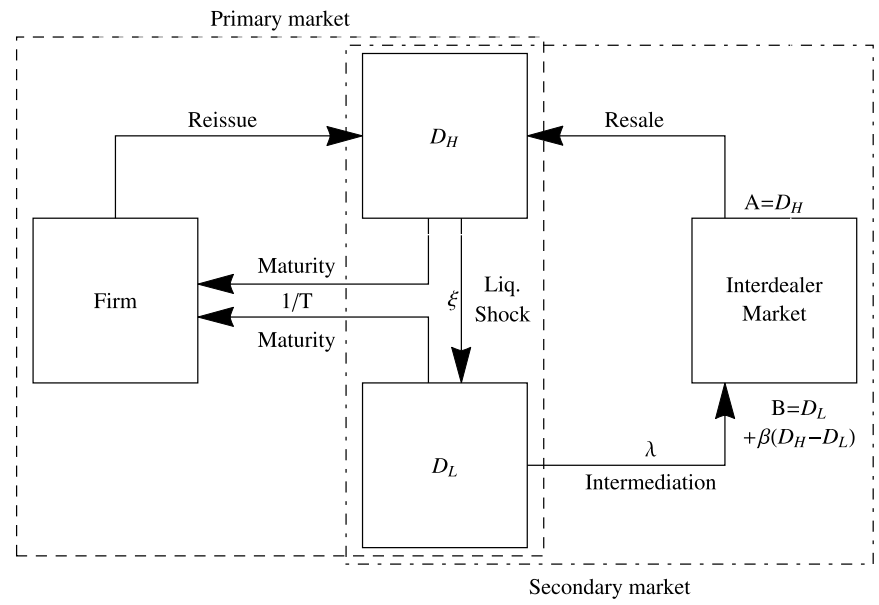

FIGURE 1.-Schematic representation of model. 
liquidity shocks, an $H$ investor transitions to an $L$ investor with intensity $\xi$ who values the bond at $D_{L}$, as represented by the "Liq. shock" arrow. Absent bankruptcy and retrading opportunities, the $L$ investor will be paid back the principal when the bond matures (the "Maturity" arrow again). 1/ $T$ indicates the flow of bonds that mature.

SECONDARY MARKET: Once we introduce the secondary market, $L$ investors can sell their holdings to $H$ investors via the help of dealers. To do so, they contact dealers with an intensity $\lambda$, as indicated by the "Intermediation" arrow. They sell their bond to the dealer at the bid price $B=D_{L}+\beta\left(D_{H}-D_{L}\right)$. The dealer turns around and immediately (re)sells the bond on the inter-dealer market for a price $M=D_{H}$, to a dealer who in turn then sells the bond at the ask price $A=D_{H}$ to an $H$ investor, as indicated by the "Resale" arrow. ${ }^{22}$

\section{MODEL SOLUTIONS}

\subsection{Debt Valuations and Credit Spread}

We first derive bond valuations by taking the firm's default boundary $\delta_{b}$ as given. Recall that $D_{H}(\delta, \tau)$ and $D_{L}(\delta, \tau)$ are the bond value with time-tomaturity $\tau \leq T$, an annual coupon payment of $c$, and a principal value of $p$, to $H$ and $L$ investors, respectively. We have the following system of PDEs for the values of $D_{H}$ and $D_{L}$, where we omit the two-dimensional argument $(\delta, \tau) \in\left(\delta_{b}, \infty\right) \times(0, T)$ for both functions:

$$
\begin{aligned}
& r D_{H}=c-\partial_{\tau} D_{H}+\mu \delta \cdot \partial_{\delta} D_{H}+\frac{\sigma^{2} \delta^{2}}{2} \partial_{\delta \delta} D_{H}+\underbrace{\xi\left(D_{L}-D_{H}\right)}_{\text {Liquidity shock }} \\
& r D_{L}=(c-\chi)-\partial_{\tau} D_{L}+\mu \delta \cdot \partial_{\delta} D_{L}+\frac{\sigma^{2} \delta^{2}}{2} \partial_{\delta \delta} D_{L}+\underbrace{\lambda\left(B-D_{L}\right)}_{\text {Secondary market }} .
\end{aligned}
$$

The boundary conditions are $D_{H}=D_{L}=p$ at $\tau=0$ because of the principal repayment at maturity, and $D_{i}=\alpha_{i} \frac{\delta_{b}}{r-\mu}$ at $\delta=\delta_{b}$, where $i \in\{H, L\}$ as in Lemma 2.

The first equation in (5) defines $D_{H}$. The left-hand side $r D_{H}$ is the required (dollar) return from holding the bond, which equals the right-hand side capturing expected returns from holding the bond. The first term is the coupon payment. The next three terms capture the expected value change due to change in time-to-maturity $\tau$ (the second term) and fluctuation in the cash flow $\delta_{t}$ (the third and fourth terms). The last term is a loss $D_{L}-D_{H}$ caused by liquidity

\footnotetext{
${ }^{22}$ Consequently, before the firm defaults, $H$ investors are indifferent between staying out of the market, buying bonds of maturity $T$ at reissue via the primary market, or buying bonds of maturities $\tau \in(0, T)$ on the secondary market.
} 
shocks that transform $H$ investors into $L$ investors, which occur with an intensity of $\xi$.

The second equation in (5) for $D_{L}$ follows a similar explanation to the one above. The two differences are on the right-hand side: the $L$ investor incurs a holding cost $\chi$, and the last term reflects the value impact of the secondary market. An $L$ investor meets a dealer with an intensity of $\lambda$ and then sells his bond (with a private value $D_{L}$ ) at the bid price $B=D_{L}+\beta\left(D_{H}-D_{L}\right)$. Plugging $B$ into equation (5), we have $\lambda\left(B-D_{L}\right)=\lambda \beta\left(D_{H}-D_{L}\right)$. One can thus interpret $\lambda \beta$ as the bargaining-weighted effective intensity of "transitioning" (via a sale) back from the $L$ state to the $H$ state.

We now define the matrix $\mathbf{A}$ that incorporates the discount factors and the effective transition intensities $\xi$ and $\lambda \beta$ of the states. The following decomposition holds:

$$
\mathbf{A} \equiv\left[\begin{array}{cc}
r+\xi & -\xi \\
-\lambda \beta & r+\lambda \beta
\end{array}\right]=\mathbf{P} \hat{\mathbf{R}} \mathbf{P}^{-1}
$$

where $\hat{\mathbf{R}} \equiv \operatorname{diag}\left[\hat{r}_{1}, \hat{r}_{2}\right]$ with $\hat{r}_{1}=r+\xi+\lambda \beta>r=\hat{r}_{2}$ is the matrix of eigenvalues of $\mathbf{A}$, and $\mathbf{P}$ is the matrix of stacked eigenvectors. We will see that the $\hat{r}_{i}$ 's are akin to effective discount rates as we will be discounting via the term $\exp (-\mathbf{A} \tau)=\mathbf{P} \exp (-\hat{\mathbf{R}} \tau) \mathbf{P}^{-1}$. For a given default boundary $\delta_{b}$, the next proposition gives the closed-form solution for bond valuations.

Proposition 1: The bond valuations are given by

$$
\begin{aligned}
\mathbf{D}(\delta, \tau) \equiv & {\left[\begin{array}{c}
D_{H}(\delta, \tau) \\
D_{L}(\delta, \tau)
\end{array}\right] } \\
= & \underbrace{\mathbf{A}^{-1} \mathbf{c}}_{\equiv \mathbf{k}_{0}^{D}}+\exp (-\mathbf{A} \tau) \underbrace{\left(\mathbf{p}-\mathbf{A}^{-1} \mathbf{c}\right)}_{\equiv \mathbf{k}_{F}^{D}}[1-F(\delta, \tau)] \\
& +\mathbf{P G}(\delta, \tau) \mathbf{P}^{-1} \underbrace{\left(\boldsymbol{\alpha} V_{b}-\mathbf{A}^{-1} \mathbf{c}\right)}_{\equiv \mathbf{k}_{G}^{D}} .
\end{aligned}
$$

Here, by defining $a \equiv \frac{\mu}{\sigma^{2}}-\frac{1}{2}, \varphi_{1} \equiv 0, \varphi_{2} \equiv-2 a, \gamma_{j 1,2} \equiv-a \pm \sqrt{a^{2}+\frac{2}{\sigma^{2}} \hat{r}_{j}}, \mathbf{p} \equiv$ $(p, p)^{\top}, \mathbf{c} \equiv(c, c-\chi)^{\top}$, and $q(\delta, \rho, t) \equiv \frac{\log \left(\delta_{b}\right)-\log (\delta)-(\rho+a) \cdot \sigma^{2} t}{\sigma \sqrt{t}}$, the functions are given by $\mathbf{G}(\delta, \tau)=\left[\begin{array}{cc}G_{1}(\delta, \tau) & 0 \\ 0 & G_{2}(\delta, \tau)\end{array}\right]$,

$$
\begin{aligned}
& F(\delta, \tau) \equiv \sum_{i=1}^{2}\left(\frac{\delta}{\delta_{b}}\right)^{\varphi_{i}} \Phi\left[q\left(\delta, \varphi_{i}, \tau\right)\right], \\
& G_{j}(\delta, \tau) \equiv \sum_{i=1}^{2}\left(\frac{\delta}{\delta_{b}}\right)^{\gamma_{j i}} \Phi\left[q\left(\delta, \gamma_{j i}, \tau\right)\right],
\end{aligned}
$$


where $\Phi(x)$ is the cumulative distribution function for a standard normal distribution.

A closer inspection of the solution reveals a linear combination (via the matrix P) of two LT96 solutions, each composed of three terms: the first term gives the value of a risk-free consol bond, the second term encapsulates the possibility that the bond will mature before default, and the third term encapsulates the possibility that the bond will default before maturity. Relative to LT96, each of these independent subsolutions $i=\{1,2\}$ has a distorted discount rate $\hat{r}_{i}$, a distorted coupon rate $\hat{c}_{i} \equiv\left(\mathbf{P}^{-1} \mathbf{c}\right)_{i}$, a distorted principal $\hat{p}_{i} \equiv\left(\mathbf{P}^{-1} \mathbf{c}\right)_{i}$, and a distorted recovery value $\hat{\alpha}_{i} \equiv\left(\mathbf{P}^{-1} \boldsymbol{\alpha}\right)_{i}{ }^{23}$ Finally, when $\lambda \rightarrow \infty$ so that the secondary market becomes perfectly liquid, bond values converge to the original LT96 case, as a simple inspection of $\mathbf{P}$ reveals.

CREDIT SPREADS: The bond credit spread is defined as the spread between the corporate bond yield and the risk-free rate $r$. Given a bond of value $D(\delta, \tau)$, the bond yield is defined as the unique yield that solves

$$
D(\delta, \tau)=\frac{c}{\text { yield }}\left(1-e^{-y i e l d \cdot \tau}\right)+p \cdot e^{-y i e l d \cdot \tau},
$$

so that the right-hand side is the present value of a bond (discounted by yield) with a constant coupon payment $c$ and a principal payment $p$, conditional on it being held to maturity without default or re-trading. Because the ask price $D_{H}$ is also the price of a newly issued bond, which is commonly used in the structural corporate bond pricing literature, for the remainder of the paper we simply take the ask price $D_{H}(\delta, T)$ in Proposition 1 as our bond price for the left-hand side of equation (7). ${ }^{24}$ For later references, we define the credit spread $c s$ as $c s \equiv$ yield $-r$.

\subsection{Equity Valuation and Firm Value}

Equity holders of the firm receive the net cash flow in (4) every instant. Because equity is naturally an infinite maturity security and we are investigating a stationary (debt maturity structure) setting, the equity value $E(\delta)$ satisfies the following ODE without time dimension:

$$
r E=\delta-(1-\pi) c+\underbrace{\frac{1}{T}\left[(1-\kappa) D_{H}(\delta, T)-p\right]}_{\text {Rollover gain/loss }}+\mu \delta E^{\prime}+\frac{\sigma^{2} \delta^{2}}{2} E^{\prime \prime}
$$

\footnotetext{
${ }^{23}$ Given a matrix $\mathbf{M},(\mathbf{M})_{i}$ selects the $i$ th row and $(\mathbf{M})_{i j}$ selects the $i$ th row and $j$ th column.

${ }^{24}$ Our later calibration results (available upon request) are almost identical if we use mid-price $\frac{1}{2}(A+B)=\frac{1}{2}\left[D_{H}+D_{L}+\beta\left(D_{H}-D_{L}\right)\right]$.
} 
where the left-hand side is the required rate of return of equity holders. On the right-hand side, the first three terms are the equity holders' net cash flows, and the next two terms are capturing the instantaneous change of $\delta_{t}$. As mentioned earlier, the term involving square brackets is the cash flow term that arises from rolling over debt (while keeping coupon, principal, and maturity stationary), with $1 / T$ being the rollover frequency.

Given a default boundary $\delta_{b}$, the next proposition solves for $E\left(\delta ; \delta_{b}\right)$ directly via (8), which is nontrivial due to the highly nonlinear form of $D_{H}(\delta, T)$ given in (6)..$^{25}$

PROPOSITION 2: Given a default boundary $\delta_{b}$, the equity value is given by

$$
\begin{aligned}
E\left(\delta, \delta_{b}\right)= & k_{2}^{E}\left(\frac{\delta}{\delta_{b}}\right)^{\eta_{2}}+\frac{\delta}{r-\mu}+k_{0}^{E} \\
& +\frac{1-\kappa}{T} \mathbf{S}\left[-\exp (-\mathbf{A} T) \mathbf{k}_{F}^{D} g_{F}(\delta)+\mathbf{P g}_{G}(\delta) \mathbf{P}^{-1} \mathbf{k}_{G}^{D}\right],
\end{aligned}
$$

where $\mathbf{g}_{G}(\delta)=\left[\begin{array}{cc}{ }_{G_{1}}(\delta) & 0 \\ 0 & g_{G_{2}}(\delta)\end{array}\right], \eta_{1,2} \equiv-a \pm \sqrt{a^{2}+\frac{2}{\sigma^{2}} r}, \Delta \eta \equiv \eta_{1}-\eta_{2}, \mathbf{S}=(1,0)$, and

$$
\begin{aligned}
k_{0}^{E} \equiv & \frac{1}{r}\{-(1-\pi) c \\
& \left.+\frac{1}{T}\left[(1-\kappa) \mathbf{S}\left(\mathbf{k}_{0}^{D}+\exp (-\mathbf{A} T) \mathbf{k}_{F}^{D}\right)-p\right]\right\}, \\
k_{2}^{E} \equiv & -\left(\frac{\delta_{b}}{r-\mu}+k_{0}^{E}\right. \\
& \left.+\frac{1}{T}(1-\kappa) \mathbf{S}\left[-\exp (-\mathbf{A} T) \mathbf{k}_{F}^{D} g_{F}\left(\delta_{b}\right)+\mathbf{P g}_{G}\left(\delta_{b}\right) \mathbf{P}^{-1} \mathbf{k}_{G}^{D}\right]\right), \\
g_{F}(x) \equiv & \frac{1}{-\Delta \eta} \frac{2}{\sigma^{2}} \sum_{i=1}^{2}\left\{\frac{x^{\eta_{2}}}{\delta_{b}} H\left(x, \varphi_{i}, \eta_{2}, T\right)-\frac{x^{\eta_{1}}}{\delta_{b}} H\left(x, \varphi_{i}, \eta_{1}, T\right)\right\}, \\
g_{G_{j}}(x) \equiv & \frac{1}{-\Delta \eta} \frac{2}{\sigma^{2}} \sum_{i=1}^{2}\left\{\frac{x^{\eta_{2}}}{\delta_{b}} H\left(x, \gamma_{j i}, \eta_{2}, T\right)-\frac{x^{\eta_{1}}}{\delta_{b}} H\left(x, \gamma_{j i}, \eta_{1}, T\right)\right\},
\end{aligned}
$$

${ }^{25}$ The two boundary conditions are $E\left(\delta_{b} ; \delta_{b}\right)=0$ (the equity value drops to zero at default) and $\lim _{\delta \rightarrow \infty}\left|\frac{E\left(\delta ; \delta_{b}\right)}{\delta}\right|<\infty$ (the equity value cannot outgrow the firm value, which is linear in $\delta$ ). It is worthwhile to point out that equity value in our model is no longer the difference between the levered firm value and debt value adjusted for tax benefits and bankruptcy costs, a common calculation performed in Leland-type models. This is because part of the firm value goes to the dealers in the secondary market, and part vanishes because of inefficient holdings by $L$ investors. 


$$
\begin{aligned}
& H(\delta, \rho, \eta, T) \\
& \equiv \begin{cases}\frac{1}{\eta-\rho}\left\{\delta^{\rho-\eta} \Phi[q(\delta, \rho, T)]\right. & \\
\left.-\delta_{b} e^{(1 / 2)\left[(\eta+a)^{2}-(\rho+a)^{2}\right] \sigma^{2} T} \Phi[q(\delta, \eta, T)]\right\}, & \rho \neq \eta, \\
\sigma \sqrt{T}[q(\delta, \rho, T) \Phi[q(\delta, \rho, T)] & \\
& +\phi(q(\delta, \rho, T))],\end{cases}
\end{aligned}
$$

where $q(\cdot, \cdot, \cdot), \mathbf{k}_{0}^{D}, \mathbf{k}_{F}^{D}$, and $\mathbf{k}_{G}^{D}$ are given in Proposition $1, \phi(x)$ is the standard normal density function, and $\mathbf{S}=(1,0)$ is the vector summarizing that debt is issued at $D_{H}$.

\subsection{Endogenous Default Boundary}

So far, we have taken the default boundary $\delta_{b}$ as given. We now use the standard smooth pasting condition $\left.\partial_{\delta} E\left(\delta ; \delta_{b}\right)\right|_{\delta=\delta_{b}}=0$ to determine the optimal $\delta_{b}$ chosen by equity holders.

PROPOSITION 3: The endogenous default boundary $\delta_{b}$ is given by

$$
\begin{aligned}
\delta_{b}= & (r-\mu)\left[\eta_{2}-1+\frac{1-\kappa}{T} \mathbf{S} \cdot \mathbf{P} \cdot \mathbf{h}_{G} \mathbf{P}^{-1} \boldsymbol{\alpha}\right]^{-1} \\
& \times\left[-\eta_{2} k_{0}^{E}+\frac{1-\kappa}{T} \mathbf{S} \cdot\left(\exp (-\mathbf{A} T) \mathbf{k}_{F}^{D} h_{F}+\mathbf{P} \cdot \mathbf{h}_{G} \mathbf{P}^{-1} \cdot \mathbf{k}_{0}^{D}\right)\right],
\end{aligned}
$$

where $\mathbf{h}_{G}=\left[\begin{array}{cc}h_{G_{1}} & 0 \\ 0 & h_{G_{2}}\end{array}\right]$, and

$$
\begin{aligned}
h_{F} \equiv & -\frac{2}{\sigma^{2}} \sum_{i=1}^{2} \frac{1}{\eta_{1}-\varphi_{i}}\left\{\Phi\left[-\left(\varphi_{i}+a\right) \sigma \sqrt{T}\right]\right. \\
& \left.-e^{r T} \Phi\left[-\left(\eta_{1}+a\right) \sigma \sqrt{T}\right]\right\}, \\
h_{G_{j}} \equiv & \left\{\begin{array}{cc}
-\frac{2}{\sigma^{2}} \sum_{i=1}^{2} \frac{1}{\eta_{1}-\gamma_{j i}}\left\{\Phi\left[-\left(\gamma_{j i}+a\right) \sigma \sqrt{T}\right]\right. \\
\left.-e^{\left(r-\hat{r}_{j}\right) T} \Phi\left[-\left(\eta_{1}+a\right) \sigma \sqrt{T}\right]\right\}, & \gamma_{j i} \neq \eta_{1}, \\
\text { see Appendix, } & \gamma_{j i}=\eta_{1} .
\end{array}\right.
\end{aligned}
$$

We note that as $T \rightarrow \infty$, the boundary converges to the one found in Leland (1994). 


\subsection{Endogenous Liquidity}

Recall that Lemma 1 showed that the (dollar) bid-ask spread is simply a fraction of the surplus $\Pi(\delta, \tau)$ :

$$
A(\delta, \tau)-B(\delta, \tau)=(1-\beta)\left[D_{H}(\delta, \tau)-D_{L}(\delta, \tau)\right]=(1-\beta) \Pi(\delta, \tau) .
$$

Empirically, the effective percentage bid-ask spread $\Delta(\delta, \tau)$ is more commonly used (e.g., EHP07, Bao, Pan, and Wang (2011), Jankowitsch, Nagler, and Subrahmanyam (2013)), which is often defined as the dollar bid-ask spread divided by the midpoint of transaction prices:

$$
\Delta(\delta, \tau) \equiv \frac{A(\delta, \tau)-B(\delta, \tau)}{\frac{1}{2} A(\delta, \tau)+\frac{1}{2} B(\delta, \tau)}=\frac{(1-\beta) \Pi(\delta, \tau)}{D_{H}(\delta, \tau)-\frac{1-\beta}{2} \Pi(\delta, \tau)} .
$$

We focus on percentage bid-ask spreads $\Delta(\delta, \tau)$ in later calibrations, and note that a rising $\Delta(\delta, \tau)$ can be due to increasing dollar bid-ask spread $(1-\beta) \Pi(\delta, \tau)$, as well as a drop in the bond value.

Proposition 4, below, gives the key comparative statics for our endogenous liquidity measures under certain sufficient conditions, which are satisfied by our baseline parameters in our later calibration. For the remainder of the text, the term par bond refers to a bond that is issued at par in the primary market, that is, $D_{H}(\delta)=p$.

PROPOSITION 4: For $(\delta, \tau) \in\left(\delta_{b}, \infty\right) \times(0, T)$, we have the following analytic results:

1. Derivative in state space $\delta$.

(a) The dollar bid-ask spread $(1-\beta) \Pi(\delta, \tau)$ is decreasing in $\delta$ if

$$
\left(\alpha_{H}-\alpha_{L}\right) \frac{\delta_{b}}{r-\mu}>\frac{\chi}{r+\xi+\lambda \beta} .
$$

In words, under (12), all else equal, bonds with a lower distance-to-default have higher dollar bid-ask spreads.

(b) Consider bonds with $p>\frac{c}{r}$, which always holds for par bonds (due to potential default). Then, the percentage bid-ask spread $\Delta(\delta, \tau)$ is decreasing in $\delta$ if (12) holds and $D_{H}(\delta, \tau)$ is increasing in $\delta$. One sufficient condition for $D_{H}(\delta, \tau)$ being increasing in $\delta$ is

$$
p>\left[\alpha_{H}+\frac{\xi}{r}\left(\alpha_{H}-\alpha_{L}\right)\right] \frac{\delta_{b}}{r-\mu} .
$$

2. Derivative in time space. The dollar bid-ask spread $(1-\beta) \Pi(\delta, \tau)$ is increasing in $\tau$ if

$$
\alpha_{H}-\alpha_{L}>0 \text {. }
$$


In words, under (14) (so that the post-default market is illiquid), all else equal, shorter-term bonds have lower dollar bid-ask spreads.

3. If the condition in (14) holds, then the surplus from trade $\Pi(\delta, \tau)$ is everywhere nonnegative. This implies that trade always takes place whenever an L-type holding the bond establishes contact with a dealer.

The first set of results implies that our structural model can generate the empirical regularity of higher transaction costs (bid-ask spreads) for bonds issued by lower rating firms. When the firm is far away from bankruptcy, or $\delta \rightarrow \infty$ so that bonds are default-free as in the original DGP05 model, we have

$$
\lim _{\delta \rightarrow \infty} \Pi(\delta, \tau)=\chi\left(\frac{1-e^{-(r+\xi+\lambda \beta) \tau}}{r+\xi+\lambda \beta}\right) .
$$

For the bid-ask spread to be decreasing in the distance-to-default, one intuitive necessary condition is that the bid-ask spread at $\delta=\delta_{b}$ is higher than that at $\delta \rightarrow \infty$. Condition (12) in part 1(a) of Proposition 4 shows that this is almost a sufficient condition, with the small change that we are using the upper bound $\frac{\chi}{r+\xi+\lambda \beta}=\lim _{\tau \rightarrow \infty} \chi\left(\frac{1-e^{-(r+\xi+\lambda \beta) \tau}}{r+\xi+\lambda \beta}\right)$ when $\tau$ becomes large. For the remainder of the paper, we concentrate on situations in which this sufficient condition (12) is satisfied.

Additionally, in (12), we observe that the difference between the valuation wedge for default-free bonds and the valuation wedge for post-default bonds is affected by the endogenous default boundary $\delta_{b}$ that is partially driven by pre-default secondary market illiquidity. As illustrated in the next subsection, the positive default-liquidity feedback leads equity holders to default earlier, which gives rise to a higher $\delta_{b}$. Interestingly, this endogenous force relaxes our sufficiency condition (12), by having a higher post-default illiquidity wedge $\left(\alpha_{H}-\alpha_{L}\right) \frac{\delta_{b}}{r-\mu}$ that is proportional to defaulted firm value, relative to the illiquidity of default-free bonds $\frac{\chi}{r+\xi+\lambda \beta}$ that is independent of $\delta_{b}$. The intuition is that post-default bond holders essentially become equity holders of the firm, and as such the value of their position and the valuation wedge are increasing in the cash-flow size $\delta_{b}$ at default. This way, the pre-default illiquidity of the secondary market endogenously affects the post-default illiquidity of the secondary market through the endogenous default policy $\delta_{b} \cdot{ }^{26}$

\footnotetext{
${ }^{26}$ In our simple post-default search-based model, the endogenous default boundary $\delta_{b}$ only affects the dollar bid-ask spread in post-default market, not the percentage bid-ask spread (which is a function of $\alpha_{H}$ and $\alpha_{L}$ only). To deliver the latter result, a richer and more realistic setting is needed where only hedge funds that are specialized in investing distressed/default securities are the marginal buyers. If these specialized hedge fund investors are wealth-constrained and dealers are also concerned about inventory risk, then a higher $\delta_{b}$, via increasing the total size of defaulted securities, may lead to a greater percentage illiquidity in post-default market. We leave this topic for future research.
} 
Next, result 1(b) shows that the same comparative static results hold for the proportional bid-ask spread, a measure commonly used in the empirical literature. For this, however, we require an additional assumption that $D_{H}(\delta, \tau)$ is increasing in $\delta$. In words, we require that the bond value is lower when closer to default, a condition that is guaranteed if the default recovery is sufficiently low, as in condition (13).

The second result, that the bid-ask spread is increasing in time-to-maturity, is similar to Feldhütter (2012), with the difference that, in our model, maturity is deterministic instead of an intensity-based random variable. A shorter time-tomaturity delivers the principal back to $L$ investors sooner, enhancing $L$-type's outside option in bargaining. This reduces the rent extracted by dealers, resulting in a smaller bid-ask spread. To the extreme, if the bond is almost immediately demandable from the firm, $L$ investors gain little value from trade with dealers, and as a result, the bid-ask spread vanishes (i.e., $\lim _{\tau \rightarrow 0} \Pi(\delta, \tau)=0$ ). In this sense, short-term debt provides liquidity for bond investors who may become impatient. ${ }^{27}$ Of course, a downside exists in that as the aggregate maturity structure is changed such that $T \rightarrow 0$, the endogenous default boundary $\delta_{b}$ tends to increase, as shown in He and Xiong (2012a). This trade-off is discussed in more detail in Section 5.1.

Finally, the third result verifies the conjecture in Lemma 1 that trade occurs with every $L$-dealer contact, which we thus far had implicitly assumed when writing down the $L$ investor's debt valuation equation in (5).

\subsection{Positive Feedback Between Default and Liquidity}

The endogenous liquidity derived in Section 3.4, together with endogenous default, gives rise to a positive default-liquidity spiral. Specifically, deterioration of firm fundamentals leads to a drop in bond values via either the worsening of pre-default secondary market liquidity, or the more likely bankruptcy and thus severe post-default illiquidity. This in turn makes equity holders less willing to rollover and thus edges the firm yet closer to default, leading (again) to a further deterioration in secondary market liquidity.

\subsubsection{Rollover Losses and Endogenous Liquidity}

To understand the mechanism, consider the rollover losses borne by equity holders (recall equation (4)):

$$
N C_{t}=\underbrace{\delta_{t}}_{\mathrm{CF}}-\underbrace{(1-\pi) c}_{\text {Coupon }}+\underbrace{\frac{1}{T}\left[(1-\kappa) D\left(\delta_{t}, T ; \text { liquidity }\right)-p\right]}_{\text {Rollover }},
$$

\footnotetext{
${ }^{27}$ We cannot provide simple sufficient conditions for the percentage bid-ask spread $\Delta(\delta, \tau)$ to be increasing in $\tau$. But, under our parameters, $\Delta(\delta, \tau)$ is increasing in time-to-maturity $\tau$, which is consistent with the empirical pattern.
} 
where $D\left(\delta_{t}, T\right.$; liquidity $)$ is a generic term for primary market debt subject to secondary market illiquidity. With infinite debt maturity $T \rightarrow \infty$ as in Leland (1994), the term "Rollover" vanishes. LT96 featured rollover given a finite debt maturity structure, but without secondary market liquidity. In LT96, when the firm fundamental $\delta$ deteriorates, there are heavier rollover losses $\frac{1}{T}\left[D\left(\delta_{t}, T\right)-p\right]$ because investors adjust the market price of newly issued bonds downward.

In our model with an illiquid secondary market for corporate bonds, "liquidity" of the secondary market enters $(15)$ in the bond pricing $D_{H}\left(\delta_{t}, T\right)=$ $D\left(\delta_{t}, T\right.$; liquidity $\left.\left(\delta_{t}\right)\right)$. This is because $H$ investors who purchase bonds on the primary market worry about the illiquidity they will face when trying to sell their holdings once hit by liquidity shocks. The worse the secondary market liquidity, the lower the primary bond price $D\left(\delta_{t}, T\right.$; liquidity $)$, the heavier the rollover losses borne by equity holders. This lowers the equity holders' option value of keeping the firm alive by servicing the debt, leading to earlier default. Without the "rollover" term (e.g., in Leland (1994) with $T=\infty$ ), the secondary market frictions cannot affect the equity holders' default decision once debt is in place, eliminating the feedback between liquidity and default.

In models with constant secondary market liquidity (e.g., He and Xiong (2012a)), "liquidity" enters $D\left(\delta_{t}, T\right.$; liquidity) in (15) exogenously, and does not depend on the firm's distance-to-default. In contrast, our model endogenously links "liquidity" in $D_{H}\left(\delta_{t}, T\right)=D\left(\delta_{t}, T\right.$; liquidity $\left.\left(\delta_{t}\right)\right)$ to firm fundamental $\delta_{t}$. First, for firms closer to default, the higher illiquidity in the postdefault market and the eventual bankruptcy losses lower the level of bond valuations; this is the "level" effect. Moreover, as shown in Proposition 4, the endogenous bid-ask spread widens especially in bad times when firms are closer to default; this is the "wedge" effect. ${ }^{28}$

\subsubsection{Positive Default-Liquidity Spiral}

Figure 2 illustrates the positive default-liquidity spiral for corporate bond markets in our paper. Imagine a negative shock to the firm's cash-flow rate $\delta$.

\footnotetext{
${ }^{28}$ The first "level" effect, but not the second "wedge" effect, can be delivered by extending He and Xiong (2012a) to allow for delayed bankruptcy payouts with a more illiquid post-default secondary market. More specifically, suppose that the exogenous proportional transaction cost in the pre-default secondary bond market is $k>0$, while the post-default secondary market has a higher constant proportional transaction cost of $K>k$. When the firm gets closer to default, bond prices go down partly due to a higher likelihood of the worse post-default illiquidity, but current liquidity remains the same. We prefer our DGP05 over-the-counter search market modeling for the following reasons. First, our model can generate endogenous rating-dependent proportional bidask spreads before default. Second, the over-the-counter search-based micro-foundation gives guidance in pinning down primitive market friction parameters, which is especially useful in evaluating counterfactuals. Last, as we discuss in Section 5.1, in He and Xiong (2012a) the long-term debt is always preferred over short-term debt because there is no inefficient waiting of $L$ investors (and thus there are less rich welfare implications).
} 


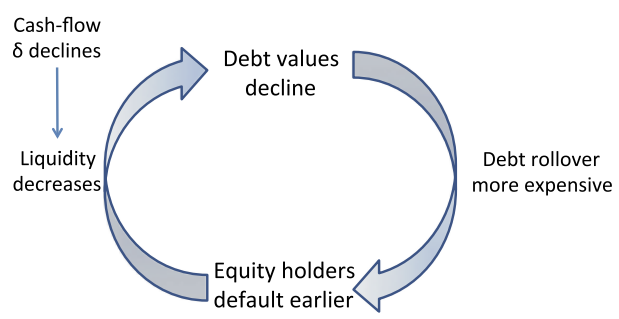

FIGURE 2.-Feedback loop between default and liquidity in the corporate bond market.

Since this negative shock brings the firm closer to default, this shock directly lowers bond investors' valuations $D_{H}$ and $D_{L}$. This force is already present in LT96 and He and Xiong (2012a).

The novelty of our model is that a negative $\delta$ shock not only lowers debt values, but also worsens the secondary market liquidity by moving closer to protracted bankruptcy court decisions and prohibitive holding costs in the postdefault market. This gives rise to two forces that can lower bond valuations even before default, because potential default worsens the seller's bond valuation when bargaining with a dealer. The first is the "level" effect illustrated before: the looming default leads bond investors to put more weight on the relatively higher post-default illiquidity discount. The second is the "wedge" effect, as the dollar bid-ask spread in the pre-default secondary market goes up, as shown in Proposition $4 .{ }^{29}$ We group both "level" and "wedge" forces together as indicated by the left large arrow with "declining liquidity" in Figure 2.

The "declining liquidity" then leads $H$ investors to value bonds less. Indicated by the arrow on the right of Figure 2, the lower bond prices-by generating larger losses in (15)—feed back to the equity holders' default decision via the rollover channel. Equity holders hence default earlier at a higher threshold $\delta_{b}$, which translates into a shorter distance to default. But as shown on the left-hand side in Figure 2, the shorter distance to default further worsens market liquidity via the declining outside option of $L$ investors. Of course, a rational $H$ investor aware of the non-constant liquidity anticipates these changes in liquidity as $\delta$ changes, and the outcome is the simple fixed point $\delta_{b}$ given in Proposition 3.

\section{MODEL CALIBRATIONS}

In this section, we calibrate our model to explore the model's cross-sectional implications. We first explain our parameter choices in Section 4.1. Section 4.2

\footnotetext{
${ }^{29}$ In our later calibration, the proportional bid-ask spread in equation (11), which is widely used in the empirical literature about corporate bond market liquidity, goes up after a negative $\delta$ shock due to both the "level" effect and "wedge" effect.
} 
presents the calibration to bonds of different rating classes, and Section 4.3 discusses the model implications on decomposing the credit spread into default and liquidity components.

\subsection{Parameters}

\subsubsection{Firm Parameters}

Without loss of generality, we normalize the bond face value to $p=1 .^{30}$ The risk-free rate $r=2 \%$ and cash flow rate volatility of $\sigma=25 \%$ are standard in the literature. We set the drift under $\mathcal{Q}$ to $\mu=-2.2 \%$, which essentially affects the overall match between credit spreads and leverage. ${ }^{31}$ We set $\pi=27 \%$ to take into account the effect that many corporate bond investors are tax-exempt financial institutions. ${ }^{32}$ We choose debt maturity $T=10$ to be consistent with the literature on structural bond pricing. This choice also implies that both the mean and median of the maturity of the firm's outstanding debt are $T / 2=5$ years, roughly consistent with Custodio, Ferreira, and Laureano (2013). The issuance cost of $\kappa=1 \%$ is from Chen (2010). Finally, we pin down the coupon $c=4 \%$ and initial cash flow $\delta_{0}=0.12$ by targeting a credit spread of 200 basis points (bps) for BBB rated par bonds (Huang and Huang (2012)).

\subsubsection{Parameters for Search Frictions}

We rely on implied bond illiquidity to determine parameters on search frictions. We choose the liquidity shock intensity $\xi=0.7$ which, together with $\lambda=26$, implies a turnover of about $68 \%$ a year, close to the turnover in the data. ${ }^{33}$ We assume holding costs are given by $\chi=\chi_{p} p+\chi_{c} c$. We choose

\footnotetext{
${ }^{30}$ It is straightforward to show that the model is homogeneous of degree 1 with respect to face value $p$ in that $D_{i}(\delta ; c, \chi, p)=p \cdot D_{i}\left(\frac{\delta}{p} ; \frac{c}{p}, \frac{\chi}{p}, 1\right), E(\delta ; c, \chi, p)=p \cdot E\left(\frac{\delta}{p} ; \frac{c}{p}, \frac{\chi}{p}, 1\right)$, and $\delta_{b}(c, \chi, p)=p \cdot \delta_{b}\left(\frac{c}{p}, \frac{\chi}{p}, 1\right)$. For example, fix the initial cash flow, coupon, holding cost, and principal, that is, fix $\left(\delta_{0}, c, \chi, p\right)$. Then all relative measures, for example, proportional bid-ask spread $\Delta=\frac{A-B}{(A+B) / 2}$, market leverage $M L=\frac{D}{D+E}$, quasi-market leverage $Q L=\frac{p}{p+E}$, and yield spreads, are the same as in a model with initial cash flow and parameters $\left(\frac{\delta_{0}}{p}, \frac{c}{p}, \frac{\chi}{p}, 1\right)$.

${ }^{31}$ Our model is cast in a risk-neutral world. The choice of $\mu=-2.2 \%$ is consistent with a drift of $1.8 \%$ under the physical measure $\mathcal{P}$, a volatility of $10 \%$ on systemic risk, and a price of risk (or Sharpe ratio) of $40 \%$. Our choices of $r$ and $\mu$ are broadly consistent with existing literature on structural corporate bond pricing models. For instance, in Bhamra, Kuehn, and Strebulaev (2010) with two macro states, their primitive parameters imply an average interest rate of $2.36 \%$ and an average real cash flow growth of $-0.66 \%$, under measure $\mathcal{Q}$. In Chen (2010) with nine macro states, under measure $\mathcal{Q}$ the average real interest rate is about $0.67 \%$ and the average real growth is about $-3.4 \%$.

${ }^{32}$ While the tax rate on bond income is $32 \%$, many institutions holding corporate bonds enjoy tax exemption. Thus, we use an effective bond income tax rate of $25 \%$. Then, the formula given by Miller (1977) implies a debt tax benefit of $1-[(1-32 \%)(1-15 \%) /(1-25 \%)]=26.5 \%$, where $32 \%$ is the marginal rate of corporate tax and $15 \%$ is the marginal rate of capital gain tax.

${ }^{33}$ The average turnover in the TRACE database is about $70 \%$ a year. In our model, the average time that an investor is holding the bond (including the time that the investor remains at $H$-type
} 
the holding costs parameters $\chi_{p}=0.32 \%$ and $\chi_{c}=0.11$ to target the bid-ask spreads for $\mathrm{BBB}$ and $\mathrm{AA}$ rated bonds (see Figure 3 below). We explain these choices in more detail in Section 4.2.

For the bargaining power allocation between dealers and investors, we set $\beta=3 \%$ (i.e., dealers get $97 \%$ of the trading surplus) in the baseline case. This is following Feldhütter (2012), which, to the best of our knowledge, is the only paper that provides an estimation of $\beta$ based on a different structural model involving search.

The parameter $\lambda$ is the meeting intensity of investors with dealers. Although we are using a search-based framework to model the secondary corporate bond market, we would like to interpret the trading friction in our model more broadly. For instance, the average time spent during search, which is $1 / \lambda$ in the model, can be interpreted as the time it takes for the liquidity-shocked investors to sell their holdings completely. We choose $\lambda=26$ in the baseline, so that it takes $L$-type investors about 2 weeks to divest of their bond holdings completely. ${ }^{34}$

Since there exist few empirical counterparts to pin down $\beta$ and $\lambda$, we will provide comparative statics with respect to these two parameters in Section 4.2.

\subsubsection{Effective Recovery Rates at Default}

The effective recovery rates at default, that is, $\alpha_{H}$ and $\alpha_{L}$, are the two parameters that anchor the pre-default prices. As the post-default trading data are very sparse, we pin down $\alpha_{H}$ and $\alpha_{L}$ in a model-free way instead of using the structural model developed in Section 2.4. To this end, we use recovery rates derived from first trading prices after default obtained in the existing literature, and the observed bid-ask spreads for defaulted bonds.

We first borrow from existing corporate bond pricing models, for example, Chen (2010), Bhamra, Kuehn, and Strebulaev (2010). The estimate of bankruptcy recovery from Chen (2010) is about $0.5 \frac{\delta_{b}}{r-\mu}$ (average across aggregate states). The bankruptcy recovery in Chen (2010) is defined as the trading price right after default, which is likely to be the bid price $\left[(1-\beta) \alpha_{L}+\beta \alpha_{H}\right] \times$ $\frac{\delta_{b}}{r-\mu}$. We then set the bid-ask spread of defaulted corporate bonds to be $300 \mathrm{bps}$,

and that he is $L$-type but searching) is $\frac{1}{\xi}+\frac{1}{\lambda}$. As we will set $\lambda=26$ in the baseline, $\frac{1}{\xi}+\frac{1}{\lambda}$ is about 1.47 , and $1 /\left(\frac{1}{\xi}+\frac{1}{\lambda}\right)=68 \%$.

${ }^{34}$ This includes the time that the investor needs to find the right dealer(s) who have either the right inventories or the right trading partners, as well as the time that this dealer in turn needs to find the right trading partners. Moreover, in the model, the seller's market in Assumption 1 implies that there are always buyer-dealer pairs waiting to complete the transaction immediately. If we take into account that, in practice, seller-dealer pairs need to wait for buyer-dealer pairs in a symmetric way, then it implies a much higher one-sided meeting intensity. Another noteworthy point is that the choice of $\lambda$ should represent the weighted average of searching length over business cycle under the risk-neutral measure. If it is much harder to find dealers to complete a trade in bad times, then the lengthy waiting time in bad times should receive a greater weight. 
a number based on Jankowitsch, Nagler, and Subrahmanyam (2013), who reported a transaction cost of 280 bps for defaulted bonds. The $\alpha_{H}, \alpha_{L}$ that match the reported trading price and bid-ask spread at default are $\alpha_{H}=51.5 \%$ and $\alpha_{L}=50 \% .{ }^{35}$ One can, of course, translate our choices of effective recovery rates $\alpha_{H}$ and $\alpha_{L}$ to deeper structural parameters in Section 2.4, but it is apparent that we can only identify two parameters with the limited amount of data we have.

\subsubsection{Ultimate Recovery Rate}

In Section 4.3, we further assess the effect of secondary market liquidity on bond pricing, taking into account the liquidity-default interaction established in this paper. This exercise requires us to estimate the ultimate recovery of defaulted bonds, so that we can evaluate the LT96 benchmark without any liquidity frictions. To this end, we use Moody's default and recovery database, which gives the trading price right after default and its eventual recovery value at the settlement (or emergence) date for a total of 641 defaulted corporate bonds from 1987 to $2011 .{ }^{36}$

As our model is cast in the risk-neutral measure, the crucial step in recovering the ultimate recovery $\alpha$ is to adjust for "risk" appropriately. We rely on the commonly accepted Fama-French factor approach. We first form a portfolio that consists of all defaulted bonds for a given year, which is rebalanced annually. Since each bond can take more than one year to emerge from bankruptcy, we amortize the total return into each calendar year based on time spent in each year. We then estimate the multi-factor alpha of the defaulted bond portfolio over 1987-2011 in the spirit of Fama and French (1989, 1992, 1993). Taking the factors to be market excess return, TERM factor (the yield difference between 10-year and 1-month treasuries), and DEF factor (the AAA-BAA spread), the defaulted bond portfolio has an estimated alpha (an annual excess return) of $23 \%(t=2.05) .{ }^{37}$ This excess return applies to the

\footnotetext{
${ }^{35}$ It matters little if we assume the trading price right after default is the bid-price or the midprice. Suppose that, at default, we have price $=y \frac{\delta_{b}}{r-\mu}$ and BAprop $=x$. Then, if we take the midpoint we have $\alpha_{H}-\alpha_{L}=\frac{x y}{1-\beta}$, whereas if we take the bid price we have $\alpha_{H}-\alpha_{L}=\frac{x y}{1-\beta} \frac{1}{1-x / 2}$. Thus, with $x=300 \mathrm{bps}$, taking the bid-price leads to a roughly $1.5 \%$ (proportionally) higher wedge. With midpoint trading price, and $y=1 / 2$, we have $\alpha_{H}=50.8 \%$ and $\alpha_{L}=49.2 \%$.

${ }^{36}$ The trading price right after default is the first transaction price up to 3 months after default. The eventual recovery value is the so-called emergence price, which can be either trading price, settlement price, or liquidation price at the time of bankruptcy emergence. We follow the Moody preferred choice in deciding the bond's eventual recovery value.

${ }^{37}$ The estimated market beta is $0.23(t=0.84)$, TERM beta is $-2.96(t=-0.79)$, and DEF beta is $-0.32(t=-0.03)$, with $R^{2}=5 \%$. When including SMB and HML factors in the regression, the resulting alpha is about $30 \%$; and if we only include market, SMB, and HML factors, the resulting alpha is about $15 \%$. All three specifications have pros and cons, and we decided to take the mean of these three, which is close to the alpha based on market, TERM, and DEF.
} 
average resolution period of 501 days or 1.37 years according to the Moody's default and recovery database. Taking into account the risk-free rate, we set the ultimate recovery in our model, as a fraction of unlevered firm value, to be $\alpha=\alpha_{L} \exp ((23 \%+r) \cdot 1.37) \approx 70.36 \%$ (with risk-free rate $r=2 \%$ ).

Hence, for the LT96 benchmark, the recovery factor at default, if there is no illiquidity in the post-default market, is estimated as $\alpha_{L T}=\alpha \exp (-r \cdot 1.37)=$ $68.46 \%$. In fact, this estimate is obtained by compounding the annual excess return $23 \%$ over the resolution period of 1.37 years (see Section 4.1.4) on the trading price right after default $\alpha_{L}=50.0 \%$, that is, $\alpha_{L T}=\alpha_{L} \exp (23 \%$. $1.37)=68.46 \%$, which is independent of our assumption of risk-free rate.

\subsection{Calibration for Bonds in Different Rating Groups}

We investigate the quantitative performance of our model for corporate bonds across rating classes. Relative to models with exogenous secondary market liquidity (say, He and Xiong (2012a)), tying secondary market liquidity to firm's distance-to-default allows us to parsimoniously generate the empirical cross-sectional pattern of illiquidity across credit ratings by adjusting the firm's distance-to-default. This joint matching requirement imposes additional discipline on our calibration. For empirical moments, from Huang and Huang (2012, page 165, Table 1) we take the leverage ratios (given by Standard \& Poor's (1999)) and credit spreads data for corporate bonds across six rating classes (from AAA to B). We augmented the credit spreads in Huang and Huang (2012) using TRACE data (see captions in Figure 3 below). For bond liquidity across rating classes, EHP07 reported that the bid-ask spread for superior grade (AAA/AA) is about 40 bps, investment grade $(\mathrm{A} / \mathrm{BBB})$ is about $50 \mathrm{bps}$, and junk grade (below BB) is about 70 bps. ${ }^{38}$

We calculate the model-implied bid-ask spreads and credit spreads for two different kinds of bonds, depending on whether we adjust the coupon to ensure the bond is priced at par (recall that we normalized the principal $p=1$ ). For the first kind of bond, the firm cash flow $\delta$ varies but we do not adjust the coupon, and thus, away from $\delta_{0}=0.12$, the bond is no longer priced at par. This treatment corresponds to bonds that have been issued in the past, and fluctuating firm fundamentals lead these bonds to receive different current ratings (e.g., fallen angels).

\footnotetext{
${ }^{38}$ These numbers are taken from EHP07, page 1441, Figure 3 Panel B (rating classes), with median trade size of $240 \mathrm{~K}$ (we take $200 \mathrm{~K}$ for a clean reading of the figure). EHP07 showed that transaction cost is decreasing in trade size, one aspect that our model cannot capture, as we only allow for one trade size for tractability. EHP07 reported one-way transaction costs, which correspond to one half of the percentage bid-ask spread. These estimated transaction costs are higher than the 27 bps reported in Schultz (2001) and Bessembinder, Maxwell, and Venkataraman (2006). We use EHP07 because they reported transaction costs for superior, investment, and junk rated bonds.
} 
For the second kind of bond, we adjust the individual and aggregate coupon $c$ to ensure that the bond is priced at par at whatever the prevailing $\delta$ is. This treatment corresponds to newly issued bonds for different firms, which is standard both in practice and in the structural bond pricing literature (e.g., LT96, Chen (2010)); for more explanation, see Appendix A.6. Unlike non-par bonds whose holding costs $\chi=\chi_{c} c+\chi_{p} p$ are constant, for par bonds the distinction between $\chi_{c}$ and $\chi_{p}$ matters: when $\delta$ varies, adjusting the coupon $c$ (to keep bonds selling at par) implicitly changes the holding costs. Recall that holding costs are a proxy for the need to liquidate assets with some urgency once hit by liquidity shocks. This urgency-related discount leads us to assume $\chi_{c}>0$ because higher coupons and thus higher bond valuation absent of liquidity problems should result in higher holding costs to generate a comparable urgency to sell. See footnote 10 and Appendix A.4 for further explanations.

In the data, bonds in each rating class can be either newly issued bonds or seasoned bonds with rating changes. As a result, we present both calibrations, with the understanding that the empirical moments are a weighted average of both bonds. In choosing parameters $\chi_{c}$ and $\chi_{p}$, we set these two parameters to roughly target the bid-ask spreads of BBB (non-par bonds) and AA (par bonds).

The calibration results are shown in Figure 3, with Panel A depicting credit spreads $c s=$ yield $-r$ and Panel B depicting proportional bid-ask spreads $\Delta$. To be consistent with Huang and Huang (2012), the horizontal axis is quasi-
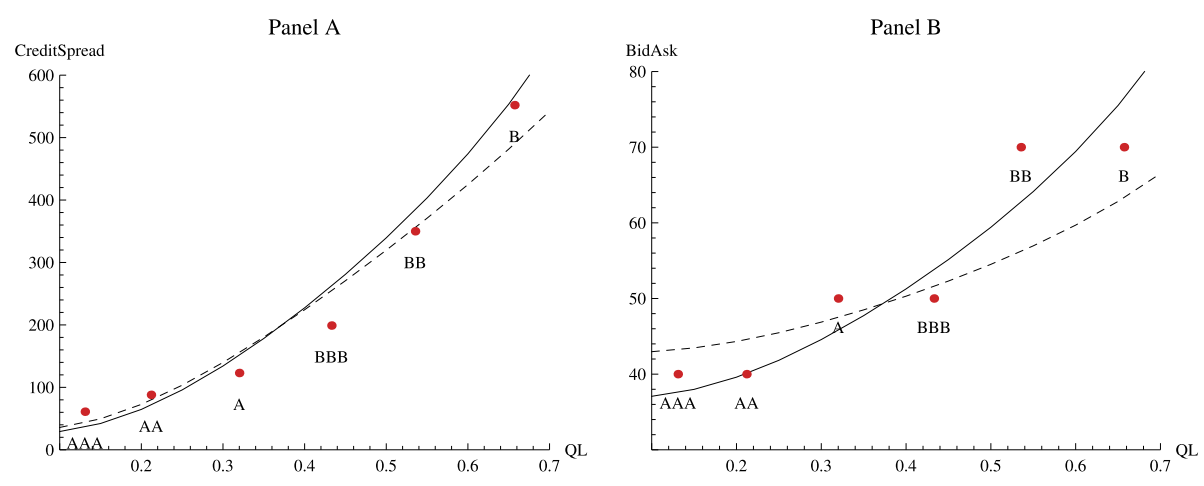

FIGURE 3.-Calibration results. Panel A: Quasi-market leverage versus credit spread. Panel B: Quasi-market leverage versus proportional bid-ask. Solid line: Adjusting $c$ so bond always priced at par. Dashed line: Fixed $c=400$ bps. Dots: Weighted average of empirical credit spreads from Huang and Huang (2012) (mainly from 1970s to 1990s with a weight of 2/3) and that from TRACE (from 2005 to 2012 with a weight of 1/3), where the weights reflect the relative sample lengths. We follow Dick-Nielsen (2009) in cleaning up the TRACE data provided by Financial Industry Regulatory Authority, and calculate credit spread as the difference between the bond's yield and the treasury yield with corresponding maturity. 
market leverage $Q L$, defined as face-value of debt divided by face-value of debt plus market value of equity,

$$
Q L(\delta) \equiv \frac{p}{p+E(\delta)},
$$

which is a simple negative monotone transform of $\delta$ if equity is increasing in $\delta .{ }^{39}$ On each panel, the empirical moments across the rating classes are plotted as solid dots. The solid line graphs the model-implied moments for bonds that are always issued at par, while the dashed line graphs the model-implied moments for bonds without coupon adjustment. In the Panel A, we observe that the model-implied credit spreads match the cross-sectional empirical pattern quite well.

The Panel B graphs model-implied bid-ask spreads as well as empirical moments across different ratings. As expected, the model-implied bid-ask spreads will depend on whether we adjust the coupon rate across different ratings (for the requirement of issue-at-par). Since, all else equal, the holding cost due to a liquidity shock increases with the coupon, this gives rise to an additional issue-at-par effect that makes the bid-ask spread go up for newly issued bonds with lower ratings. As a result, for par bonds (that feature a coupon adjustment to keep the par-pricing throughout varying leverage) the implied bid-ask spreads tend to vary with credit ratings more than that for (non-par) bonds without coupon adjustment. Quantitatively, in our calibration for bonds without coupon adjustment, the change of implied proportional bid-ask spread when varying from superior grade to junk grade is about $24 \mathrm{bps}$ (43 bps for AAA to 67 bps for B), which explains about $2 / 3$ of the bid-ask spread difference in the data. ${ }^{40}$ Overall, acknowledging that the data are some weighted average of both types of bonds that proxy for newly issued and legacy bonds, Figure 3 suggests that our baseline model does a reasonably good job at jointly matching the cross-sectional pattern of credit spread and liquidity quantitatively.

Figure 4 gives comparative static analysis for model-implied bid-ask spreads when we consider a higher meeting intensity $\lambda=52$ (Panel A) and a higher bargaining power $\beta=6 \%$ (Panel $\mathrm{B}$ ). The quantitative effect of $\beta$ is worth discussing. Recall that the dollar bid-ask spread is $(1-\beta) \Pi$ in Proposition 1. The direct effect of a higher $\beta=6 \%$, relative to the baseline $\beta=3 \%$, is quite small (0.94 versus 0.97 , so about $3 \%$ lower). However, a higher $\beta$ reduces the

\footnotetext{
${ }^{39}$ This leverage measure is used by Standard \& Poor's. Note that $Q L \in[0,1]$ with $Q L\left(\delta_{b}\right)=1$, $\lim _{\delta \rightarrow \infty} Q L(\delta)=0$, and $Q L^{\prime}(\delta)<0$ iff $E^{\prime}(\delta)>0$.

${ }^{40}$ The variation of proportional bid-ask spreads can be due to changes in both bond values and dollar bid-ask spreads. Most quantitative evidence of transaction costs being higher for lower rated bonds is on proportional bid-ask spreads (EHP07, Chen, Lesmond, and Wei (2007), Bao, Pan, and Wang (2011)), and we do not have well-established empirical moments of dollar bid-ask spreads to judge the quantitative performance of our model.
} 

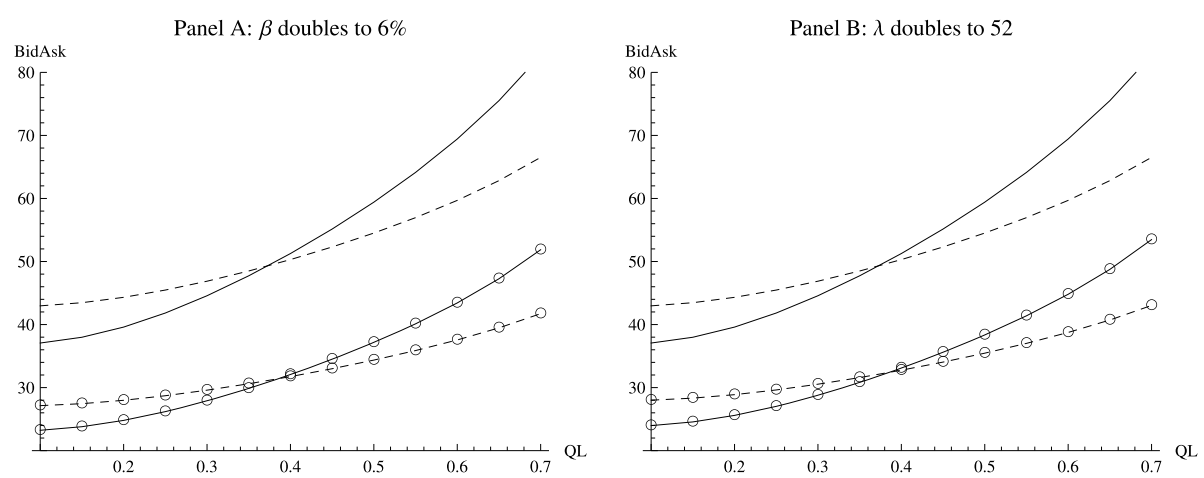

FIGURE 4.-Comparative static results. Panel A: Doubling $\beta$ from baseline 3\% (without circles) to $6 \%$ (with circles). Panel B: Doubling $\lambda$ from baseline 26 (without circles) to 52 (with circles). In both graphs, the solid lines are for par bonds with adjustment in coupon $c$, whereas the dashed lines have a fixed $c=400 \mathrm{bps}$.

endogenous debt valuation wedge $\Pi=D_{H}-D_{L}$ by improving the secondary market liquidity, and indirectly improves primary market prices $D_{H}$ that lead to a more efficient default decision. Figure 4, Panel A, shows a greatly amplified equilibrium effect: controlling for leverage and bond price (BBB par bonds), a higher $\beta=6 \%$ lowers the bid-ask spread from the baseline level 54 bps to $33 \mathrm{bps}$, a relative decrease of $39 \%$.

It is a strong empirical regularity that, in the corporate bond market, transactions costs decrease with trade sizes (e.g., EHP07), and a reasonable explanation is that large trades are executed by large institutional traders who have either higher bargaining power $(\beta)$ or higher connection to dealers $(\lambda)$. This view is consistent with our model, and we leave the analysis with heterogeneous investors for future research.

\subsection{Quantifying the Endogenous Liquidity-Default Interaction}

It has been widely recognized that the credit spread of corporate bonds reflects not only a default premium determined by the firm's credit risk, but also a liquidity premium due to the illiquidity of the secondary debt market (e.g., Longstaff, Mithal, and Neis (2005)). We propose a model-based decomposition which not only nests the additive default-liquidity decomposition used in the literature, but also highlights the novel liquidity-default interaction in our model. We then apply this decomposition to the corporate bond market in the recent 2007/2008 financial crisis.

\subsubsection{A Model-Based Liquidity-Default Decomposition}

It is common practice to decompose firms' credit spreads into liquidity and default components based on CDS prices, and then assess their quantitative 
contributions independently; see, for example, Longstaff, Mithal, and Neis (2005), Beber, Brandt, and Kavajecz (2009), and Schwarz (2010). In the data, however, liquidity and default components of corporate bonds exhibit strong positive correlation (EHP07, Bao, Pan, and Wang (2011)). More recently, Dick-Nielsen, Feldhütter, and Lando (2012) and Friewald, Jankowitsch, and Subrahmanyam (2012) documented that liquidity in the corporate bond market dried up substantially during the $2007 / 2008$ crisis, with a stronger effect for bonds with speculative grade.

Our model further implies that the intuitively appealing decomposition exemplified in Longstaff, Mithal, and Neis (2005) may oversimplify how liquidity and default affect the credit spread. Often, this decomposition leads to the interpretation that liquidity or default is the cause of its corresponding component, and each component would be the resulting credit spread when shutting down the other channel. However, in our model, both liquidity and default are consequences of underlying frictions. For example, improved secondary market liquidity helps mitigate the firm's default risk, suggesting that part of the default premium is in fact driven by liquidity.

To address this issue, we propose a finer decomposition which nests the additive default-liquidity decomposition commonly used in the literature. Essentially, we further decompose the default (liquidity) part into a pure-default (pure-liquidity) part and a liquidity-driven default (default-driven liquidity) part, as follows:

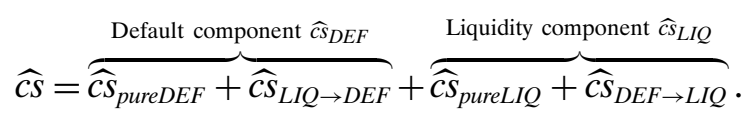

By separating causes from consequences, our decomposition emphasizes that liquidity (default) can lead to the rise of spread through default (liquidity). This conceptually important point is particularly relevant in evaluating the economic consequence of government policies (e.g., improving secondary market liquidity).

Let us start with the default component. Imagine a hypothetical investor who is not subject to liquidity problems (both pre- and post-default) and consider the spread that this investor requires over the treasury rate for holding the corporate bond. The resulting spread, which is $\widehat{c S}_{D E F}$, only prices the default event of hitting $\delta_{b}$. Importantly, the default boundary $\delta_{b}$ in calculating $\widehat{c S}_{D E F}$ is under the assumption that the bond investors are still facing the liquidity and search frictions central to our model. In contrast, we define the "Pure-Default" component $\widehat{c s}_{\text {pureDEF }}$ as the spread implied by the benchmark LT96 model and its corresponding default boundary $\delta_{b}^{L T}$ absent any liquidity frictions in the primary and secondary market. Because illiquidity in the bond market leads to heavier rollover losses and thus an earlier default, the default component $\widehat{c s}_{D E F}$ is larger than the pure-default component $\widehat{c s}_{\text {pureDEF }}$ under LT96. We call the difference $\widehat{c s}_{D E F}-\widehat{c s}_{\text {pure } D E F}$ the "Liquidity-Driven Default" part, which quantifies 
the effect that bond illiquidity in the secondary bond market makes default more likely.

The liquidity component is defined as the difference between the credit spread required by a representative $H$ investor who is subject to liquidity shocks, which is just $\widehat{c S}$ implied by our model, and that required by a hypothetical investor without liquidity shocks while facing the same default boundary, which is $\widehat{c s}_{D E F}$. The definition $\widehat{c s}_{L I Q} \equiv \widehat{c s}-\widehat{c s}_{D E F}$ in (16) is in line with Longstaff, Mithal, and Neis (2005). We then calculate the "Pure-Liquidity" part $\widehat{c s}_{\text {pureLIQ }}$ as the spread implied by the benchmark DGP05 with liquidity frictions but without default. The remaining residual, $\widehat{c s}_{L I Q}-\widehat{c s}_{\text {pureLIQ }}$, is the "Default-Driven Liquidity" part. Economically, the default-driven liquidity part arises because default leads to a more illiquid post-default secondary market, and this in turn affects pre-default liquidity.

\subsubsection{Decomposition Results}

Friewald, Jankowitsch, and Subrahmanyam (2012) reported credit spreads and liquidity measures for both investment and speculative bonds over normal and crisis times, which are given in Table I, Panel A. We focus our exercise on par bonds in the main text; Appendix A.8 gives qualitatively similar results for non-par bonds with a baseline coupon rate of $400 \mathrm{bps}$ (see baseline parameters in Table II).

This subsection focuses on the model-based decomposition in normal times. In Table I, we choose cash flow levels to target the credit spreads of both par bonds in normal times, and Panel $\mathrm{C}$ gives the decomposition under our baseline calibrations. For the LT96 benchmark, recall that the estimated recovery rate was estimated to be $61.67 \%$ in Section 4.1.3 based on Moody's ultimate recovery database.

Not surprisingly, the pure-liquidity component is more important for investment grade bonds $(28 \%)$ compared to speculative grade bonds $(10 \%)$, while the pure-default component is more important for speculative bonds $(62 \%)$ compared to investment grade bonds (47\%). Our main focus, however, is the liquidity-default interaction terms. For investment (speculative) grade bonds with a credit spread of 100 (350) bps, 16\% (21\%) of this credit spread is the default-driven liquidity component, while about $9 \%(7 \%)$ belongs to the liquidity-driven default component. In total, both interaction terms account for about $25 \%-28 \%$ of observed credit spreads for investment and speculative grades.

\subsubsection{Decompositions in Normal Time and Crisis Time}

The 2007/2008 financial crisis exhibited both rising credit spreads and illiquidity in the corporate bond market (Dick-Nielsen, Feldhütter, and Lando (2012), and Friewald, Jankowitsch, and Subrahmanyam (2012)). How much of this change came from a deteriorating fundamental and how much was due 
TABLE I

Default-Liquidity DeCOMPOSITION FOR INVESTMENT AND SPECUlATIVE GRADE PAR BONDS IN NORMAL AND CRISIS TIMES ${ }^{\mathrm{a}}$

\begin{tabular}{|c|c|c|c|c|c|c|}
\hline & \multicolumn{3}{|c|}{ Investment Grade } & \multicolumn{3}{|c|}{ Speculative Grade } \\
\hline & Normal & Crisis & Change & Normal & Crisis & Change \\
\hline \multicolumn{7}{|c|}{ Panel A: Data } \\
\hline Credit spread bps & 97 & 321 & $\begin{array}{c}224 \\
(3.3 \times)\end{array}$ & 348 & 1082 & $\begin{array}{c}734 \\
(3.1 \times)\end{array}$ \\
\hline Illiquidity & 1 & 1.5 & $\begin{array}{c}0.5 \\
(1.5 \times)\end{array}$ & 1 & 2 & $\begin{array}{c}1 \\
(2.0 \times)\end{array}$ \\
\hline \multicolumn{7}{|c|}{ Panel B: Model } \\
\hline Credit spread bps & 100 & 336 & $\begin{array}{c}236 \\
(3.4 \times)\end{array}$ & 350 & 1032 & $\begin{array}{c}682 \\
(2.9 \times)\end{array}$ \\
\hline BA spread bps & 42 & 52 & $\begin{array}{c}10 \\
(1.2 \times)\end{array}$ & 60 & 121 & $\begin{array}{c}61 \\
(2.0 \times)\end{array}$ \\
\hline \multicolumn{7}{|c|}{ Panel C: Model-Based Decomposition } \\
\hline Pure default & $\begin{array}{c}47 \\
(47 \%)\end{array}$ & $\begin{array}{c}216 \\
(64 \%)\end{array}$ & $\begin{array}{c}169 \\
(72 \%)\end{array}$ & $\begin{array}{c}218 \\
(62 \%)\end{array}$ & $\begin{array}{c}714 \\
(69 \%)\end{array}$ & $\begin{array}{c}496 \\
(73 \%)\end{array}$ \\
\hline Liquidity-driven default & $\begin{array}{c}9 \\
(9 \%)\end{array}$ & $\begin{array}{c}19 \\
(6 \%)\end{array}$ & $\begin{array}{c}10 \\
(4 \%)\end{array}$ & $\begin{array}{c}23 \\
(7 \%)\end{array}$ & $\begin{array}{c}38 \\
(4 \%)\end{array}$ & $\begin{array}{c}15 \\
(2 \%)\end{array}$ \\
\hline Pure liquidity & $\begin{array}{c}28 \\
(28 \%)\end{array}$ & $\begin{array}{c}28 \\
(8 \%)\end{array}$ & $\begin{array}{c}0 \\
(0 \%)\end{array}$ & $\begin{array}{c}35 \\
(10 \%)\end{array}$ & $\begin{array}{c}35 \\
(3 \%)\end{array}$ & $\begin{array}{c}0 \\
(0 \%)\end{array}$ \\
\hline Default-driven liquidity & $\begin{array}{c}16 \\
(16 \%)\end{array}$ & $\begin{array}{c}73 \\
(22 \%)\end{array}$ & $\begin{array}{c}57 \\
(24 \%)\end{array}$ & $\begin{array}{c}74 \\
(21 \%)\end{array}$ & $\begin{array}{c}246 \\
(24 \%)\end{array}$ & $\begin{array}{c}172 \\
(25 \%)\end{array}$ \\
\hline Total & $\begin{array}{c}100 \\
(100 \%)\end{array}$ & $\begin{array}{c}336 \\
(100 \%)\end{array}$ & $\begin{array}{c}236 \\
(100 \%)\end{array}$ & $\begin{array}{c}350 \\
(100 \%)\end{array}$ & $\begin{array}{c}1032 \\
(100 \%)\end{array}$ & $\begin{array}{c}682 \\
(100 \%)\end{array}$ \\
\hline
\end{tabular}

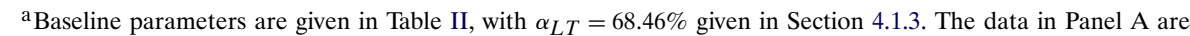
from Friewald, Jankowitsch, and Subrahmanyam (2012). Panel B and Panel C give model-implied moments for par bonds so that credit spread and coupon spread coincide in normal times. To match normal time credit spreads, we adjust the initial cash flow to deliver credit spreads of $100 \mathrm{bps}$ and $350 \mathrm{bps}$ for investment and speculative grade, respectively. Crisis is modeled as a negative cash flow shock of $-50 \%$, which is chosen to target the rise of credit spread of investment grade bonds. Bonds are not at par in crisis times.

to worsening liquidity? Our model allows us to make the first, yet crude, attempt to quantitatively match the observed patterns across both investment and speculative bonds, and quantitatively assess the relative contribution of each component based on the liquidity-default decomposition in (16).

Friewald, Jankowitsch, and Subrahmanyam (2012) reported liquidity measures for both investment and speculative bonds over normal and crisis times, which are shown in Table I, Panel A. To better match our model, we take two well-established transaction cost measures used in Friewald, Jankowitsch, and Subrahmanyam (2012), the Amihud measure and the Roll measure, normalize their normal time levels to be 1 , and report the (simple) average of the rela- 
TABLE II

Model PARAmeters for BASEline CALIBRATIONS

\begin{tabular}{|c|c|c|c|c|c|}
\hline \multicolumn{3}{|c|}{ Firm Characteristics } & \multicolumn{3}{|c|}{ Illiquid Secondary Market } \\
\hline Parameter & Interpretation & Value & Parameter & Interpretation & Value \\
\hline$\sigma$ & Volatility & $25 \%$ & $r$ & Interest rate & $2 \%$ \\
\hline$\mu$ & Drift & $-2.2 \%$ & $\chi_{p}$ & Holding cost prop to $p$ & $0.32 \%$ \\
\hline$\pi$ & Tax shield & $27 \%$ & $\chi_{c}$ & Holding cost prop to $c$ & 0.11 \\
\hline$p$ & Principal & 1 & $\xi$ & Intensity of liquidity shock & 0.7 \\
\hline$c$ & Coupon & $4 \%$ & $\lambda$ & Intensity to meet dealers & 26 \\
\hline$T$ & Bond maturity & 10 & $\beta$ & Bargaining power of investors & $3 \%$ \\
\hline$\kappa$ & Issuance costs & $1 \%$ & $\alpha_{H}$ & Recovery value $H$ type & $51.5 \%$ \\
\hline$\delta_{0}$ & Initial cash flow & 0.12 & $\alpha_{L}$ & Recovery value $L$ type & $50.0 \%$ \\
\hline
\end{tabular}

tive rise of illiquidity in crisis time.$^{41}$ Overall, the bond illiquidity goes up by a factor of 1.5 for investment grade and by a factor of 2.0 for speculative grade. Regarding credit spreads, investment (speculative) grade credit spreads rise from 97 (348) bps to 321 (1082) bps in crisis time.

As our model only has one source of exogenous (cash flow) shocks, we interpret the crisis as a common (aggregate) negative shock $d Z_{t}$ in (1) which affects the cash flow $\delta$ of all firms. Recall that, in Section 4.3.2, we set the normal time initial cash flow rate $\delta_{0}$ for each rating class by targeting the corresponding credit spreads in normal times and pricing at par. We then impose a negative fundamental shock of $d Z_{t}=-50 \%$ to target the rise of the credit spread for investment grade bonds observed in the crisis. Given this negative common shock, Table I, Panel B calculates the model-implied rise in credit spread and illiquidity for bonds with investment grade and speculative grade ratings. Because we are interested in the impact of negative fundamental shocks only, we do not adjust the coupon post-shock, so bonds are not priced at par anymore and there is no change in holding costs. The model roughly matches the data in Panel A (except that the implied multiplier of illiquidity for investment grade is only 1.2 in the model, while it is 1.5 in the data). Interestingly, the smaller of the interaction terms, the liquidity-driven default component, is of the same magnitude as the pure-liquidity component for both bonds in the crisis state.

Panel $\mathrm{C}$ answers the question raised in the beginning: how important is each of the four components in the decomposition (16) in explaining the total rise of

\footnotetext{
${ }^{41}$ For detailed definitions, see Friewald, Jankowitsch, and Subrahmanyam (2012). Friewald, Jankowitsch, and Subrahmanyam (2012, Table 7, page 33) considered four other trading measures: volume, trades, trade intervals, and fraction of zero-return days; all these four measures vary little from normal time to crisis time. They also considered price dispersion, which also tends to be contaminated by trading activities. We focus on the Amihud and the Roll measures because these two measures roughly capture transaction costs (thus close to the endogenous bidask spread in our model), rather than trading intensities.
} 
credit spreads for both grades? For both bonds, the pure-default component $\widehat{c s}_{\text {PUreDEF }}$ rises significantly, and contributes about $72 \%-73 \%$ of the total rise in credit spreads. As expected, there is no rise in the pure-liquidity component, because our model features constant secondary market liquidity without default. On the interaction terms, both default-driven liquidity and liquiditydriven default components go up in crisis, with the default-driven liquidity part being the more quantitatively important one (about 24\%-25\%).

Our model biases against the liquidity-driven default mechanism, because underlying shocks take the form of only cash flow shocks, but not shocks to parameters that characterize the liquidity of the secondary corporate bond market. The recent financial crisis involved both aggregate fundamental shocks and aggregate liquidity shocks, and the latter are missing from our model. Presumably, the aggregate liquidity shock was caused by financial intermediaries (dealers, mutual funds, insurance companies) going into distress and thereby disrupting the functioning of the secondary corporate bond market, which should lend more weight to the liquidity-driven default component. A full investigation of this issue requires one to model time-varying aggregate liquidity states fluctuating with macroeconomic conditions. We pursue such a model and its quantitative performance in matching the non-default component of credit spreads both across ratings and over business cycles in the ongoing project Chen et al. (2013).

\section{DISCUSSION}

\subsection{Optimal Debt Maturity}

In our model, debt maturity features a natural trade-off between liquidity provision and earlier inefficient default. Section 3.4 has shown that bonds with shorter maturity have a more liquid secondary market, suggesting a role of liquidity provision for short-term debt. First, shortening maturity alleviates this inefficiency because of the firm's superior primary market liquidity: whenever debt matures, the firm moves debt from inefficient $L$ investors to efficient $H$ investors via new bond issuance. Second, a shorter maturity reduces the rent extracted by dealers in the secondary market, because a shorter maturity—by allowing $L$ investors to receive principal payment earlier-raises their outside option of waiting. ${ }^{42}$

\footnotetext{
${ }^{42}$ The firm could, instead of providing liquidity via maturity, allow bondholders with liquidity shocks to put back their bonds at face value $p$. There are two important drawbacks. First, if the firm cannot distinguish who was hit by a liquidity shock, whenever $D_{H}<p$ all $H$ investors will put back their debt at the same time. In fact, the put provision is akin to making bonds demand deposits and we are in a traditional model of a bank run. Second, even if the liquidity shock is observable, there will be an additional flow term $\xi\left[D_{H}-p\right] d t$ as $L$ investors are putting back their bonds to the firm every instant. These additional refinancing losses may influence the bankruptcy boundary in an adverse way and destroy the liquidity thus provided. The full implications of expanded bond contract terms are left for future work.
} 
On the other hand, a positive primary market issuing cost $\kappa$ naturally pushes the firm away from using short-term debt. More importantly, as first shown in LT96 (and formally proven in He and Xiong (2012a) and Diamond and He (2013)), ${ }^{43}$ shorter debt maturity in an LT96 style model leads to earlier default and thus greater dead-weight bankruptcy costs. In fact, the optimal maturity in LT96 and He and Xiong (2012a) (even without primary issuing cost $\kappa$ ) is $T^{*}=\infty$, that is, an infinitely lived consol bond is optimal. To see this, recall that the equity holders' rollover gains or losses are $\frac{1}{T}\left[(1-\kappa) D_{H}(\delta, T)-p\right]$ each instant. In bad times (low fundamental $\delta$ ), notwithstanding the fact that shortterm debt has a greater market price $D_{H}(\delta, T)$, the effect of a higher rollover frequency $1 / T$ dominates, leading to heavier rollover losses. As a result, equity holders default earlier if the firm is using a shorter debt maturity structure.

Thus, when equity holders set the firm's maturity structure to maximize the initial firm value (the sum of debt and equity; for the closed-form solution of firm value, see Appendix A.2), the above inherent trade-off between liquidity provision and bankruptcy risk can lead to an interior optimal $T^{*}<\infty .{ }^{44}$ Of course, this is an optimal strategy only in the restricted strategy space of Leland-type models, in that it is within the class of strategies with fixed $T, c$, and $p$. In an earlier version of the paper (He and Milbradt (2013)), we showed that, for low (high) initial leverage, bankruptcy becomes more (less) remote, and the effect of liquidity provision (bankruptcy cost) dominates, resulting in a shorter (longer) optimal debt maturity. A poorly intermediated market also pushes the debt maturity structure to be shorter because there is more liquidity provision benefit via a short maturity structure.

\subsection{Discussion of Asymmetric Information}

In our model, the important driving force behind the spiking bid-ask spread near default is that there is a significant valuation wedge between $H$ - and $L$-type investors for defaulted bonds. In the literature as well as in practice, an equally compelling explanation for the deteriorating liquidity of corporate bonds near default is a possibly worsening adverse selection problem due to information asymmetry. More specifically, one can imagine that some bond investors have private information regarding the bond's recovery value in de-

\footnotetext{
${ }^{43} \mathrm{He}$ and Xiong (2012a) proved this claim for given $(c, p)$ in the LT96 framework. Diamond and $\mathrm{He}$ (2013) proved this claim controlling for leverage, that is, adjusting $(c, p)$ to maintain the same debt value as shifts in the bankruptcy boundary caused by maturity shortening move the value of debt, in the random maturity framework of Leland (1998).

${ }^{44}$ Segura and Suarez (2011) presented a related trade-off in a banking model without secondary markets but with periodic disruptions of the primary market for debt funding. Although the probability of these disruptions is exogenous, the severity of the disruptions is determined by how short the bank's maturity structure is. This is traded off against short-term debt being cheaper outside crisis states. In contrast, our model features an endogenous probability of default that is driven by the maturity structure, and we trade this off against endogenously cheaper short-term debt due to search frictions.
} 
fault. As the firm edges closer to default, the informed agent's information becomes more valuable and he is more likely to attempt to sell his bonds. Thus, to guard against such adversely selected investors, a market maker in the Glosten and Milgrom (1985) tradition would raise the bid-ask spread. Modeling such persistent adverse selection with long-lived bond investors, however, requires a lot more technical apparatus and thus awaits future research. Back and Crotty (2013) provided an interesting paper in this direction.

We believe that search-based frictions play an important role in the overthe-counter-based market. First, if "liquidity" in financial markets is all driven by asymmetric information, then equity markets should be more illiquid than bond markets, contrary to what we observe in practice. Second, the fact that large-sized trades in the secondary corporate bond market are associated with lower transaction costs (see, e.g., EHP07 and Feldhütter (2012)) lends support to the search-based mechanism. In the data, one way to gauge the relative importance between search-based liquidity and asymmetric information is to consider whether the bid-ask spread rises more for small investors (more likely to be driven by search frictions) or large investors (more likely to be driven by information) as the firm nears default. ${ }^{45}$

Last but not least, to the extent that an adverse-selection-based model could conceivably lead to a similar qualitative result if asymmetric information is concentrated in the bond's recovery value, then on the quantitative front our model has the advantage of incorporating standard structural bond valuation models in a simpler setting while still delivering first-order empirical patterns.

\section{CONCLUSION}

We investigate the default-liquidity interactions in the corporate bond market by studying the endogenous liquidity of defaultable bonds in search-based OTC markets jointly with the endogenous default decision by equity holders from the firm side. By solving a system of PDEs and an ODE, we derive the endogenous secondary market liquidity jointly with the debt valuations, equity valuations, and the endogenous default policy, all in closed form. Our calibration suggests that our model is able to quantitatively match the cross-sectional pattern of bid-ask spreads observed in the data.

The equity holders' option value of keeping the firm alive is hurt both by the presence of the rollover channel that exposes the equity holders to the repricing of maturing bonds and by the fact that the liquidity of corporate bonds worsens at the same time that the fundamental cash flow deteriorates significantly. As a result, illiquidity of the secondary corporate bond market feeds back to the distance-to-default of corporate bonds by edging the firm closer to bankruptcy. Our model implies that the endogenous interaction between default and liquidity, which is captured by our model-based default-liquidity de-

\footnotetext{
${ }^{45}$ We thank an anonymous referee for this excellent point.
} 
composition, can be quantitatively important. We hope our fully solved structural model and the resulting structural decomposition are useful in paving the way for more research in understanding the impact of liquidity factors on credit spreads of corporate bonds.

In earlier working paper versions, we further incorporated endogenous firm investment and showed that the mechanism, that is, a feedback loop between the firm fundamental and the firm's (debt) financing liquidity, should encompass a broader set of firm level decisions beyond default.

\section{APPENDIX A: PROOFS AND EXTENSIONS}

\section{A.1. Proofs}

\section{A.1.1. Notation}

First, let us introduce possibly different discount rates for the $H$ and $L$ agents, $r_{H} \equiv r, r_{L} \geq r_{H}, \mathbf{r}=\left(r_{H}, r_{L}\right)^{\top}$. For most of the proofs, we will look at the special case $\mathbf{r}=r \mathbf{1}$, that is, $r=r_{H}=r_{L}$. Second, define $\xi_{H} \equiv \xi$ and $\xi_{L} \equiv \lambda \beta$, and $\tilde{\mu}=\mu-\frac{\sigma^{2}}{2}$, and the $\log$-transform $y=\log (\delta)$ so that $d y=\tilde{\mu} d t+\sigma d Z$. Third, for brevity we use the notation $D^{\prime} \equiv \frac{\partial D}{\partial \delta}$ and $\dot{D} \equiv \frac{\partial D}{\partial \tau}$. We will, with abuse of notation, write $q(y, \ldots)$ to mean $\frac{y_{b}-y+\ldots}{\ldots}$. Let $\Phi(x)$ be the cumulative normal function. We will use $d_{H}(y, T)$ as the debt value in terms of the log-cash flow, so that $d_{H}(y, T)=D_{H}\left(e^{y}, T\right)$. Lastly, $\mathbb{E}[\cdot]$ is the expectations operator.

\section{A.1.2. Pre-Default Debt}

ProOF OF Proposition 1: Applying the $\log$-transform $y=\log (\delta)$ to the system of PDEs, we are left with a linear system of PDEs:

$$
\begin{aligned}
& {\left[\begin{array}{cc}
r_{H}+\xi_{H} & -\xi_{H} \\
-\xi_{L} & r_{L}+\xi_{L}
\end{array}\right]\left[\begin{array}{c}
d_{H} \\
d_{L}
\end{array}\right]=\left[\begin{array}{c}
c \\
c-\chi
\end{array}\right]+\tilde{\mu}\left[\begin{array}{c}
d_{H} \\
d_{L}
\end{array}\right]^{\prime}+\frac{\sigma^{2}}{2}\left[\begin{array}{c}
d_{H} \\
d_{L}
\end{array}\right]^{\prime \prime}-\left[\begin{array}{c}
\dot{d}_{H} \\
d_{L}
\end{array}\right]} \\
& \Longleftrightarrow \mathbf{A} \times \mathbf{d}=\mathbf{c}+\tilde{\mu} \mathbf{d}^{\prime}+\frac{\sigma^{2}}{2} \mathbf{d}^{\prime \prime}-\dot{\mathbf{d}},
\end{aligned}
$$

where $\mathbf{c}=(c, c-\chi)^{\top}$. Let us decompose $\mathbf{A}=\mathbf{P} \hat{\mathbf{D}} \mathbf{P}^{-1}$, where $\hat{\mathbf{R}}$ is a diagonal matrix with its diagonal elements the eigenvalues of $\mathbf{A}$ and $\mathbf{P}$ is a matrix of the respective stacked eigenvectors. For $r_{H}=r_{L}=r$, we have

$$
\begin{aligned}
& \hat{\mathbf{R}}=\left[\begin{array}{cc}
r+\xi+\lambda \beta & 0 \\
0 & r
\end{array}\right], \\
& \mathbf{P}=\left[\begin{array}{cc}
-\xi & 1 \\
\lambda \beta & 1
\end{array}\right], \\
& \mathbf{P}^{-1}=\frac{1}{\xi+\lambda \beta}\left[\begin{array}{ll}
-1 & 1 \\
\lambda \beta & \xi
\end{array}\right] .
\end{aligned}
$$


Premultiplying the system by $\mathbf{P}^{-1}$ and noting that $\mathbf{P}^{-1} \mathbf{A}=\hat{\mathbf{R}} \mathbf{P}^{-1}$, we have a delinked system of PDEs with a common bankruptcy boundary $y_{b} \equiv \log \left(\delta_{b}\right)$ and payout boundary $t=0$ :

$$
\begin{gathered}
\hat{\mathbf{R}} \mathbf{P}^{-1} \mathbf{d}=\mathbf{P}^{-1} \mathbf{c}+\tilde{\mu} \mathbf{P}^{-1} \mathbf{d}^{\prime}+\frac{\sigma^{2}}{2} \mathbf{P}^{-1} \mathbf{d}^{\prime \prime}-\mathbf{P}^{-1} \dot{\mathbf{d}} \\
\Longleftrightarrow \quad \hat{\mathbf{R}} \hat{\mathbf{d}}=\hat{\mathbf{c}}+\tilde{\mu} \hat{\mathbf{d}}^{\prime}+\frac{\sigma^{2}}{2} \hat{\mathbf{d}}^{\prime \prime}-\dot{\hat{\mathbf{d}}},
\end{gathered}
$$

where $\hat{\mathbf{d}}=\mathbf{P}^{-1} \mathbf{d}$ and $\hat{\mathbf{c}}=\mathbf{P}^{-1} \mathbf{c}$. The rows of the system are now delinked, and we are left with two PDEs of the form

$$
\hat{r}_{i} \hat{d}_{i}=\hat{c}_{i}+\tilde{\mu} \hat{d}_{i}^{\prime}+\frac{\sigma^{2}}{2} \hat{d}_{i}^{\prime \prime}-\dot{\hat{d}}_{i}
$$

with given boundary conditions at $t=0$ and $y=y_{b}$, whose solutions are known from LT96. The decomposition works because the boundaries are the same across rows. The solution takes the form

$$
\begin{aligned}
& \hat{d}_{i}=\left(\hat{\mathbf{k}}_{0}^{D}\right)_{i}+\left(\hat{\mathbf{k}}_{F}^{D}\right)_{i} e^{-\hat{r}_{i} t}\left(1-F_{i}\right)+\left(\hat{\mathbf{k}}_{G}^{D}\right)_{i} G_{i}, \\
& F_{j}(y, t)=\sum_{i=1}^{2} e^{\left(y-y_{b}\right) \varphi_{i j}} \Phi\left[q\left(y, \varphi_{i j}, t\right)\right], \\
& G_{j}(y, t)=\sum_{i=1}^{2} e^{\left(y-y_{b}\right) \gamma_{j i}} \Phi\left[q\left(y, \gamma_{j i}, t\right)\right],
\end{aligned}
$$

where

$$
q(y, \rho, t)=\frac{y_{b}-y-(\rho+a) \cdot \sigma^{2} t}{\sigma \sqrt{t}}
$$

and constants

$$
\begin{aligned}
\left(\hat{\mathbf{k}}_{0}^{D}\right)_{i} & =\frac{\hat{c}_{i}}{\hat{r}_{i}}, \\
\left(\hat{\mathbf{k}}_{F}^{D}\right)_{i} & =\left(\hat{p}_{i}-\frac{\hat{c}_{i}}{\hat{r}_{i}}\right), \\
\left(\hat{\mathbf{k}}_{G}^{D}\right)_{i} & =\left(\hat{\alpha}_{i} \frac{e^{y_{b}}}{r-\mu}-\frac{\hat{c}_{i}}{\hat{r}_{i}}\right),
\end{aligned}
$$

and some yet to be determined parameters $\varphi_{i j}, \gamma_{j i}$. Note that $\lim _{t \rightarrow 0} q(y, \rho, t)=$ $\lim _{t \rightarrow 0} \frac{y_{b}-y}{\sigma \sqrt{t}}=-\infty$ as $y_{b}<y$, so $\Phi[q(y, \rho, 0)]=0$ for all $i$ and $y>y_{b}$. Further note that $\lim _{y \rightarrow \infty} q(y, \rho, t)=-\infty$, so $\lim _{y \rightarrow \infty} \Phi[q(y, \rho, t)]=0$. Substituting the 
candidate solution $\hat{d}_{i}$ into the PDE with $\left(\hat{\mathbf{k}}_{0}^{D}\right)_{i}=\frac{\hat{c}_{i}}{\hat{r}_{i}},\left(\hat{\mathbf{k}}_{F}^{D}\right)_{i}=\hat{p}_{i}-\frac{\hat{c}_{i}}{\hat{r}_{i}},\left(\hat{\mathbf{k}}_{G}^{D}\right)_{i}=$ $\hat{\alpha}_{i} \frac{\exp \left(y_{b}\right)}{r-\mu}-\frac{\hat{c}_{i}}{\hat{r}_{i}}$, we see that

$$
\begin{gathered}
b_{i} e^{-\hat{r}_{i} t}\left[\hat{r}_{i}\left(1-F_{i}\right)+\tilde{\mu} F_{i}^{\prime}+\frac{\sigma^{2}}{2} F^{\prime \prime}-\left[\hat{r}_{i}\left(1-F_{i}\right)+\dot{F}_{i}\right]\right] \\
+c_{i}\left[\hat{r}_{i} G_{i}-\tilde{\mu} G_{i}^{\prime}-\frac{\sigma^{2}}{2} G_{i}^{\prime \prime}+\dot{G}_{i}\right]=0 \\
\Longleftrightarrow \quad b_{i} e^{-\hat{r}_{i} t}\left[\tilde{\mu} F^{\prime}+\frac{\sigma^{2}}{2} F^{\prime \prime}-\dot{F}\right] \\
+c_{i}\left[\hat{r}_{i} G_{i}-\tilde{\mu} G_{i}^{\prime}-\frac{\sigma^{2}}{2} G_{i}^{\prime \prime}+\dot{G}_{i}\right]=0 .
\end{gathered}
$$

We see that both $\dot{F}_{i}$ and $\dot{G}_{i}$ have no term $\Phi(\cdot)$. As $q$ is linear in $y$, we have $q^{\prime \prime}=0$ (where $q^{\prime}=q_{y}$ and $\dot{q}=q_{t}$ ). We thus have, for $F$,

$$
\begin{aligned}
& \Phi[q(y, \varphi, t)]\left[\tilde{\mu} \varphi+\frac{\sigma^{2}}{2} \varphi^{2}\right] \\
& \quad+\phi[q(v, \varphi, t)]\left[\tilde{\mu} q^{\prime}+\frac{\sigma^{2}}{2}\left[2 \varphi q^{\prime}-q\left(q^{\prime}\right)^{2}\right]-\dot{q}\right]=0 .
\end{aligned}
$$

So the roots for $F_{i}$ are $\varphi_{1}=-a+a=0$ and $\varphi_{2}=-a-a=-2 a$, where $a \equiv \frac{\tilde{\mu}}{\sigma^{2}}$. We see that this is independent of $i$, that is, it is independent of what row of $\hat{\mathbf{R}}$ we picked, as $\hat{r}_{i}$ is cancelled out. Further, for $G$, we have

$$
\begin{aligned}
& \Phi[q(v, \gamma, t)]\left[\tilde{\mu} \gamma+\frac{\sigma^{2}}{2} \gamma^{2}-\hat{r}_{i}\right] \\
& \quad+\phi[q(v, \gamma, t)]\left[\tilde{\mu} q^{\prime}+\frac{\sigma^{2}}{2}\left[2 \gamma q^{\prime}-q\left(q^{\prime}\right)^{2}\right]-\dot{q}\right]=0,
\end{aligned}
$$

so the roots for $G_{i}$ are $\gamma_{i 1}=\frac{-\tilde{\mu}+\sqrt{\tilde{\mu}^{2}+2 \sigma^{2} \hat{r}_{i}}}{\sigma^{2}}=-a+\sqrt{a^{2}+\frac{2}{\sigma^{2}} \hat{r}_{i}}>0$ and $\gamma_{i 2}=$ $-a-\sqrt{a^{2}+\frac{2}{\sigma^{2}} \hat{r}_{i}}<0$. Simply plugging in the functional form of $q$ results in the term in square brackets in the second row vanishing.

For the boundary condition, we have

$$
\begin{aligned}
& \hat{\mathbf{d}}(y, 0)=\mathbf{P}^{-1} \mathbf{1} \cdot p=\hat{\mathbf{p}}, \\
& \hat{\mathbf{d}}\left(y_{b}, t\right)=\mathbf{P}^{-1} \boldsymbol{\alpha} \frac{\exp \left(y_{b}\right)}{r-\mu}=\hat{\boldsymbol{\alpha}} \frac{\exp \left(y_{b}\right)}{r-\mu},
\end{aligned}
$$

which defines the remaining parameters of the solution. 
As a last step, we retranslate the system back into the original debt functions by premultiplying by $\mathbf{P}$ and noting that $F(v, t)=F_{i}(v, t)=F_{-i}(v, t)$ by the symmetry of the $\varphi$ 's, and by rewriting it in terms of $\delta=\exp (y)$. Q.E.D.

\section{A.1.3. Equity}

ProOf OF Proposition 2: Equity has the following ODE where

$$
r E=\exp (y)-(1-\pi) c+\tilde{\mu} E^{\prime}+\frac{\sigma^{2}}{2} E^{\prime \prime}+\frac{1}{T}\left[D_{H}(y, T)-p\right] .
$$

The term in square brackets is the cash flow term that arises out of rollover of debt (while keeping coupon, principal, and maturity stationary), a term first pointed out by LT96. We will establish the (closed-form) solution in several steps.

First, the homogeneous solutions to the ODE are $M(y)=e^{\eta_{1} y}$ and $U(y)=$ $e^{\eta_{2} y}$, where

$$
\frac{\sigma^{2}}{2} \eta^{2}+\tilde{\mu} \eta-r=0
$$

so that

$$
\eta_{1 / 2}=\frac{-\tilde{\mu} \pm \sqrt{\tilde{\mu}^{2}+2 \sigma^{2} r}}{\sigma^{2}}=-a \pm \sqrt{a^{2}+\frac{2}{\sigma^{2}} r}
$$

and $\eta_{1}>1>0>\eta_{2}$ by $\mu<r$.

Next, let us establish the Wronskian

$$
\begin{aligned}
W r(s) & =M(s) U^{\prime}(s)-M^{\prime}(s) U(s) \\
& =-\left(\eta_{1}-\eta_{2}\right) \exp \left\{\left(\eta_{1}+\eta_{2}\right) s\right\} \\
& =-\Delta \eta \cdot M(s) U(s) .
\end{aligned}
$$

Then, by the variation of coefficient solutions to linear ODEs, a technique described in most textbooks on differential equations, we have for an ODE

$$
r g=\tilde{\mu} g^{\prime}+\frac{\sigma^{2}}{2} g^{\prime \prime}+\operatorname{part}(s)
$$

the following particular solution $g_{p}$ :

$$
\begin{aligned}
g_{p}(x \mid l) & =\frac{2}{\sigma^{2}} \int_{x}^{l} \operatorname{part}(s) \frac{M(s) U(x)-M(x) U(s)}{W r(s)} d s \\
& =\frac{2}{\sigma^{2}} \int_{x}^{l} \operatorname{part}(s) \frac{e^{-\eta_{2} s} e^{\eta_{2} x}-e^{\eta_{1} x} e^{-\eta_{1} s}}{-\Delta \eta} d s
\end{aligned}
$$




$$
\begin{aligned}
g_{p}^{\prime}(x \mid l)= & \frac{2}{\sigma^{2}} \int_{x}^{l} \operatorname{part}(s) \frac{M(s) U^{\prime}(x)-M^{\prime}(x) U(s)}{W r(s)} d s \\
= & \frac{2}{\sigma^{2}} \int_{x}^{l} \operatorname{part}(s) \frac{\eta_{2} M(s) U(x)-\eta_{1} M(x) U(s)}{W r(s)} d s, \\
g_{p}^{\prime \prime}(x \mid l)= & \frac{2}{\sigma^{2}} \int_{x}^{l} \operatorname{part}(s) \frac{\eta_{2}^{2} M(s) U(x)-\eta_{1}^{2} M(x) U(s)}{W r(s)} d s \\
& -\frac{2}{\sigma^{2}} \operatorname{part}(x)
\end{aligned}
$$

for an arbitrary limit $l \in\left(y_{b}, \infty\right)$.

Second, as the debt term $D_{H}$ is bounded, to impose the condition that equity does not grow orders of magnitude faster than the unlevered value of the firm $V(y)=\frac{e^{y}}{r-\mu}$ we need $\lim _{y \rightarrow \infty}\left|\frac{E(y)}{V(y)}\right|<\infty$. Let us write the solution as

$$
\begin{aligned}
E(y)= & k_{U}^{E} U(y)+k_{M}^{E} M(y)+V(y)+k_{0}^{E} \\
& +\int_{y}^{l} \frac{2}{\sigma^{2}} \operatorname{part}(s) \frac{M(s) U(y)-M(y) U(s)}{W r(s)} d s,
\end{aligned}
$$

where we incorporated all constant terms of the ODE into the definition of $k_{0}^{E}$ and $\operatorname{part}(s)$ is thus just composed of cumulative normal functions of the form $\Phi[-a a \cdot y+b b]$ where $a a>0$. Let us gather terms of $U(y)$ and $M(y)$ to get

$$
\begin{aligned}
E(y)= & U(y)\left[k_{U}^{E}+\int_{y}^{l} \frac{2}{\sigma^{2}} \operatorname{part}(s) \frac{M(s)}{W r(s)} d s\right] \\
& +M(y)\left[k_{M}^{E}-\int_{y}^{l} \frac{2}{\sigma^{2}} \operatorname{part}(s) \frac{U(s)}{W r(s)} d s\right]+\frac{e^{y}}{r-\tilde{\mu}}+k_{0}^{E} .
\end{aligned}
$$

First, let us note that the integrals all converge, as $\Phi[-a a \cdot y+b b]$ converges faster than any function $e^{c s t y}$ for any constant cst. Second, to impose the boundary condition of $\lim _{y \rightarrow \infty}\left|\frac{E(y)}{V(y)}\right|<\infty$, we note that $\lim _{y \rightarrow \infty} U(y)=0$ so the first term in the above equation converges for any choice of $K_{U}$. However, the second term contains $M(y)$, which explodes to infinity faster than $e^{y}$ as $\eta_{1}>1$. We thus need to pick

$$
k_{M}^{E}(l)=-\int_{l}^{\infty} \frac{2}{\sigma^{2}} \operatorname{part}(s) \frac{U(s)}{W r(s)} d s
$$


as a necessary condition to have the term stay bounded. Next, plugging it in, we see that the term in question becomes

$$
\begin{gathered}
M(y)\left[K_{M}(l)-\int_{y}^{l} \frac{2}{\sigma^{2}} \operatorname{part}(s) \frac{U(s)}{W r(s)} d s\right] \\
=-M(y) \int_{y}^{\infty} \frac{2}{\sigma^{2}} \operatorname{part}(s) \frac{U(s)}{W r(s)} d s
\end{gathered}
$$

and we now show that this term converges to 0 as $y \rightarrow \infty$. Let us rewrite to get

$$
\begin{gathered}
\lim _{y \rightarrow \infty}-M(y) \int_{y}^{\infty} \frac{2}{\sigma^{2}} \operatorname{part}(s) \frac{U(s)}{W r(s)} d s \\
=\lim _{y \rightarrow \infty} \frac{-\int_{y}^{\infty} \frac{2}{\sigma^{2}} \operatorname{part}(s) \frac{U(s)}{W r(s)} d s}{\frac{1}{M(y)}}=\frac{" 0 "}{“ 0 ”} \\
\stackrel{\text { L'Hopital\} }}{=} \lim _{y \rightarrow \infty} \frac{\frac{2}{\sigma^{2}} \operatorname{part}(y) \frac{U(y)}{W r(y)}}{\frac{M^{\prime}(y)}{[M(y)]^{2}}}=0,
\end{gathered}
$$

and again, we see that since $U(y), W r(y), M(y), M^{\prime}(y)$ are all of exponential form and $\operatorname{part}(y)$ is of cumulative normal form, this term converges to zero rapidly, and the solution to $E(y)$ is verified. Let us take the arbitrary limit $l \rightarrow \infty$ and define $g_{p}(x) \equiv g_{p}(x \mid \infty)$. We note that the complement of the integrals (i.e., $\int_{l}^{\infty} \cdot d s$ ) vanishes, so that $\lim _{l \rightarrow \infty} K_{M}(l)=0$. We see that $g_{p}(x)$ and $g_{p}^{\prime}(x)$ (and so forth) consist of a finite sum of integrals of the form $\int_{x}^{\infty} e^{c s t . s} \Phi[q(s, \rho, T)] d s$ where $c s t$ is a constant.

Third, let us briefly establish two auxiliary results. First, let us note that, for $a a>0$, we have

$$
a a \int_{x}^{\infty} \phi(-a a \cdot s+b b) d s=\int_{-\infty}^{-a a \cdot x+b b} \phi(y) d y=\Phi[-a a \cdot x+b b]
$$

by simple change of variables. Second, note that

$$
\begin{aligned}
& e^{c s t \cdot x} \phi(-a a \cdot x+b b) \\
& \quad=\frac{1}{\sqrt{2 \pi}} \exp \left\{-\frac{1}{2}\left[(-a a \cdot x+b b)^{2}-2 c s t \cdot x\right]\right\}
\end{aligned}
$$




$$
\begin{aligned}
& =\frac{1}{\sqrt{2 \pi}} \exp \left\{-\frac{1}{2}\left[\left(-a a \cdot x+b b+\frac{c s t}{a a}\right)^{2}+b b^{2}-\left(b b+\frac{c s t}{a a}\right)^{2}\right]\right\} \\
& =\phi\left(-a a \cdot x+b b+\frac{c s t}{a a}\right) e^{(c s t /(a a))(b b+(1 / 2)(c s t /(a a)))}
\end{aligned}
$$

by a simple completion of the square. Now, we can solve the integral in question via integration by parts:

$$
\begin{aligned}
\int_{x}^{\infty} & e^{c s t \cdot s} \Phi[-a a \cdot s+b b] d s \\
= & \left.\frac{e^{c s t \cdot s}}{c s t} \Phi[-a a \cdot s+b b]\right|_{s=x} ^{\infty} \\
& +\frac{1}{c s t}\left[a a \cdot \int_{x}^{\infty} e^{c s t \cdot s} \phi(-a a \cdot s+b b) d s\right] \\
= & -\frac{e^{c s t \cdot x}}{c s t} \Phi[-a a \cdot x+b b] \\
& +\frac{1}{c s t}\left[a \int_{x}^{\infty} \phi\left(-a a \cdot s+b b+\frac{c s t}{a a}\right) d s\right] e^{(c s t /(a a))(b b+(1 / 2)(c s t /(a a)))} \\
= & -\frac{e^{c s t} \cdot x}{c s t} \Phi[-a a \cdot x+b b] \\
& +\frac{1}{c s t} \Phi\left[-a a \cdot x+b b+\frac{c s t}{a a}\right] e^{(c s t /(a a))(b b+(1 / 2)(c s t /(a a)))},
\end{aligned}
$$

where we again used the fact that the cumulative normal vanishes faster than any exponential function explodes. We also need

$$
\begin{aligned}
\int_{x}^{\infty} & \Phi[-a a \cdot s+b b] d s \\
= & \left.s \Phi[-a a \cdot s+b b]\right|_{s=x} ^{\infty}+a a \int_{x}^{\infty} \phi(-a a \cdot s+b b) d s \\
= & -x \Phi[-a a \cdot x+b b] \\
& +\frac{1}{a a}\{\phi(-a a \cdot x+b b)+b b \cdot \Phi[-a a \cdot x+b b]\} \\
= & \frac{1}{a a}[(-a a \cdot x+b b) \Phi[-a a \cdot x+b b]+\phi(-a a \cdot x+b b)],
\end{aligned}
$$

which is essentially $\lim _{c s t \rightarrow 0} \int_{x}^{\infty} e^{c s t \cdot s} \Phi[-a a \cdot s+b b] d s$. Next, note that $D_{i}(y, t)=$ $\cdots+\cdots e^{\left(y-y_{b}\right) \rho} \Phi[q(y, \rho, t)]+\cdots$ for some $\rho$, so that we are essentially facing 
integrals

$$
\begin{aligned}
\frac{2}{\sigma} \int_{x}^{\infty} e^{\left(s-y_{b}\right) \rho} \Phi[q(s, \rho, t)] \frac{M(s) U(x)}{W r(s)} d s \\
=\frac{2}{\sigma} \frac{1}{-\Delta \eta} e^{\eta_{2} x} e^{-y_{b} \rho} \int_{x}^{\infty} e^{\left(\rho-\eta_{2}\right) s} \Phi[q(s, \rho, t)] d s \\
=\frac{2}{\sigma} \frac{1}{-\Delta \eta} e^{\eta_{2} x} e^{-y_{b} \rho} \\
\quad \times \frac{1}{\rho-\eta_{2}}\left[-e^{\left(\rho-\eta_{2}\right)} \Phi[q(x, \rho, t)]\right. \\
\left.\quad+\Phi\left[q\left(x, \eta_{2}, t\right)\right] e^{\left(\rho-\eta_{2}\right)\left\{y_{b}-(1 / 2)\left[(\eta+a)^{2}-(\rho+a)^{2}\right] \sigma^{2} T\right\}}\right] .
\end{aligned}
$$

Here, we used $c s t=\left(\rho-\eta_{2}\right), a a=\frac{1}{\sigma \sqrt{T}}, b=\frac{y_{b}-(\rho+a) \sigma^{2} T}{\sigma \sqrt{T}}, q(x, \rho, t)+(\rho-\eta) \times$ $\sigma \sqrt{t}=q(x, \eta, t)$, and the fact that

$$
\begin{aligned}
& (\rho-\eta)(-)\left[\rho+a-\frac{1}{2}(\rho-\eta)\right] \\
& =(\rho-\eta)(-)\left[\frac{1}{2} \rho+\frac{1}{2} a+\frac{1}{2} \eta+\frac{1}{2} a\right] \\
& =\frac{1}{2}\left[(\eta+a)^{2}-(\rho+a)^{2}\right],
\end{aligned}
$$

where we note that the last term is independent of whether we pick the larger or smaller root, as both $\eta$ and all possible $\rho$ are centered around $-a$. Lastly, we note that $\frac{2}{\sigma} \int_{x}^{\infty} e^{\left(s-y_{b}\right) \rho} \Phi[q(s, \rho, t)] \frac{M(x) U(s)}{W r(s)} d s$ has the same form of solution only with $\eta_{1}$ replacing $\eta_{2}$. Define

$$
\begin{aligned}
H(x, \rho, \eta, T) \equiv & \int_{x}^{\infty} e^{(\rho-\eta) \cdot s} \Phi[q(s, \rho, T)] d s \\
= & -\frac{1}{c s t}\left\{e^{c s t \cdot x} \Phi[q(x, \rho, T)]\right. \\
& -e^{c s t \cdot y_{b}} \exp \left\{-c s t\left(\rho+a-\frac{1}{2} c s t\right) \sigma^{2} T\right\} \\
& \times \Phi[q(x, \rho, T)+c s t \cdot \sigma \sqrt{T}]\} \\
= & \frac{1}{\eta-\rho}\left\{e^{(\rho-\eta) x} \Phi[q(x, \rho, T)]\right. \\
& \left.-e^{(\rho-\eta) y_{b}} e^{(1 / 2)\left[(\eta+a)^{2}-(\rho+a)^{2}\right] \sigma^{2} T} \Phi[q(x, \eta, T)]\right\}
\end{aligned}
$$


if $\rho \neq \eta$, and define

$$
\begin{aligned}
H(x, \rho, \eta, T) & \equiv \int_{x}^{\infty} e^{(\rho-\eta) \cdot s} \Phi[q(s, \rho, T)] d s=\int_{x}^{\infty} \Phi[q(s, \rho, T)] d s \\
& =\sigma \sqrt{T}[q(s, \rho, T) \Phi[q(s, \rho, T)]+\phi(q(s, \rho, T))]
\end{aligned}
$$

for $\rho=\eta$. Note that

$$
\begin{aligned}
& H\left(y_{b}, \rho, \eta, T\right)
\end{aligned}
$$

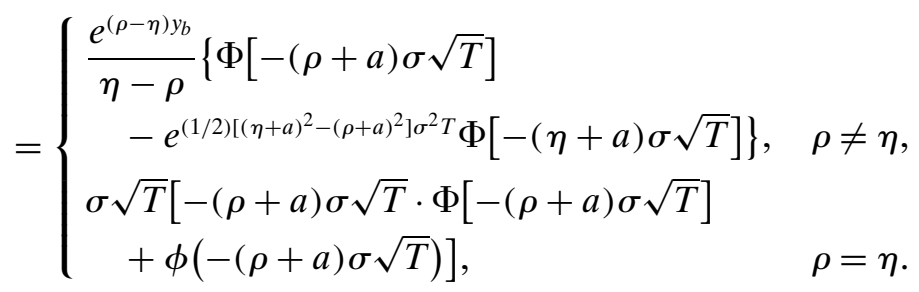

The solution to the particular part for $F$ then is

$$
\begin{aligned}
g_{F}(x) \equiv & \frac{2}{\sigma^{2}} \int_{x}^{\infty} F(s) \frac{M(s) U(x)-M(x) U(s)}{W r(s)} d s \\
= & \frac{1}{-\Delta \eta} \frac{2}{\sigma^{2}} \sum_{i=1}^{2}\left\{e^{\eta_{2} x} e^{-\varphi_{i} y_{b}} H\left(x, \varphi_{i}, \eta_{2}, T\right)\right. \\
& \left.-e^{\eta_{1} x} e^{-\varphi_{i} y_{b}} H\left(x, \varphi_{i}, \eta_{1}, T\right)\right\}, \\
g_{F}^{\prime}(x) \equiv & \frac{2}{\sigma^{2}} \int_{x}^{\infty} F(s) \frac{\eta_{2} M(s) U(x)-\eta_{1} M(x) U(s)}{W r(s)} d s \\
= & \frac{1}{-\Delta \eta} \frac{2}{\sigma^{2}} \sum_{i=1}^{2}\left\{\eta_{2} e^{\eta_{2} x} e^{-\varphi_{i} y_{b}} H\left(x, \varphi_{i}, \eta_{2}, T\right)\right. \\
& \left.-\eta_{1} e^{\eta_{1} x} e^{-\varphi_{i} y_{b}} H\left(x, \varphi_{i}, \eta_{1}, T\right)\right\},
\end{aligned}
$$

and the solution to the particular part for $G_{j}$ is

$$
\begin{aligned}
g_{G_{j}}(x) \equiv & \frac{2}{\sigma^{2}} \int_{x}^{\infty} G_{j}(s) \frac{M(s) U(x)-M(x) U(s)}{W r(s)} d s \\
= & \frac{1}{-\Delta \eta} \frac{2}{\sigma^{2}} \sum_{i=1}^{2}\left\{e^{\eta_{2} x} e^{-\gamma_{j i} y_{b}} H\left(x, \gamma_{j i}, \eta_{2}, T\right)\right. \\
& \left.-e^{\eta_{1} x} e^{-\gamma_{j i} y_{b}} H\left(x, \gamma_{j i}, \eta_{1}, T\right)\right\},
\end{aligned}
$$




$$
\begin{aligned}
g_{G_{j}}^{\prime}(x) \equiv & \frac{2}{\sigma^{2}} \int_{x}^{\infty} G_{j}(s) \frac{\eta_{2} M(s) U(x)-\eta_{1} M(x) U(s)}{W r(s)} d s \\
= & \frac{1}{-\Delta \eta} \frac{2}{\sigma^{2}} \sum_{i=1}^{2}\left\{\eta_{2} e^{\eta_{2} x} e^{-\gamma_{j i} y_{b}} H\left(x, \gamma_{j i}, \eta_{2}, T\right)\right. \\
& \left.-\eta_{1} e^{\eta_{1} x} e^{-\gamma_{j i} y_{b}} H\left(x, \gamma_{j i}, \eta_{1}, T\right)\right\}
\end{aligned}
$$

Plugging in $x=y_{b}$, and noting that $q\left(y_{b}, \rho, t\right)=-(\rho+a) \sigma \sqrt{t}$, we make the important observation that

$$
\begin{aligned}
e^{\eta y_{b}} e^{-\rho y_{b}} H\left(y_{b}, \rho, \eta, T\right)= & \frac{1}{\eta-\rho}\{\Phi[-(\rho+a) \sigma \sqrt{T}] \\
& \left.-e^{(1 / 2)\left[(\eta+a)^{2}-(\rho+a)^{2}\right] \sigma^{2} T} \Phi[-(\eta+a) \sigma \sqrt{T}]\right\}
\end{aligned}
$$

is independent of $y_{b}$. We thus conclude that for any particular part, $g_{p}\left(y_{b}\right)$, of the form given above, and its derivative $g_{p}^{\prime}\left(y_{b}\right)$ are independent of $y_{b}$ besides $C\left(y_{b}\right)$ containing $e^{y_{b}}$. Also note that for $\rho=\left\{\varphi_{1}, \varphi_{2}\right\}$, we have

$$
e^{(1 / 2)\left[(\eta+a)^{2}-(\varphi+a)^{2}\right] \sigma^{2} T}=e^{r T}
$$

and for $\rho=\left\{\gamma_{i 1}, \gamma_{i 2}\right\}$ we have

$$
e^{(1 / 2)\left[(\eta+a)^{2}-\left(\gamma_{j i}+a\right)^{2}\right] \sigma^{2} T}=e^{\left(r-\hat{r}_{i}\right) T} .
$$

Total equity is now easily written out to be

$$
\begin{aligned}
E(y)= & k_{2}^{E} e^{\eta_{2}\left(y-y_{b}\right)}+\frac{e^{y}}{r-\mu}+k_{0}^{E}+g_{p}(y) \\
= & k_{2}^{E} e^{\eta_{2}\left(y-y_{b}\right)}+\frac{e^{y}}{r-\mu}+k_{0}^{E} \\
& +\frac{1}{T} \mathbf{S} \cdot \mathbf{P}\left[-\exp (-\hat{\mathbf{R}} T) \hat{\mathbf{k}}_{F}^{D} g_{F}(y)+\mathbf{g}_{G}(y) \hat{\mathbf{k}}_{G}^{D}\right],
\end{aligned}
$$

where we scaled the constants $k_{U}^{E}$ by $e^{-\eta_{2} y_{b}}$ so that $k_{2}^{E}=k_{U}^{E} \cdot e^{-\eta_{2} y_{b}}$. The constant term $k_{0}^{E}$ is

$$
k_{0}^{E}=\frac{1}{r}\left\{-(1-\pi) c+\frac{1}{T} \mathbf{S} \cdot \mathbf{P}\left[\hat{\mathbf{k}}_{0}^{D}+\exp (-\hat{\mathbf{R}} T) \hat{\mathbf{k}}_{F}^{D}-p\right]\right\} .
$$

The constant $K$ is derived by setting

$$
\begin{aligned}
0 & =E\left(y_{b}\right) \\
& =k_{2}^{E}+\frac{e^{y_{b}}}{r-\mu}+k_{0}^{E}+\frac{1}{T} \mathbf{S} \cdot \mathbf{P}\left[-\exp (-\hat{\mathbf{R}} T) \hat{\mathbf{k}}_{F}^{D} g_{F}\left(y_{b}\right)+\mathbf{g}_{G}\left(y_{b}\right) \hat{\mathbf{k}}_{G}^{D}\right]
\end{aligned}
$$




$$
\begin{aligned}
\Longleftrightarrow \quad k_{2}^{E}\left(y_{b}\right)= & -\left(\frac{e^{y_{b}}}{r-\mu}+k_{0}^{E}\right. \\
& \left.+\frac{1}{T} \mathbf{S} \cdot \mathbf{P}\left[-\exp (-\hat{\mathbf{R}} T) \hat{\mathbf{k}}_{F}^{D} g_{F}\left(y_{b}\right)+\mathbf{g}_{G}\left(y_{b}\right) \hat{\mathbf{k}}_{G}^{D}\right]\right) .
\end{aligned}
$$

The term in brackets only features linear combinations of constants independent of $y_{b}$.

Q.E.D.

\section{A.1.4. Optimal Default}

Proof of Proposition 3: The optimal $\delta_{b}=e^{y_{b}}$ is now easily derived. Plugging $k_{2}^{E}\left(y_{b}\right)$ into the smooth pasting condition $E^{\prime}\left(y_{b}\right)=0$, we can derive $\delta_{b}=e^{y_{b}}$ in closed form:

$$
\begin{aligned}
0= & E^{\prime}\left(y_{b}\right) \\
= & k_{2}^{E}\left(y_{b}\right) \eta_{2}+\frac{e^{y_{b}}}{r-\mu}+\frac{1}{T} \mathbf{S} \cdot \mathbf{P}\left[\exp (-\hat{\mathbf{R}} T) \hat{\mathbf{k}}_{F}^{D} g_{F}^{\prime}\left(y_{b}\right)+\mathbf{g}_{G}^{\prime}\left(y_{b}\right) \hat{\mathbf{k}}_{G}^{D}\right] \\
= & \eta_{2}\left(\frac{e^{y_{b}}}{r-\mu}+k_{0}^{E}+\frac{1}{T} \mathbf{S} \cdot \mathbf{P}\left[-\exp (-\hat{\mathbf{R}} T) \hat{\mathbf{k}}_{F}^{D} g_{F}\left(y_{b}\right)+\mathbf{g}_{G}\left(y_{b}\right) \hat{\mathbf{k}}_{G}^{D}\right]\right) \\
& +\frac{e^{y_{b}}}{r-\mu}+\frac{1}{T} \mathbf{S} \cdot \mathbf{P}\left[\exp (-\hat{\mathbf{R}} T) \hat{\mathbf{k}}_{F}^{D} g_{F}^{\prime}\left(y_{b}\right)+\mathbf{g}_{G}^{\prime}\left(y_{b}\right) \hat{\mathbf{k}}_{G}^{D}\right] \\
= & -\frac{e^{y_{b}}}{r-\mu}\left[\eta_{2}-1+\frac{1}{T} \mathbf{S} \cdot \mathbf{P}\left\{\eta_{2} \mathbf{g}_{G}\left(y_{b}\right)-\mathbf{g}_{G}^{\prime}\left(y_{b}\right)\right\} \hat{\boldsymbol{\alpha}}_{1}\right]-\eta_{2} k_{0}^{E} \\
& +\frac{1}{T} \mathbf{S} \cdot \mathbf{P}\left[\exp (-\hat{\mathbf{R}} T) \hat{\mathbf{k}}_{F}^{D}\left\{\eta_{2} g_{F}\left(y_{b}\right)-g_{F}^{\prime}\left(y_{b}\right)\right\}\right. \\
& \left.+\left\{\eta_{2} \mathbf{g}_{G}\left(y_{b}\right)-\mathbf{g}_{G}^{\prime}\left(y_{b}\right)\right\}\left(\hat{\mathbf{k}}_{0}^{D}-\hat{\boldsymbol{\alpha}}_{0}\right)\right],
\end{aligned}
$$

which yields

$$
\begin{aligned}
\delta_{b}= & e^{y_{b}} \\
= & (r-\mu)\left[\eta_{2}-1+\frac{1}{T} \mathbf{S} \cdot \mathbf{P}\left\{\eta_{2} \mathbf{g}_{G}\left(y_{b}\right)-\mathbf{g}_{G}^{\prime}\left(y_{b}\right)\right\} \hat{\boldsymbol{\alpha}}_{1}\right]^{-1} \\
& \times\left[-\eta_{2} k_{0}^{E}+\frac{1}{T} \mathbf{S} \cdot \mathbf{P} \exp (-\hat{\mathbf{R}} T) \hat{\mathbf{k}}_{F}^{D}\left\{\eta_{2} g_{F}\left(y_{b}\right)-g_{F}^{\prime}\left(y_{b}\right)\right\}\right. \\
& \left.+\frac{1}{T} \mathbf{S} \cdot \mathbf{P}\left\{\eta_{2} \mathbf{g}_{G}\left(y_{b}\right)-\mathbf{g}_{G}^{\prime}\left(y_{b}\right)\right\}\left(\hat{\mathbf{k}}_{0}^{D}-\hat{\boldsymbol{\alpha}}_{0}\right)\right],
\end{aligned}
$$

where we note that the right-hand side is independent of $y_{b}$ by previous results. We can simplify further by noting that each of the terms in curly brackets can 
be written as

$$
\begin{aligned}
\eta_{2} g_{F}\left(y_{b}\right)-g_{F}^{\prime}\left(y_{b}\right) \\
=\eta_{2} \frac{2}{\sigma^{2}} \int_{y_{b}}^{\infty} F(s) \frac{M(s) U\left(y_{b}\right)-M\left(y_{b}\right) U(s)}{W r\left(y_{b}\right)} d s \\
\quad-\frac{2}{\sigma^{2}} \int_{y_{b}}^{\infty} F(s) \frac{\eta_{2} M(s) U\left(y_{b}\right)-\eta_{1} M\left(y_{b}\right) U(s)}{W r\left(y_{b}\right)} d s \\
=\frac{2}{\sigma^{2}} \int_{y_{b}}^{\infty} F(s) \frac{\left(\eta_{1}-\eta_{2}\right) M\left(y_{b}\right) U(s)}{W r\left(y_{b}\right)} d s \\
=-\frac{2}{\sigma^{2}} \sum_{i=1}^{2} e^{\left(\eta_{1}-\varphi_{i}\right) y_{b}} H\left(y_{b}, \varphi_{i}, \eta_{1}, T\right) .
\end{aligned}
$$

We thus established a closed form, albeit quite complex, for the optimal $y_{b}$.

The $\operatorname{limit}_{\lim _{T \rightarrow \infty}} \delta_{b}$ can be easily derived by noting that the normal distributions converge either to 0 or 1 , so the only difficulty remaining is the term $e^{(1 / 2)\left[\left(\eta_{1}+a\right)^{2}-\left(\varphi_{i}+a\right)^{2}\right] \sigma^{2} T}$. Let us establish a series of results.

First, we note that in addition to $e^{(1 / 2)\left[\left(\eta_{1}+a\right)^{2}-\left(\varphi_{i}+a\right)^{2}\right] \sigma^{2} T}=e^{r_{H} T}$, we have

$$
e^{(1 / 2)\left[\left(\eta_{1}+a\right)^{2}-\left(\gamma_{j i}+a\right)^{2}\right] \sigma^{2} T}=e^{\left(r_{H}-\hat{r}_{j}\right) T},
$$

and since we established that $\hat{r}_{j}>r_{H}$, we note that this term is converging to zero.

Second, we note that

$$
\begin{aligned}
& \lim _{T \rightarrow \infty} \frac{\Phi\left[-\left(\eta_{1}+a\right) \sigma \sqrt{T}\right]}{e^{-r_{H} T}} \\
& =\frac{\text { “0” }}{“ 0 ”}=\lim _{T \rightarrow \infty} \frac{\left(\Phi\left[-\left(\eta_{1}+a\right) \sigma \sqrt{T}\right]\right)^{\prime}}{\left(e^{-r_{H} T}\right)^{\prime}} \\
& =\lim _{T \rightarrow \infty} \frac{\left(\eta_{1}+a\right) \sigma}{2 r_{H} \sqrt{T}} \exp \left\{-\frac{1}{2}\left(\eta_{1}+a\right)^{2} \sigma^{2} T+r_{H} T\right\} \\
& =\lim _{T \rightarrow \infty} \frac{\left(\eta_{1}+a\right) \sigma}{2 r_{H} \sqrt{T}} \exp \left\{-T\left[\frac{\tilde{\mu}^{2}}{2 \sigma^{2}}+r_{H}-r_{H}\right]\right\} \\
& =\lim _{T \rightarrow \infty} \frac{\left(\eta_{1}+a\right) \sigma}{2 r_{H} \sqrt{T}} \exp \left\{-\frac{\tilde{\mu}^{2}}{2 \sigma^{2}} T\right\}=0,
\end{aligned}
$$

where we used the fact that $\left(\eta_{1}+a\right)^{2}=\frac{\tilde{\mu}^{2}+2 \sigma^{2} r_{H}}{\sigma^{4}}$. Thus, all terms involving functions $g$ vanish and no complication arises from premultiplying by $m=\frac{1}{T}$, and 
we are left with

$$
\lim _{T \rightarrow \infty} \frac{\delta_{b}}{r-\mu}=\lim _{T \rightarrow \infty} V_{b}=\lim _{T \rightarrow \infty} \frac{-\eta_{2} k_{0}^{E}(T)}{\eta_{2}-1}=\frac{\eta_{2}(1-\pi) c}{\eta_{2}-1},
$$

where $V_{b} \equiv \frac{\delta_{b}}{r-\mu}$, which is the same result as in Leland (1994) once we identify (in Leland's notation) $x=-\eta_{2}$, so that $\lim _{T \rightarrow \infty} V_{b}=\frac{(1-\pi)(c / r) x}{x+1}$. In the infinite maturity limit, the equity holders care about the illiquidity they impose on bondholders via the valuation spread between $H$ and $L$ only at the beginning when issuing bonds, but since there is no rollover, their default decision is not affected by bond market illiquidity for a given level of aggregate face value and coupon.

Next, let us investigate $T \rightarrow 0$, which essentially renders the secondary bond market completely liquid. But of course there is a large effect of $T \rightarrow 0$ on the bankruptcy decision of the equity holders. Using L'Hopital's rule, we need to investigate

$$
\lim _{T \rightarrow 0} \frac{1}{T}\left[\eta_{2} g_{F}\left(\delta_{b}\right)-g_{F}^{\prime}\left(\delta_{b}\right)\right] .
$$

We see that two terms that exactly give $\eta_{i}-\rho$ explode at the rate $\frac{1}{\sqrt{T}}$, so that, in the limit, we have

$$
\lim _{T \rightarrow 0} \frac{\delta_{b}(T)}{r-\mu}=\frac{p}{\alpha_{H}} .
$$

If $\alpha=\alpha_{H}=\alpha_{L}$, we are back to the LT96 solution of $V_{b}=\frac{p}{\alpha}$.

Q.E.D.

\section{A.2. Firm Valuation}

We derive the initial firm valuation as a function of $T$. Following LT96, we assume that, at time 0 , the firm issues new bonds with maturities uniformly distributed $\tau \in[0, T]$ on the primary market, which guarantees that the firm is always at its stationary debt maturing structure. Thus the levered initial firm value $T V_{0}\left(\delta_{0}, T ; \delta_{b}\right)$ is the sum of equity valuation plus how much money has been raised by the initial bond issuance: ${ }^{46}$

$$
\begin{aligned}
T V_{0}\left(\delta_{0}, T ; \delta_{b}\right)= & E\left(\delta_{0} ; \delta_{b}\right) \\
& +(1-\kappa) \frac{1}{T} \int_{0}^{T} \mathbf{S} \cdot \mathbf{D}\left(\delta_{0}, \tau ; \delta_{b}\right) d \tau
\end{aligned}
$$

\footnotetext{
${ }^{46}$ The reader should note that we have one unit measure of bonds, whereas LT96 expanded the measure of bonds according to maturity while keeping overall face-value constant.
} 


$$
\begin{aligned}
= & E\left(\delta_{0}\right) \\
& +(1-\kappa) \mathbf{S}\left[\mathbf{k}_{0}^{D}+\frac{1}{T} \mathbf{A}^{-1}\left(\mathbf{I}-\mathbf{P G}\left(\delta_{0}, T\right) \mathbf{P}^{-1}\right.\right. \\
& \left.-\exp (-\mathbf{A} T)\left[1-F\left(\delta_{0}, T\right)\right]\right) \mathbf{k}_{F}^{D} \\
& \left.+\mathbf{P J}\left(\delta_{0}, T\right) \mathbf{P}^{-1} \mathbf{k}_{G}^{D}\right],
\end{aligned}
$$

where $\mathbf{J}(\delta, T)=\left[\begin{array}{cc}J_{1}(\delta, T) & 0 \\ 0 & J_{2}(\delta, T)\end{array}\right], \mathbf{I}=\left[\begin{array}{ll}1 & 0 \\ 0 & 1\end{array}\right]$, and

$$
\begin{aligned}
J_{j}(\delta, T)= & \frac{1}{\left(\gamma_{1 j}+a\right) \sigma \sqrt{T}} \\
& \times \sum_{i=1}^{2}(-1)^{i}\left(\frac{\delta}{\delta_{b}}\right)^{\gamma_{j i}} \Phi\left[q\left(\delta, \gamma_{j i}, T\right)\right] q\left(\delta, \gamma_{j i}, T\right) .
\end{aligned}
$$

\section{A.3. Bid-Ask Spread Comparative Statics Proofs}

Let us split up the proof of Proposition 4 into parts. Let us first establish a preliminary result.

LEMMA 3: The valuation wedge $\Pi$ can be represented as

$$
\begin{aligned}
\Pi(\delta, \tau)= & \mathbb{E}\left[\int_{0}^{\tau \wedge \tau_{b}} e^{-\hat{r}_{1} s} \chi d s+e^{-\hat{r}_{1}\left(\tau \wedge \tau_{b}\right)} \Pi\left(\delta_{\tau \wedge \tau_{b}}, \tau \wedge \tau_{b}\right)\right] \\
= & \frac{\chi}{\hat{r}_{1}}+\mathbb{E}\left[e^{-\hat{r}_{1}\left(\tau \wedge \tau_{b}\right)} 1_{\left\{\tau>\tau_{b}\right\}}\right]\left[V_{b}\left(\alpha_{H}-\alpha_{L}\right)-\frac{\chi}{\hat{r}_{1}}\right] \\
& +\mathbb{E}\left[e^{-\hat{r}_{1}\left(\tau \wedge \tau_{b}\right)} 1_{\left\{\tau<\tau_{b}\right\}}\right]\left(0-\frac{\chi}{\hat{r}_{1}}\right) .
\end{aligned}
$$

PROOF: Taking the difference between the PDE of $D_{H}$ and $D_{L}$, we see that surplus follows the following linear PDE:

$$
\underbrace{(r+\xi+\lambda \beta)}_{\hat{r}_{1}} \Pi=\chi-\frac{\partial \Pi}{\partial \tau}+\mu \delta \cdot \frac{\partial \Pi}{\partial \delta}+\frac{\sigma^{2} \delta^{2}}{2} \frac{\partial^{2} \Pi}{\partial \delta^{2}},
$$

which again is in the form of the classic LT96 equation, with boundary conditions $\Pi(\delta, 0)=0$ and $\Pi\left(\delta_{b}, \tau\right)=\frac{\delta_{b}}{r-\mu}\left(\alpha_{H}-\alpha_{L}\right)$. For brevity, define $V_{b} \equiv \frac{\delta_{b}}{r-\mu}$. Then, using the Feynman-Kac formula, with slight abuse of notation, we have the result stated in the lemma.

Q.E.D. 
A.3.1. Sufficient Conditions for $\partial_{\delta} \Pi<0$ and $\partial_{\delta} \Delta<0$

PROOF OF PROPOSITION 4-PART 1: Simple inspection reveals that $\partial_{\delta} \mathbb{E}\left[e^{-\hat{r}_{1}\left(\tau \wedge \tau_{b}\right)} 1_{\left\{\tau>\tau_{b}\right\}}\right]=\partial_{\delta} \mathbb{E}\left[e^{-\hat{r}_{1} \tau_{b}} 1_{\left\{\tau>\tau_{b}\right\}}\right]<0$ and that $\partial_{\delta} \mathbb{E}\left[e^{-\hat{r}_{1}\left(\tau \wedge \tau_{b}\right)} 1_{\left\{\tau<\tau_{b}\right\}}\right]=$ $e^{-\hat{r}_{1} \tau} \partial_{\delta} \mathbb{P}\left[\tau<\tau_{b}\right]>0,{ }^{47}$ so that a sufficient condition for $\Pi_{\delta}<0$ is given by

$$
\left[V_{b}\left(\alpha_{H}-\alpha_{L}\right)-\frac{\chi}{\hat{r}_{1}}\right]>0 \quad \Longleftrightarrow \quad V_{b}\left(\alpha_{H}-\alpha_{L}\right)>\frac{\chi}{\hat{r}_{1}} .
$$

To show that $\Pi_{\delta}<0$ implies $\Delta_{\delta}<0$, note that $\Delta_{\delta}=\frac{2(1-\beta)\left(\partial_{\delta} D_{H} \cdot D_{L}-\partial_{\delta} D_{L} \cdot D_{H}\right)}{(\cdot \cdot)^{2}}$. If we can show that $\partial_{\delta} D_{H}>0$, then we have

$$
\partial_{\delta} D_{H} \cdot D_{L}-\partial_{\delta} D_{L} \cdot D_{H}<\partial_{\delta} D_{H} \cdot D_{H}-\partial_{\delta} D_{L} \cdot D_{H}=\partial_{\delta} \Pi \cdot D_{H}<0,
$$

where the last inequality uses the fact that $\Pi_{\delta}<0$ and $D_{H}>0$. Using the Feynman-Kac formula to represent $D_{H}$, treating $\Pi(\delta, \tau)$ as an exogenous function entering the flow payoff, we can write

$$
\begin{aligned}
D_{H}(\delta, \tau)= & \mathbb{E}\left[\int_{0}^{\tau \wedge \tau_{b}} e^{-r s}[c-\xi \Pi(\delta, s)] d s\right. \\
& \left.+e^{-r\left(\tau \wedge \tau_{b}\right)} D_{H}\left(\delta_{\tau \wedge \tau_{b}}, \tau \wedge \tau_{b}\right) p\right] \\
= & \mathbb{E}\left[\int_{0}^{\tau \wedge \tau_{b}} e^{-r s} c \cdot d s+e^{-r\left(\tau \wedge \tau_{b}\right)}\left(1_{\left\{\tau_{b}<\tau\right\}} \alpha_{H} V_{b}+1_{\left\{\tau_{b}>\tau\right\}} p\right)\right. \\
& \left.+\xi \Pi\left(\delta_{\tau \wedge \tau_{b}}, \tau \wedge \tau_{b}\right) \frac{e^{-r\left(\tau \wedge \tau_{b}\right)}}{r}\right] \\
& -\xi \mathbb{E}\left[\int_{0}^{\tau \wedge \tau_{b}} e^{-r s} \Pi(\delta, s) d s\right. \\
& \left.+\int_{\tau \wedge \tau_{b}}^{\infty} e^{-r s} \Pi\left(\delta_{\tau \wedge \tau_{b}}, \tau \wedge \tau_{b}\right) d s\right] \\
= & \mathbb{E}\left[\int_{0}^{\tau \wedge \tau_{b}} e^{-r s} c \cdot d s\right. \\
& \left.+e^{-r\left(\tau \wedge \tau_{b}\right)}\left(1_{\left\{\tau_{b}<\tau\right\}}\left[\alpha_{H} V_{b}+\frac{\xi}{r} \Pi\left(\delta_{b}, \tau_{b}\right)\right]+1_{\left\{\tau_{b}>\tau\right\}} p\right)\right]
\end{aligned}
$$

\footnotetext{
${ }^{47}$ These statements can be easily checked via the following steps: fix a probability path $\omega$ (that essentially fixes the Brownian shocks). Then suppose, given $\omega$, we shift $\delta_{0}$ to $\delta_{0}^{\prime}>\delta_{0}$. It is now clear that $\tau_{b}^{\prime}>\tau_{b}$. As this holds for any path $\omega$, the result follows taking expectations over all possible paths.
} 


$$
\begin{aligned}
& -\xi \mathbb{E}\left[\int_{0}^{\infty} e^{-r s} \Pi(\delta, s) d s\right] \\
= & \frac{c}{r}+\mathbb{E}\left[e^{-r\left(\tau \wedge \tau_{b}\right)} 1_{\left\{\tau>\tau_{b}\right\}}\right]\left[\alpha_{H} V_{b}+\frac{\xi}{r} V_{b}\left(\alpha_{H}-\alpha_{L}\right)-\frac{c}{r}\right] \\
& +\mathbb{E}\left[e^{-r\left(\tau \wedge \tau_{b}\right)} 1_{\left\{\tau<\tau_{b}\right\}}\right]\left(p-\frac{c}{r}\right) \\
& -\xi \mathbb{E}\left[\int_{0}^{\infty} e^{-r s} \Pi(\delta, s) d s\right] .
\end{aligned}
$$

Here, we defined $\Pi(\delta, s)$ post default as the constant of $\Pi\left(\delta_{b}, s\right)=$ $V_{b}\left(\alpha_{H}-\alpha_{L}\right)$ or post maturity as the constant of $\Pi(\delta, \tau)=0$. Next, note that we have

$$
\partial_{\delta} \mathbb{E}\left[e^{-r\left(\tau \wedge \tau_{b}\right)}\right]=\partial_{\delta} \mathbb{E}\left[e^{-r\left(\tau \wedge \tau_{b}\right)} 1_{\left\{\tau>\tau_{b}\right\}}\right]+\partial_{\delta} \mathbb{E}\left[e^{-r\left(\tau \wedge \tau_{b}\right)} 1_{\left\{\tau<\tau_{b}\right\}}\right]<0 .
$$

This is because a higher initial $\delta$, path by path, will increase the hitting time $\tau \wedge \tau_{b}$, lowering the $e^{-r\left(\tau \wedge \tau_{b}\right)}$ path by path. As already argued, we have $\partial_{\delta} \mathbb{E}\left[e^{-\hat{r}_{1}\left(\tau \wedge \tau_{b}\right)} 1_{\left\{\tau<\tau_{b}\right\}}\right]=e^{-\hat{r}_{1} \tau} \partial_{\delta} \mathbb{P}\left[\tau<\tau_{b}\right]>0$. Define $a(\delta, \tau) \equiv$ $-\partial_{\delta} \mathbb{E}\left[e^{-r\left(\tau \wedge \tau_{b}\right)} 1_{\left\{\tau>\tau_{b}\right\}}\right]>0$. Thus, we have the following inequality:

$$
0<\partial_{\delta} \mathbb{E}\left[e^{-r\left(\tau \wedge \tau_{b}\right)} 1_{\left\{\tau<\tau_{b}\right\}}\right]<-\partial_{\delta} \mathbb{E}\left[e^{-r\left(\tau \wedge \tau_{b}\right)} 1_{\left\{\tau>\tau_{b}\right\}}\right]=a(\delta, \tau) .
$$

Since $p-\frac{c}{r} \leq 0$ by assumption, then

$$
\begin{aligned}
\partial_{\delta} D_{H}(\delta, \tau)= & -\partial_{\delta} \mathbb{E}\left[e^{-r\left(\tau \wedge \tau_{b}\right)} 1_{\left\{\tau>\tau_{b}\right\}}\right]\left[\frac{c}{r}-\alpha_{H} V_{b}-\frac{\xi}{r} V_{b}\left(\alpha_{H}-\alpha_{L}\right)\right] \\
& +\partial_{\delta} \mathbb{E}\left[e^{-r\left(\tau \wedge \tau_{b}\right)} 1_{\left\{\tau<\tau_{b}\right\}}\right]\left(p-\frac{c}{r}\right) \\
> & a(\delta, \tau)\left[\frac{c}{r}-\alpha_{H} V_{b}-\frac{\xi}{r} V_{b}\left(\alpha_{H}-\alpha_{L}\right)\right]+a(\delta, \tau)\left(p-\frac{c}{r}\right) \\
= & a(\delta, \tau)\left[p-\alpha_{H} V_{b}-\frac{\xi}{r} V_{b}\left(\alpha_{H}-\alpha_{L}\right)\right],
\end{aligned}
$$

which is positive if the constant inside the bracket is positive.

Q.E.D.

\section{A.3.2. Sufficient Conditions for $\partial_{\tau} \Pi>0$}

PROOF OF PROPOSITION 4-PART 2: Let us make two observations:

$$
\begin{aligned}
& \partial_{\tau} \mathbb{E}\left[e^{-\hat{r}_{1}\left(\tau \wedge \tau_{b}\right)}\right]<0, \\
& \partial_{\tau} \mathbb{E}\left[e^{-\hat{r}_{1}\left(\tau \wedge \tau_{b}\right)} 1_{\left\{\tau>\tau_{b}\right\}}\right]=\partial_{\tau} \mathbb{E}\left[e^{-\hat{r}_{1} \tau_{b}} 1_{\left\{\tau>\tau_{b}\right\}}\right]>0 .
\end{aligned}
$$


Then, rewrite

$$
\begin{aligned}
\partial_{\tau} \Pi(\delta, \tau)= & \partial_{\tau} \mathbb{E}\left[e^{-\hat{r}_{1}\left(\tau \wedge \tau_{b}\right)} 1_{\left\{\tau>\tau_{b}\right\}}\right]\left[V_{b}\left(\alpha_{H}-\alpha_{L}\right)-\frac{\chi}{\hat{r}_{1}}\right] \\
& -\partial_{\tau} \mathbb{E}\left[e^{-\hat{r}_{1}\left(\tau \wedge \tau_{b}\right)} 1_{\left\{\tau<\tau_{b}\right\}}\right] \frac{\chi}{\hat{r}_{1}} \\
= & \partial_{\tau} \mathbb{E}\left[e^{-\hat{r}_{1}\left(\tau \wedge \tau_{b}\right)} 1_{\left\{\tau>\tau_{b}\right\}}\right]\left[V_{b}\left(\alpha_{H}-\alpha_{L}\right)\right] \\
& -\partial_{\tau} \mathbb{E}\left[e^{-\hat{r}_{1}\left(\tau \wedge \tau_{b}\right)}\right] \frac{\chi}{\hat{r}_{1}} \\
> & \partial_{\tau} \mathbb{E}\left[e^{-\hat{r}_{1}\left(\tau \wedge \tau_{b}\right)} 1_{\left\{\tau>\tau_{b}\right\}}\right]\left[V_{b}\left(\alpha_{H}-\alpha_{L}\right)\right],
\end{aligned}
$$

which is positive if $\alpha_{H}>\alpha_{L}$. Unfortunately, the maturity derivative of $\Delta$ is not easily established. From $\dot{\Delta}=\frac{2(1-\beta)\left(\partial_{\tau} D_{H} \cdot D_{L}-\partial_{\tau} D_{L} \cdot D_{H}\right)}{(\cdot)^{2}}$, we again have a sufficient condition in $\dot{D}_{H}<0$. But we note that if a bond is issued at par, we have $D_{H}(\delta, 0)=D_{H}(\delta, T)=p$ by definition. However, since we can show that $\dot{D}_{H}(\delta, 0) \neq 0$, we know that $\dot{D}_{H}(\delta, \tau)$ has to change signs on $\tau \in[0, T]$ and thus this sufficient condition does not hold for all $\tau$.

Q.E.D.

\section{A.3.3. Sufficient Conditions for $\Pi \geq 0$}

Proof of Proposition 4-PART 3: Let us rewrite $\Pi(\delta, \tau)=(1-$ $\left.\mathbb{E}\left[e^{-\hat{r}_{1}\left(\tau \wedge \tau_{b}\right)}\right]\right) \frac{X}{\hat{r}_{1}}+\mathbb{E}\left[e^{-\hat{r}_{1}\left(\tau \wedge \tau_{b}\right)} 1_{\left\{\tau>\tau_{b}\right]}\right] V_{b}\left(\alpha_{H}-\alpha_{L}\right)$. We see that this is always positive as long as $\alpha_{H}>\alpha_{L}$ because $\tau \wedge \tau_{b} \geq 0$ and $\hat{r}_{1}>0$.

Q.E.D.

\section{A.4. Alternative Modeling of Liquidity Shocks}

In the main text, we model the consequence of liquidity shocks as a positive holding cost. In the working paper version (He and Milbradt (2013)), we modeled liquidity shocks as rise in the discount rate $\bar{r}$ above the risk-free rate $r$, which captures the idea of "urgency to sell." More specifically, normal $H$ investors discount future cash flows by $r$, while $L$ investors who have been hit by liquidity shocks discount future cash flows by $\bar{r}=r+\rho$ with $\rho>0$. We show that this modeling is consistent with the assumption in the main model with holding cost $\chi=\chi_{c} c+\chi_{p} p$, where $\chi_{c}>0$ and $\chi_{p}>0$. For expositional purposes, set the benchmark discount rate $r=0$, and assume that there is no default.

In general, the holding cost $\chi$ should be interpreted as the difference between the efficient holding value without liquidity shocks, and the inefficient holding value of impatient $L$ investors (who remain in $L$ state always). To see this, imagine that we are in the model with holding costs. Suppose that there is no secondary market trading, which makes this point stark. The valuation 
difference then is proportional to holding cost $\chi=\chi_{c} c+\chi_{p} p$ :

$$
\begin{aligned}
& \underbrace{\int_{0}^{T} c d t+p}_{\text {Efficient valuation }}-\underbrace{\left[\int_{0}^{T} c d t+p-\int_{0}^{T}\left(\chi_{c} c+\chi_{p} p\right) d t\right]}_{L \text {-type valuation }} \\
& \quad=T \chi_{c} \cdot c+T \chi_{p} \cdot p .
\end{aligned}
$$

Now we turn to the model of impatient investors. The valuation difference, which can be interpreted as holding cost, is

$$
\begin{aligned}
& \underbrace{\int_{0}^{T} c d t+p}_{\text {Efficient valuation }}-\underbrace{\left[\int_{0}^{T} e^{-\rho t} c d t+e^{-\rho T} p\right]}_{L \text {-type valuation }} \\
& =\int_{0}^{T}\left(1-e^{-\rho t}\right) d t \cdot c+\left(1-e^{-\rho T}\right) \cdot p .
\end{aligned}
$$

One can easily check that this term is increasing in coupon $c$, with a positive coefficient of

$$
\int_{0}^{T}\left(1-e^{-\rho t}\right) d t=\frac{e^{-\rho T}-1+\rho T}{\rho}>0 .
$$

Similarly, the coefficient on $p$ is also positive.

\section{A.5. Micro-Founded Conditions for Assumption 1}

Recall that the transitioning intensity from $H$ investors to $L$ investors is $\xi$; for the purpose of this subsection we will denote this transitioning intensity by $\xi_{H L}$. To embed the model into a fully fledged search framework, we need to introduce a recovery shock $\xi_{L H}$ that hits agents of type $L$; otherwise we would get a degenerate type distribution with only $L$-types in the long run. We note that the model in the main text did not contain $\xi_{L H}$ for ease of exposition but required a more exogenous assumption on the contact flows. Let us also introduce types $L 0$ and $H 0$ as $L$ - and $H$-types not holding the bond, and types $L 1$ and $H 1$ as $L$ - and $H$-types currently holding the bond.

Suppose that there is a total mass $\mu$ of agents in the economy; we have $\mu=$ $\mu_{H 0}+\mu_{H 1}+\mu_{L 0}+\mu_{L 1}$, where $\mu_{s}$ denotes the measure of type $s$. Consider the type-only distribution, that is, $\mu_{H} \equiv \mu_{H 1}+\mu_{H 0}$ and $\mu_{L} \equiv \mu_{L 1}+\mu_{L 0}$. As the type-only dynamics are independent of trading and bond positions, we have $\dot{\mu}_{H}=\xi_{L H} \mu_{L}-\xi_{H L} \mu_{H}=\xi_{L H} \mu-\left(\xi_{H L}+\xi_{L H}\right) \mu_{H}$. We solve this ODE to get

$$
\begin{aligned}
\mu_{H}(t) & =\frac{\xi_{L H} \mu}{\xi_{H L}+\xi_{L H}}+e^{-\left(\xi_{H L}+\xi_{L H}\right) t}\left[\mu_{H}(0)-\frac{\xi_{L H} \mu}{\xi_{H L}+\xi_{L H}} \mu\right] \\
& =\mu_{H}^{\mathrm{ss}}+e^{-\left(\xi_{H L}+\xi_{L H}\right) t}\left[\mu_{H}(0)-\mu_{H}^{\mathrm{ss}}\right],
\end{aligned}
$$


where $\mu_{H}(0)$ is the exogenous initial state and $\mu_{H}^{\mathrm{ss}} \equiv \lim _{t \rightarrow \infty} \mu_{H}(t)=\frac{\xi_{L H} \mu}{\xi_{H L}+\xi_{L H}}$ is the steady state. We note that $\dot{\mu}_{H}(t)=\left(\xi_{H L}+\xi_{L H}\right) e^{-(\cdots) t}\left[\mu_{H}^{\text {ss }}-\mu_{H}(0)\right]$, which implies that $\mu_{H}(t)$ is monotonically increasing in time if and only if $\mu_{H}^{\text {ss }}>\mu_{H}(0)$ (and vice versa), that is, if the initial value is below the steady state value.

To ensure Assumption 1 that the secondary market is a seller's market, that is, there is always a larger flow of potential buyers contacting the dealers than the flow of potential sellers, we need $\mu_{H 0}(t)>\mu_{L 1}(t), \forall t \in(0, \infty)$. Let us rewrite $\mu_{H 0}$ as follows:

$$
\mu_{H 0}=\mu-\mu_{H 1}-\mu_{L 0}-\mu_{L 1}=\mu-\left(1-\mu_{L 1}\right)-\mu_{L}=\mu_{H}-1+\mu_{L 1},
$$

where we used the fact that $\mu_{L 1}+\mu_{H 1}=1$ as the measure of outstanding bonds is always 1 . Hence,

$$
\mu_{H 0}(t)>\mu_{L 1}(t), \forall t \in(0, \infty) \quad \Longleftrightarrow \quad \mu_{H}(t)>1, \forall t \in(0, \infty) .
$$

Thus, the necessary and sufficient condition for the market to always be a seller's market is given by

$$
\min \left\{\mu_{H}(0), \mu_{H}^{\mathrm{ss}}\right\}>1 \text {. }
$$

In the special case in which $\mu_{H}(0)>\mu_{H}^{\text {ss }}$, this condition simplifies to

$$
\mu_{H}^{\mathrm{ss}}=\frac{\xi_{L H} \mu}{\xi_{H L}+\xi_{L H}}>1 .
$$

Thus, we need a sufficiently high recovery times total mass of agents, $\xi_{L H} \mu$, to have a surplus of potential buyers in the model. We note that although this condition is very simple, the actual functions of $\mu_{H 0}(t)$ and $\mu_{L 1}(t)$ are complicated non-stationary functions of $t$ that require the solution to the full cross-sectional distribution across $(t, \tau)$.

The pricing of debt and equity changes only in so far as that the effective recovery rate in the pricing equations is now $\xi_{L H}^{\text {effective }} \equiv\left(\lambda \beta+\xi_{L H}\right)$ instead of $\lambda \beta$ alone. Our main model can be understood as having an almost negligible recovery intensity $\xi_{L H}$ and a very large total mass $\mu$ that satisfies the sufficient conditions above.

Similarly, we can also establish conditions for the post-default market to be a seller's market as assumed in the main text. By the same equation, we have

$$
\mu_{H 0}^{b}=\mu-\mu_{H 1}^{b}-\mu_{L 0}^{b}-\mu_{L 1}^{b}=\mu-\left(1-\mu_{L 1}^{b}\right)-\mu_{L}^{b}=\mu_{H}^{b}-1+\mu_{L 1}^{b},
$$

so that $\mu_{H}^{b}(t)>\mu_{L 1}^{b}(t) \Longleftrightarrow \mu_{H}^{b}(t)>1$. As we have a different shock intensity $\xi_{H L}^{b}>\xi_{H L}$, we see that

$$
\mu_{H}(t)=\mu_{L}^{\mathrm{ss}, b}+e^{-\left(\xi_{H L}^{b}+\xi_{L H}\right)\left(t-\tau_{b}\right)}\left[\mu_{H}\left(\tau_{b}\right)-\mu_{L}^{\mathrm{ss}, b}\right]
$$


where $\tau_{b}$ is the random default time and $\mu_{H}^{\mathrm{ss}, b}=\frac{\xi_{L H} \mu}{\xi_{H L}^{b}+\xi_{L H}}<\mu_{H}^{\mathrm{ss}}$. The sufficient condition can thus be written as $\min \left\{\mu_{H}\left(\tau_{b}\right), \mu_{H}^{\text {ss, } b}\right\}>1, \forall \tau_{b} \in(0, \infty)$. Thus, we have

$$
\min \left\{\mu_{H}(0), \mu_{H}^{\text {ss, } b}\right\}>1
$$

as the sufficient condition for $\mu_{H 0}^{b}(t)>\mu_{L 1}^{b}(t)$ and $\mu_{H 0}(t)>\mu_{L 1}(t)$. If $\mu_{H}(0)=$ $\mu_{H}^{\text {ss }}$, then the condition becomes

$$
\frac{\xi_{L H} \mu}{\xi_{H L}^{b}+\xi_{L H}}>1
$$

\section{A.6. Par Bonds, Cash Flows, and Coupons}

In some of our graphs, we show credit spreads and bid-ask spreads for par bonds. To keep the bond at par at different cash flow levels (and thus different quasi-market leverage levels), we have to adjust the coupon $c$. Formally, for par bonds we have $D_{H}(\delta, c)=p$. Differentiating, we have

$$
\partial_{\delta} D_{H}(\delta, c)+\partial_{c} D_{H}(\delta, c) c^{\prime}(\delta)=0
$$

and we thus have $c^{\prime}(\delta)=-\frac{\partial_{\delta} D_{H}}{\partial_{c} D_{H}}$. Next, let us differentiate $Q L=\frac{p}{p+E(\delta, c)}$ along the par-ray $(\delta, c(\delta))$ to see that

$$
\frac{d Q L}{d \delta}=-\frac{p}{(p+E(\delta, c))^{2}}\left[\partial_{\delta} E(\delta, c)+\partial_{c} E(\delta, c) c^{\prime}(\delta)\right] .
$$

If $D_{H}$ is increasing in $\delta$ and increasing in $c$, then $c^{\prime}(\delta)<0$. Furthermore, if $E$ is increasing in $\delta$ and decreasing in $c$, then we see that $Q L$ is monotonically decreasing in $\delta$. The solid line in Figures 3 and 4 traces out $Q L$ along the par-ray $(\delta, c(\delta))$. It is important to note that different initial $\delta$ imply different coupons values $c$ (and possibly different holding costs $\chi$ ) and thus result in different default boundaries.

\section{A.7. An Expanded Secondary Market Modeling With Richer Post-Default Market}

We present a richer post-default market in this section. The main idea is that the market itself does not have to be shocked in its fundamentals, but rather that some investor-specific shocks arise. In a nutshell, the marginal buyer of the bond pre-default is sidelined in default, and outside buyers step in to buy the bonds. As these outside buyers are not in large supply, there is a shift from a seller's to a buyer's market, which shifts the surplus from trade away from the (common) sellers to the (specialized) buyers. 
We assume that there are two classes of $H$-type investors who are ready to buy bonds from dealers, and they differ in how default affects their preference/ability of investing in corporate bonds. More specifically, one class of investors is sensitive to the default event. They have a liquidity shock intensity of $\xi$ before default; after default, their liquidity shock intensity is $\xi_{b} \geq \xi$ to possibly reflect the fact that they might not be allowed to hold defaulted bonds. ${ }^{48}$ Additionally, they cannot purchase defaulted bonds. Without risk of confusion, we keep referring to these investors as $H$-types. In contrast, there is another class of investors, denoted by $S$ (for Specialists), who have a constant liquidity shock intensity $\xi$ independent of whether the bond has defaulted or not, and are able to buy bonds pre- and post-default. For simplicity, we assume that after purchasing the bond, if a liquidity shock hits either an $H$ or $S$ investor, both transition to the same $L$-type.

The following assumption replaces Assumption 1 in the main text.

ASSUMPTION 2: Before default, the flow of L-type sellers in contact with dealers is greater than the flow of S-type buyers in contact with dealers, but smaller than the flow of $H$-type buyers in contact with dealers, a situation we denote by the term seller's market. After default, H-type investors withdraw from the buy side, and the flow of L-type sellers in contact with dealers is smaller than the flow of S-type buyers in contact with dealers, a situation we term a buyer's market.

Note that an $S$ investor's surplus is always weakly higher than an $H$ investor's one. Under Assumption 2, however, in equilibrium the marginal buyer is an $H$-type before the default, as there is an oversupply of $H$-type buyers and an undersupply of $S$-type buyers, whereas after default the marginal agent is an $S$ type. Interestingly, under that assumption, we show that the valuation of $S$-type investors does not affect the pre-default equilibrium outcome.

The classes of $H$ and $S$ represent different institutional buyers of corporate bond in practice. The class of $H$ investors represents normal corporate bond funds (say, money market funds, high yield bond funds, etc.) who can only invest in bonds that have not defaulted yet, while the class of $S$ investors represents hedge funds that are specializing in buying defaulted bonds and waiting for recovery. Our modeling of $H$ investors and $S$ investors captures this important difference in the most stark way, and we make an assumption below about the relative mass of $H$ investors to $S$ investors to reflect the scarcity of hedge funds who specialize in distressed securities. Moreover, the presence of $S$-type investors before default will not change the pre-default equilibrium outcome, as along as their measure is sufficiently small, so that the pre-default marginal buyer remains the $H$-type investor.

${ }^{48} \mathrm{As} \xi_{b} \rightarrow \infty$, this proxies for an aggregate event in which all of these investors are hit by a shock at the exact moment of default. This would, however, be an undesirable assumption as it would result in no valuation wedge between $H$ - and $L$-types and thus would contradict the data. 
Again, we use " $b$ " to indicate the state of bankruptcy. Relative to the market before default where there are always sufficient $H$-type buyers to meet the supply from $L$-type sellers, buy orders drop abruptly and selling pressure increases. In other words, the post-default market is a buyer's market.

Denote the post-default debt valuation for $H(L)$ investors by $D_{H}^{b, i}\left(D_{L}^{b, i}\right)$, where the index $i \in\{0,1\}$ indicates the investors' holding. Clearly, the continuation values are $D_{H}^{b, 0}=D_{L}^{b, 0}=0$ because $H$-type investors cannot buy defaulted bonds, and $L$-type investors exit after selling their bonds. For $S$ investors, we denote their values by $D_{S}^{b, i}$, where the index $i \in\{0,1\}$ indicates the holding of the $S$ investor. $D_{S}^{b, 0} \geq 0$ because $S$ investors provide liquidity to the market and thus earn weakly positive rents in equilibrium.

The surplus generated from an $L$ investor selling to a dealer who sells on the bond for a price $M$ on the competitive inter-dealer market is given by

$$
\Pi_{L}^{b}=M^{b}-\left(D_{L}^{b}-D_{L}^{b, 0}\right)=M^{b}-D_{L}^{b} .
$$

Because the inter-dealer market is competitive in the Bertrand sense, the equilibrium inter-dealer market price $M^{b}=D_{L}^{b}$ so that $\Pi_{L}^{b}=0$. Otherwise, if $M^{b}>D_{L}^{b}$ so that $\Pi_{L}^{b}>0$, then other dealer- $L$-type pairs can lower their selling price $M^{b}$ in the inter-dealer market to obtain a sure trade and a positive profit. The equilibrium bid price generically is given by $B^{b}=D_{L}^{b}+\beta \Pi_{L}^{b}$. Zero surplus then implies

$$
B^{b}=D_{L}^{b}=M^{b} .
$$

As the buy side is made up of dealer-S-type pairs, define the surplus from trade for an $S$-type as

$$
\Pi^{b} \equiv \Pi_{S}^{b} \equiv\left(D_{S}^{b 1}-D_{S}^{b 0}\right)-M^{b}>0 .
$$

Following Nash-bargaining, the ask price at which $S$-types (with a bargaining power of $\beta_{S}$ ) buy from the dealer is given by

$$
A^{b}=D_{S}^{b 0}+\beta_{S} \Pi^{b} .
$$

Thus, a buyer's market is characterized by positive surplus from trade for buyers, and zero surplus from trade for sellers.

We now solve for the equilibrium values in the secondary market for defaulted bonds. Recall that the bankruptcy payout occurs with intensity $\theta$. Further assume that post-default holding costs are proportional the ultimate recovery payout, $\chi \frac{\delta_{B}}{r-\mu}$. We then have the following linear system:

(A.2) $\quad r D_{H}^{b}=0+\xi_{b}\left(D_{L}^{b}-D_{H}^{b}\right)+\theta\left(\alpha \frac{\delta_{b}}{r-\mu}-D_{H}^{b}\right)$, 


$$
\text { (A.3) } \quad \begin{aligned}
r D_{L}^{b} & =-\chi \frac{\delta_{b}}{r-\mu}+0+\theta\left(\alpha \frac{\delta_{b}}{r-\mu}-D_{L}^{b}\right), \\
r D_{S}^{b 1} & =0+\xi\left(D_{L}^{b}-D_{S}^{b 1}\right)+\theta\left(\alpha \frac{\delta_{b}}{r-\mu}-D_{S}^{b 1}\right), \\
r D_{S}^{b 0} & =0+\lambda_{S}\left(D_{S}^{b 1}-A-D_{S}^{b 0}\right)+\theta\left(0-D_{S}^{b 0}\right) .
\end{aligned}
$$

On the right-hand side of (A.3), the first term is the holding cost $\chi \frac{\delta_{b}}{r-\mu}$. The second term captures the value increment in contacting the dealer successfully; but it is zero because $L$ investors sell their bond always at their reservation price $D_{L}^{b}$. We solve the linear system for the values $D_{H}^{b}$ and $D_{L}^{b}$ and for the proportional bid-ask price $\Delta^{b} \equiv \frac{A^{b}-B^{b}}{(1 / 2)\left(A^{b}+B^{b}\right)}$ in the following proposition.

PROPOSITION 5: Under Assumption 2, post default the debt valuations for $H$ and $L$ investors are

$$
\left[\begin{array}{l}
D_{H}^{b}\left(\delta_{b}\right) \\
D_{L}^{b}\left(\delta_{b}\right)
\end{array}\right]=\left[\begin{array}{l}
\alpha_{H} \\
\alpha_{L}
\end{array}\right] \frac{\delta_{b}}{r-\mu}
$$

where

$$
\alpha_{H}=\frac{\theta \alpha}{r+\theta}-\frac{\xi_{b} \chi_{b}}{(r+\theta)\left(r+\theta+\xi_{b}\right)}
$$

and

$$
\alpha_{L}=\frac{\theta \alpha}{r+\theta}-\frac{\chi_{b}}{r+\theta} .
$$

The bid price is given by $B^{b}=D_{L}^{b}$, whereas the ask price is given by $A^{b}=D_{S}^{b 0}+$ $\beta_{S} \Pi^{b}$, and the proportional bid-ask spread is given by

$$
\begin{aligned}
\Delta^{b}= & 2\left(\alpha \theta(r+\theta+\xi)\left[2\left(\beta_{S}-1\right) \lambda_{S}-r-\theta\right]\right. \\
& +\chi\left[(r+\theta)\left[\xi-\left(\beta_{S}-2\right)(r+\theta)\right]\right. \\
& \left.\left.-2 \lambda_{S}[2(r+\theta)+\xi]\left(\beta_{S}-1\right)\right]\right) \\
& /\left(\left(2 \lambda_{S}+r+\theta\right)\left(\alpha \theta(r+\theta+\xi)-\beta_{S} \chi(r+\theta)-\chi \xi\right)\right) .
\end{aligned}
$$

Note that the boundary conditions for $D_{H}^{b}$ and $D_{L}^{b}$ are independent of the secondary market in this formulation (or rather, are equivalent to a nonexistent secondary market) as all the surplus accrues to the outside specialists. The bid-ask spread, however, reflects the search-frictions present in the secondary market. Thus, the market in itself does not have to become more illiquid (e.g., 
contact intensities, bargaining power, etc.), only that it becomes more illiquid for the pre-default marginal holders of the asset.

Further, recall that, in the text, we defined the hypothetical LT96 recovery value as $\alpha_{L T}=\frac{\theta}{r+\theta} \alpha$. Plugging in, we see $\alpha_{H}=\alpha_{L T}-\frac{\xi_{b} X_{b}}{(r+\theta)\left(r+\theta+\xi_{b}\right)}$ and $\alpha_{L}=\alpha_{L T}-\frac{\chi b}{r+\theta}$. The values $D_{H}^{b}, D_{L}^{b}$ serve as our boundary conditions for solving bond valuation functions before the firm defaults, with a valuation wedge of

$$
\alpha_{H}-\alpha_{L}=\frac{\chi_{b}}{r+\theta+\xi_{b}}>0
$$

Thus, a difference arises between the bid-ask just before default, given by

$$
\begin{aligned}
\lim _{\delta \rightarrow \delta_{b}} \Delta(\delta, \tau) & =\frac{(1-\beta)\left(\alpha_{H}-\alpha_{L}\right)}{\frac{1}{2}\left[(1+\beta) \alpha_{H}+(1-\beta) \alpha_{L}\right]} \\
& =-\frac{2(\beta-1) \chi(r+\theta)}{2 \alpha \theta\left(r+\theta+\xi_{b}\right)+(\beta-1) \chi(r+\theta)-2 \chi \xi_{b}},
\end{aligned}
$$

and the bid-ask spread just after default, $\Delta^{b}$. We thus can generate a jump in trading prices and in the bid-ask spread that is documented in empirical work.

\section{A.8. Decomposition Results for Non-Par Bonds}

TABLE III

\begin{tabular}{|c|c|c|c|c|c|c|}
\hline \multirow[b]{2}{*}{ Non-Par Bonds } & \multicolumn{3}{|c|}{ Investment Grade } & \multicolumn{3}{|c|}{ Speculative Grade } \\
\hline & Normal & Crisis & Change & Normal & Crisis & Change \\
\hline \multicolumn{7}{|c|}{ Panel A: Data } \\
\hline Credit spread bps & 97 & 321 & $\begin{array}{c}224 \\
(3.3 \times)\end{array}$ & 348 & 1082 & $\begin{array}{c}734 \\
(3.1 \times)\end{array}$ \\
\hline Illiquidity & 1 & 1.5 & $\begin{array}{c}0.5 \\
(1.5 \times)\end{array}$ & 1 & 2 & $\begin{array}{c}1 \\
(2 \times)\end{array}$ \\
\hline \multicolumn{7}{|c|}{ Panel B: Model } \\
\hline Credit spread bps & 100 & 332 & $\begin{array}{c}232 \\
(3.3 \times)\end{array}$ & 350 & 970 & $\begin{array}{c}620 \\
(2.8 \times)\end{array}$ \\
\hline BA spread bps & 45 & 55 & $\begin{array}{c}10 \\
(1.2 \times)\end{array}$ & 56 & 116 & $\begin{array}{c}47 \\
(2.1 \times)\end{array}$ \\
\hline
\end{tabular}

DEFAULT-LIQUIDITY DECOMPOSITION FOR INVESTMENT AND SPECULATIVE GRADE NON-PAR BONDS IN NORMAL AND CRISIS TIMES ${ }^{\mathrm{a}}$ 
TABLE III-Continued

\begin{tabular}{|c|c|c|c|c|c|c|}
\hline \multirow[b]{2}{*}{ Non-Par Bonds } & \multicolumn{3}{|c|}{ Investment Grade } & \multicolumn{3}{|c|}{ Speculative Grade } \\
\hline & Normal & Crisis & Change & Normal & Crisis & Change \\
\hline \multicolumn{7}{|c|}{ Panel C: Model-Based Decomposition } \\
\hline Pure default & $\begin{array}{c}44 \\
(44 \%)\end{array}$ & $\begin{array}{c}210 \\
(63 \%)\end{array}$ & $\begin{array}{c}166 \\
(72 \%)\end{array}$ & $\begin{array}{c}223 \\
(64 \%)\end{array}$ & $\begin{array}{c}681 \\
(70 \%)\end{array}$ & $\begin{array}{c}457 \\
(74 \%)\end{array}$ \\
\hline Liq.-driven def. & $\begin{array}{c}9 \\
(9 \%)\end{array}$ & $\begin{array}{c}20 \\
(6 \%)\end{array}$ & $\begin{array}{c}11 \\
(5 \%)\end{array}$ & $\begin{array}{c}21 \\
(6 \%)\end{array}$ & $\begin{array}{c}18 \\
(2 \%)\end{array}$ & $\begin{array}{c}-3 \\
(-0.5 \%)\end{array}$ \\
\hline Pure liquidity & $\begin{array}{c}31 \\
(31 \%)\end{array}$ & $\begin{array}{c}31 \\
(9 \%)\end{array}$ & $\begin{array}{c}0 \\
(0 \%)\end{array}$ & $\begin{array}{c}31 \\
(9 \%)\end{array}$ & $\begin{array}{c}31 \\
(3 \%)\end{array}$ & $\begin{array}{c}0 \\
(0 \%)\end{array}$ \\
\hline Def.-driven liq. & $\begin{array}{c}16 \\
(16 \%)\end{array}$ & $\begin{array}{c}71 \\
(21 \%)\end{array}$ & $\begin{array}{c}55 \\
(24 \%)\end{array}$ & $\begin{array}{c}75 \\
(21 \%)\end{array}$ & $\begin{array}{c}240 \\
(25 \%)\end{array}$ & $\begin{array}{c}165 \\
(27 \%)\end{array}$ \\
\hline Total & $\begin{array}{c}100 \\
(100 \%)\end{array}$ & $\begin{array}{c}332 \\
(100 \%)\end{array}$ & $\begin{array}{c}232 \\
(100 \%)\end{array}$ & $\begin{array}{c}350 \\
(100 \%)\end{array}$ & $\begin{array}{c}970 \\
(100 \%)\end{array}$ & $\begin{array}{c}620 \\
(100 \%)\end{array}$ \\
\hline
\end{tabular}

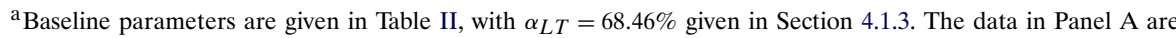
from Friewald, Jankowitsch, and Subrahmanyam (2012). Panel B and Panel C give model-implied moments for nonpar bonds, that is, credit spread and coupon spread do not coincide. To match normal time credit spreads, we adjust the initial cash flow to deliver a credit spread of $100 \mathrm{bps}$ and $350 \mathrm{bps}$ for investment and speculative grade, respectively. Crisis is modeled as a negative cash flow shock of $-50 \%$, which is chosen to target the rise of credit spread of investment grade bonds. Bonds are not at par in normal or in crisis times.
\end{abstract}

\title{
REFERENCES
}

AfONSO, G., AND R. LAGOS (2011): “Trade Dynamics in the Market for Federal Funds,” Working Paper. [1447]

Aminud, Y., AND H. Mendelson (1986): "Asset Pricing and the Bid-Ask Spread,” Journal of Financial Economics, 17, 223-249. [1447]

BACK, K., AND S. BARUCH (2004): "Information in Securities Markets: Kyle Meets Glosten and Milgrom," Econometrica, 72, 433-465. [1448]

BACK, K., AND K. CROTTY (2013): “The Informational Role of Stock and Bond Volume,” Working Paper. [1448,1480]

BAO, J., J. PAN, AND J. WANG (2011): "The Illiquidity of Corporate Bonds," Journal of Finance, 66, 911-946. [1444,1445,1455,1462,1472,1474]

BEBER, A., M. BRANDT, AND K. KAVAJECZ (2009): "Flight-to-Quality or Flight-to-Liquidity? Evidence From the Euro-Area Bond Market," Review of Financial Studies, 22, 925-957. [1446, 1474]

Bessembinder, H., W. MaXwell, And K. Venkataraman (2006): “Market Transparency, Liquidity Externalities, and Institutional Trading Costs in Corporate Bonds," Journal of Financial Economics, 82, 251-288. [1470]

Bhamra, H. S., L.-A. Kuehn, AND I. A. Strebulaev (2010): "The Levered Equity Risk Premium and Credit Spreads: A Unified Framework," Review of Financial Studies, 23, 645-703. $[1467,1468]$

BIAIS, B., AND P.-O. WeILl (2009): "Liquidity Shocks and Order Book Dynamics,” Working Paper. [1447]

BLACK, F., AND J. C. COX (1976): "Valuing Corporate Securities: Some Effects of Bond Indenture Provisions," Journal of Finance, 31, 351-367. [1446] 
Chen, H. (2010): "Macroeconomic Conditions and the Puzzles of Credit Spreads and Capital Structures," Journal of Finance, 65, 2171-2212. [1467,1468,1471]

Chen, H., R. CuI, Z. HE, AND K. Milbradt (2013): "Liquidity and Default of Corporate Bonds Over the Business Cycle," Working Paper. [1478]

Chen, L., D. LeSmond, AND J. WeI (2007): "Corporate Yield Spreads and Bond Liquidity," Journal of Finance, 62, 119-149. [1472]

Cheng, I., AND K. MiLBRADT (2012): “The Hazards of Debt: Rollover Freezes, Incentives, and Bailouts," Review of Financial Studies, 25 (4), 1070-1110. [1446]

CHOI, J., D. HACKBARTH, AND J. ZECHNER (2012): "Granularity of Corporate Debt: Theory and Tests," Working Paper. [1449]

Custodio, C., M. Ferreira, And L. LaUREano (2013): "Why Are US Firms Using More Short Term Debt?” Journal of Financial Economics, 108 (1), 182-212. [1467]

Diamond, D. W. (1993): "Seniority and Maturity of Debt Contracts," Journal of Financial Economics, 33, 341-368. [1447]

DiAmond, D. W., AND Z. HE (2013): "A Theory of Debt Maturity: The Long and Short of Debt Overhang," Journal of Finance, 69 (2), 719-762. [1447,1479]

Dick-NiElSEN, J. (2009): “Liquidity Biases in TRACE," Journal of Fixed Income, 19, 43-55. [1471]

DiCK-Nielsen, J., P. FeldhÜTTER, AND D. LANDo (2012): “Corporate Bond Liquidity Before and After the Onset of the Subprime Crisis," Journal of Financial Economics, 103, 471-492. [1444,1474,1475]

DufFIE, D., AND D. LANDO (2001): “Term Structures of Credit Spreads With Incomplete Accounting Information," Econometrica, 69, 633-664. [1447]

Duffie, D., N. GÂRLEANU, AND L. H. Pedersen (2005): "Over-the-Counter Markets," Econometrica, 73, 1815-1847. [1444]

(2007): "Valuation in Over-the-Counter Markets," Review of Financial Studies, 20, 1865-1900. [1447,1450]

EDWARDS, A., L. HARRIS, AND M. PIWOWAR (2007): "Corporate Bond Market Transaction Costs and Transparency," Journal of Finance, 62, 1421-1451. [1444]

ERICSSON, J., AND O. Renault (2006): "Liquidity and Credit Risk," Journal of Finance, 61, 2219-2250. [1446]

FAMA, E., AND K. R. FRENCH (1989): "Business Conditions and Expected Returns on Stocks and Bonds," Journal of Financial Economics, 25, 23-49. [1469]

[1469] (1992): "The Cross-Section of Expected Stock Returns," Journal of Finance, 47, 427-465.

(1993): "Common Risk Factors in the Returns on Stocks and Bonds," Journal of Financial Economics, 33, 3-56. [1469]

FeldhütTER, P. (2012): "The Same Bond at Different Prices: Identifying Search Frictions and Selling Pressures," Review of Financial Studies, 25, 1155-1206. [1447,1448,1454,1464,1468,1480]

FRIEWALD, N., R. JANKOWITSCH, AND M. G. SubRAhMANYAM (2012): "Illiquidity or Credit Deterioration: A Study of Liquidity in the US Corporate Bond Market During Financial Crises," Journal of Financial Economics, 105 (1), 18-36. [1444,1446,1474-1477,1505]

GILSON, S., K. JoHN, AND L. LANG (1990): "Troubled Debt Restructurings: An Empirical Study of Private Reorganization of Firms in Default," Journal of Financial Economics, 27, 315-353. [1454]

Glosten, L. R., AND P. R. Milgrom (1985): "Bid, Ask and Transaction Prices in a Specialist Market With Heterogeneously Informed Traders," Journal of Financial Economics, 14, 71-100. [1448,1480]

GReEN, R. C., B. Hollifield, AND N. SChURhOFF (2007a): "Dealer Intermediation and Price Behavior in the Aftermarket for New Bond Issues," Journal of Financial Economics, 86, 643-682. [1444] 
(2007b): "Financial Intermediation and the Costs of Trading in an Opaque Market," Review of Financial Studies, 20, 275-314. [1444]

Guerrieri, V., R. SHIMER, AND R. Wright (2010): “Adverse Selection in Competitive Search Equilibrium,” Econometrica, 78, 1823-1862. [1448]

HARRIS, L., AND M. PIWOWAR (2006): "Secondary Trading Costs in the Municipal Bond Market," Journal of Finance, 61, 1361-1397. [1444]

HE, Z., AND K. Milbradt (2013): “Endogenous Liquidity and Defaultable Bonds,” Working Paper w18408, NBER. [1450,1479,1497]

(2014): "Supplement to 'Endogenous Liquidity and Defaultable Bonds'," Econometrica Supplemental Material, 82, http://www.econometricsociety.org/ecta/supmat/11039_data_and_ programs.zip. [1448]

HE, Z., AND W. XIONG (2012a): “Rollover Risk and Credit Risk,” Journal of Finance, 67, 391-430. [1447,1464-1466,1470,1479]

- (2012b): "Dynamic Debt Runs," Review of Financial Studies, 25 (2), 1799-1843. [1446]

Hong, G., AND A. WARGA (2000): "An Empirical Study of Bond Market Transactions," Financial Analysts Journal, 56, 32-46. [1444]

HuANG, J.-Z., AND M. HuANG (2012): "How Much of the Corporate-Treasury Yield Spread Is Due to Credit Risk?" Review of Asset Pricing Studies, 2, 153-202. [1467,1470,1471]

IVASHINA, V., D. C. SMITH, AND B. IVERSON (2013): "The Ownership and Trading of Debt Claims in Chapter 11 Restructurings," Working Paper. [1454]

JANKowitsch, R., F. NAGLER, AND M. G. SubRAhMANYAM (2013): “The Determinants of Recovery Rates in the US Corporate Bond Market,” Working Paper. [1444,1445,1454,1455,1462, 1469]

KYLE, A. S. (1985): “Continuous Auctions and Insider Trading,” Econometrica, 53, 1315-1335. [1448]

LAGOS, R., AND G. RocheTEAU (2007): "Search in Asset Markets: Market Structure, Liquidity, and Welfare," American Economic Review, 97, 198-202. [1447]

[1447]

(2009): "Liquidity in Asset Markets With Search Frictions," Econometrica, 77, 403-426.

LAUERMAnN, S., AND A. Wolinsky (2011): "Search With Adverse Selection,” Working Paper. [1448]

LELAND, H. (1994): "Corporate Debt Value, Bond Covenants, and Optimal Capital Structure," Journal of Finance, 49, 1213-1252. [1446,1461,1465,1493]

(1998): "Agency Costs, Risk Management, and Capital Structure," Journal of Finance, 53, 1213-1243. [1447,1479]

LELAND, H., AND K. B. TOFT (1996): "Optimal Capital Structure, Endogenous Bankruptcy, and the Term Structure of Credit Spreads," Journal of Finance, 51, 987-1019. [1444]

LongStafF, F. A., S. Mithal, AND E. NeIs (2005): "Corporate Yield Spreads: Default Risk or Liquidity? New Evidence From the Credit Swap Market,” Journal of Finance, 60, 2213-2253. [1446,1473-1475]

MiLlER, M. H. (1977): “Debt and Taxes," Journal of Finance, 32, 261-275. [1467]

Schultz, P. (2001): "Corporate Bond Trading Costs: A Peek Behind the Curtain," Journal of Finance, 56, 677-698. [1444,1470]

SCHWARZ, K. (2010): "Mind the Gap: Disentangling Credit and Liquidity in Risk Spreads," Working Paper. [1446,1474]

SEGURA, A., AND J. SuAREZ (2011): “Dynamic Maturity Transformation,” Working Paper. [1479]

SuAREZ, G., E. SCHROTH, AND L. TAYLOR (2014): "Dynamic Debt Runs and Financial Fragility: Evidence From the 2007 ABCP Crisis," Journal of Financial Economics, 112 (4), 164-189. [1447]

VAYAnos, D., AND P.-O. WeILl (2008): "A Search-Based Theory of the On-the-Run Phenomenon," Journal of Finance, 63, 1361-1398. [1447] 
WeILL, P.-O. (2007): “Leaning Against the Wind,” Review of Economic Studies, 74, 1329-1354. [1447]

Booth School of Business, University of Chicago, 5807 South Woodlawn Ave., Chicago, IL 60637, U.S.A., and NBER; zhiguo.he@chicagobooth.edu

$$
\text { and }
$$

Kellogg School of Management, Northwestern University, 2001 Sheridan Rd., Evanston, IL 60208, U.S.A., and NBER; milbradt@northwestern.edu. 